\title{
Do Individual Investors Trade on Investment-related Internet Postings?*
}

\author{
Manuel Ammann, Nic Schaub
}

June 5,2020

\begin{abstract}
Many people share investment ideas online. This study investigates whether individual investors trade on investment-related Internet postings. We use unique data from a social trading platform that allow us to observe the shared portfolios of traders, their posted comments, and the replicating transactions of followers. We find robust evidence that followers increasingly replicate shared portfolios of traders after the posting of comments. However, postings do not help followers identify portfolios that deliver superior performance in the future. In a cross-sectional analysis, we show that it is mainly followers who are typically considered to be unsophisticated who trade after comment postings.
\end{abstract}

JEL Classification: D14, G11, G23

Keywords: Internet postings, individual investors, trading behavior, social trading, FinTech

${ }^{*}$ We are grateful to Tyler Shumway (the editor), an anonymous associate editor, two anonymous referees, Lauren Cohen, Zhi Da, Rüdiger Fahlenbrach, Marc Gerritzen, Reint Gropp, Alexander Hillert, Markku Kaustia, Christine Laudenbach, Peter Limbach, Holger Müller, Per Östberg, Markus Schmid, Daniel Schmidt, Michael Ungeheuer, Felix von Meyerinck, Florian Weigert, Roy Zuckerman, conference participants at the 2016 Boulder Summer Conference on Consumer Financial Decision Making, the $8^{\text {th }}$ Professional Asset Management Conference in Rotterdam, the $24^{\text {th }}$ annual meeting of the German Finance Association (DGF) in Ulm, the $8^{\text {th }}$ TAU Finance Conference in Tel Aviv, the $78^{\text {th }}$ annual meeting of the American Finance Association (AFA) in Philadelphia, and seminar participants at the University of St. Gallen, the University of Mannheim, Aalto University, WHU - Otto Beisheim School of Management, Karlsruhe Institute of Technology, the University of Cologne, and the University of Neuchâtel for helpful comments. We gratefully acknowledge data from Boerse Stuttgart. This paper was previously circulated under the title "The Impact of Internet Postings on Individual Investors".

${ }^{\dagger}$ Swiss Institute of Banking and Finance, University of St. Gallen, CH-9000 St. Gallen, Switzerland, manuel.ammann@unisg.ch

${ }^{\ddagger}$ WHU - Otto Beisheim School of Management, D-56179 Vallendar, Germany, nic.schaub@whu.edu 


\section{Introduction}

Many people share investment opinions on the web. Existing research shows that some of these investment-related online postings contain informational value, whereas others do not (e.g., Antweiler and Frank, 2004; Das and Chen, 2007; Chen et al., 2014; Crawford et al., 2017). Regulators around the globe have repeatedly expressed concerns about individual investors' executing costly trades based on investment-related online postings. ${ }^{1}$ However, little is known about whether individual investors actually trade on these postings. In this paper, we use unique data from a social trading platform to address two main questions: First, do individual investors rely on investment-related Internet postings when making investment decisions? Second, do postings help individual investors identify investment strategies that deliver superior performance in the future?

Social trading platforms provide an ideal setting for such an investigation. They are social networks for individual investors. On these platforms, traders can share their portfolios and can post comments about their shared portfolios. In addition, followers can study shared portfolios and posted comments and can directly replicate investment decisions of traders in their own accounts in real time. Thus, we observe the trading behavior of those who post comments, the postings themselves, and the trading behavior of those who potentially rely on these postings.

Our data come from a leading European social trading platform and cover the time period from January 2013 to December 2014. The sample contains more than 2,000 shared portfolios of traders. Traders managing these portfolios post about 30,000 comments on their profile pages. In addition, replicating transactions of followers into and out of these shared trading strategies amount to about EUR 234 million (equivalent to roughly USD 311 million) over our sample period.

We first explore the relation between comments posted by traders and investment decisions of followers. In all our regressions, we control for variables that likely influence both the posting of comments and investment decisions of followers such as past portfolio performance. Moreover, we include portfolio fixed effects to account for unobservable portfolio and trader characteristics that are constant over time. We also control for potential time trends by adding day fixed effects

\footnotetext{
${ }^{1}$ For example, the Securities and Exchange Commission (SEC) warns investors that "while some messages may be true, many turn out to be bogus" (SEC, 2011). Other regulators such as the Federal Financial Supervisory Authority (BaFin) in Germany and the Financial Conduct Authority (FCA) in the U.K. have issued similar warnings (e.g., BaFin, 2015; FCA, 2018).
} 
to all our regression specifications. We find that the posting of comments is associated with a significant increase in the trading activity of followers. Specifically, if a trader posted a comment yesterday, today's net investments of followers in the shared trading strategy increase by about $6 \%$ compared to the average daily net investments for the same portfolio. When estimating the comment-follower relation separately for investments and withdrawals, we find that investments are more than $10 \%$ higher after the posting of comments. However, we also document a positive and significant relation between the posting of comments and withdrawals, suggesting that comments motivate some investors to walk away. We show that net investments of followers are not only higher on the day after the posting of a comment but that the effect lasts for about three weeks.

We also examine whether followers' decision-making is related to comment tone. To extract the tone of comments, we follow previous research and compute the fraction of positive words and the fraction of negative words in the text (e.g., Tetlock, 2007; Kothari et al., 2009; Feldman et al., 2010; Loughran and McDonald, 2011; Engelberg et al., 2012; Chen et al., 2014; Hillert et al., 2014; Huang et al., 2014; Hillert et al., 2016). We find that a one standard deviation increase in the fraction of positive words is associated with a significant increase in net investments of followers by about $4 \%$ on average. This is consistent with the story that followers frequently read the comments of traders and then trade accordingly. We also document a negative link between the negativity of postings and net investments of followers. However, this effect is not statistically significant at conventional levels.

We run a number of additional tests to rule out alternative explanations. First, to account for the fact that the posting of comments is not random but influenced by characteristics that are correlated with followers' trading behavior, we apply propensity score matching and construct a matched sample of days with comments and days without comments that are otherwise similar across observable dimensions. We then reproduce our main tests using this matched sample. Second, to address the concern that traders post comments when they make changes to their portfolios and that these portfolio changes, rather than the comments themselves, are the main drivers of followers' trading behavior, we drop all comments with confounding portfolio changes and rerun our analyses. Third, it could be the case that comments of traders and investment decisions of followers reflect news that both traders and followers observe directly. To address this issue, we 
eliminate all comments with confounding news on one of the portfolio holdings. Moreover, in an alternative test to alleviate the concern that our results are driven by confounding firm-specific news, we repeat our analyses excluding comments classified as firm-specific. Across all these tests, we document a significant relation between comments of traders and replicating transactions of followers.

We then investigate whether postings help followers identify portfolios of traders that deliver superior performance in the future. We show that neither the posting of comments nor the tone of comments have predictive power for the future performance of traders' portfolios. Consistent with this finding, we document that trades of followers executed after the posting of comments deliver about the same performance as trades of followers executed on all other days. Both types of trades tend to underperform common benchmarks. Thus, we do not find any evidence that comments posted by traders help followers improve decision-making.

Next, we analyze cross-sectional differences in the relation between comments posted by traders and the trading behavior of followers. To categorize followers, we rely on previous literature that suggests that large investors tend to be more sophisticated than small investors (e.g., Lee and Radhakrishna, 2000; Malmendier and Shanthikumar, 2007; Mikhail et al., 2007; Hvidkjaer, 2008; Barber et al., 2009; Peress and Schmidt, 2020). We find a highly significant reaction following the posting of comments for small investors but no reaction for large investors. This suggests that it is mainly unsophisticated individuals who rely on investment-related Internet postings when making investment decisions, but this does not help them identify traders with superior skills.

Although all our analyses indicate that alternative explanations for the significant commentfollower relation are unlikely to be the main drivers of our results, it is of course not possible to empirically observe and control for all potential determinants of followers' investment decisions. Thus, in a final test to shed light on the question of whether followers really care about the comments posted by traders, we conduct an experiment that should allow us to identify a causal impact of comments on investment decisions. In this experiment, subjects have to decide between two portfolios shared on our social trading platform. We randomize a positive comment and a negative comment across the two profile pages. If subjects ignore the comments, we should not find any impact of comments on the chosen portfolio. However, we observe that subjects are significantly 
more likely to follow a trader if that trader has posted a positive comment as compared to a negative comment. Our results are particularly pronounced for subjects that have invested in investment ideas shared online. Moreover, consistent with our findings from the field study, we show that the reaction to comments is stronger for less financially literate subjects.

Our study contributes to several strands of research. First, our paper relates to the literature on the value of investment opinions shared on the web. These studies report mixed results. Whereas some papers document that there is a statistically significant and economically meaningful relation between opinions posted in online communities and future returns (e.g., Chen et al., 2014; Avery et al., 2016; Crawford et al., 2017), others find no such relationship (e.g., Tumarkin and Whitelaw, 2001; Dewally, 2003; Antweiler and Frank, 2004; Das and Chen, 2007; Kim and Kim, 2014). However, none of these existing studies observes directly how investors react to shared investment ideas. Our paper adds to this strand of research by documenting that individual investors rely on investment-related Internet postings, even if there is not much evidence that they contain valuerelevant information. ${ }^{2}$

Second, our study contributes to the literature on individual investor behavior. Existing research shows that individual investors on average generate negative risk-adjusted portfolio returns (e.g., Odean, 1999; Barber and Odean, 2000, 2001, 2002; Grinblatt and Keloharju, 2009). In a recent study, Heimer and Simsek (2019) provide evidence of underperformance of traders from a social trading platform. ${ }^{3}$ One explanation for the negative returns is excessive trading driven by overconfidence. Barber and Odean (2002) argue that the Internet makes individual investors even

\footnotetext{
${ }^{2}$ We are not the first to use data from a social trading platform. Heimer and Simon (2015) and Heimer (2016) have data from a social trading platform that focuses on retail foreign exchange trading. Heimer and Simon (2015) show that when a brokerage house enters into a partnership with the social trading platform, traders increase their trading activity if their peers perform well, possibly driven by private messages received from peers. Heimer (2016) documents that traders' disposition effect increases significantly when a brokerage firm enters into a partnership with the social trading platform. Our study differs from Heimer and Simon (2015) and Heimer (2016) in that we do not analyze peer effects in the general investment behavior of traders. Rather, we focus on whether publicly available Internet postings motivate followers to replicate investment decisions of traders and whether reliance on postings helps followers identify traders with superior skills.

${ }^{3}$ Although risk-adjusted portfolio returns of individual investors appear to be negative in the long term, a strand of the literature documents that returns earned by individual investors over short horizons are significantly positive (e.g., Kaniel et al., 2008; Kelley and Tetlock, 2013, 2017; Barrot et al., 2016). These studies argue that both liquidity provision and private information contribute to the strong short-term returns. However, Barrot et al. (2016) show that it is mainly experienced individuals who generate positive returns in the short term, not inexperienced ones. Similarly, Kelley and Tetlock (2017) conjecture that retail investors who profitably short sell stocks are potentially more sophisticated than typical retail investors. Consistent with these studies, we find that it is mainly unsophisticated followers who trade on uninformative postings, but we do not find any trading response of sophisticated followers after comment postings.
} 
more overconfident as the vast amount of investment data available on the web enables individual investors to confirm their prior beliefs. Consistent with this view, they show that individual investors trade more actively and less profitably after switching from phone-based trading to online trading. However, Barber and Odean (2002) do not further specify the online information sources that individual investors act on. Our findings suggest that one source of information online investors rely on is comments posted in investment-related online communities. In line with prior research, we do not find any evidence that the information contained in these comments justifies trading.

Third, our study is related to the literature on financial advice. Prior research shows that traditional financial advice tends to be biased and does not help individual investors improve their investment decisions (e.g., Hackethal et al., 2012; Foerster et al., 2017; Hoechle et al., 2018). However, in recent years, new technology has led to substantial changes in the market for financial advice. Robo-advice has emerged as an alternative to traditional financial advice. In fact, a recent paper by D'Acunto, Prabhala, and Rossi (2019) suggests that robo-advice can reduce behavioral biases of individual investors. Alternatively, new technology also makes it easier to turn to fellow investors for financial advice. We contribute to this literature by showing that individual investors indeed rely on fellow investors online. However, we do not find any evidence that this leads to better decision-making.

Our results stress the importance of the ongoing debate on the quality of investment ideas shared online. In numerous publications, the SEC has expressed concerns about individual investors' reliance on investment recommendations distributed online that do not convey value-relevant information (e.g., SEC, 2001, 2007, 2011, 2015, 2016, 2017a). Other regulators have issued similar warnings (albeit to a lesser extent) (e.g., BaFin, 2015; FCA, 2018). So far, however, regulators tend to take an educational approach, informing investors about the risks inherent in trading on investment-related Internet postings, but they have largely refrained from taking additional measures. ${ }^{4}$ To the best of our knowledge, our paper is the first to document empirically that individual investors trade on investment-related Internet postings, even though postings do not help them uncover investment strategies that deliver superior performance.

\footnotetext{
${ }^{4}$ Only recently the SEC took enforcement action against a handful of companies and individuals for generating deceptive articles on investment-related online platforms (SEC, 2017b).
} 
The remainder of the paper is organized as follows. In the next section, we explain the concept of social trading in greater detail and introduce our dataset from the social trading platform. In Section 3, we first investigate whether followers' trading behavior is related to the postings of traders. We go on to analyze the informational value of comments. We then examine heterogeneity in the comment-follower relation. Finally, we conduct an experiment to better identify the effect of comments on investment decisions. Section 4 concludes.

\section{Data and variables}

\subsection{Social trading platforms}

Social trading platforms are considered a subcategory of classic online social networks. They allow traders to share their portfolios with followers and enable them to post comments about the shared investment strategies. Followers can study traders' portfolios and postings and can directly replicate investment decisions of traders in their own accounts. The first social trading platforms were created in the late 2000s. As of 2019, there are several dozen platforms worldwide that offer similar services. eToro claims to be the largest one with over 10 million users. Investments of followers in shared trading strategies are estimated to amount to several billion euros across all platforms. ${ }^{5}$

To share their investment ideas, traders have to register with the platform. They either create a virtual portfolio on the platform or set up a real money account. Social trading platforms typically cooperate with brokerage firms. Thus, real money accounts are essentially the same as brokerage accounts. The investment universe is predefined by the platform. Most social trading platforms focus on equity trading and foreign exchange trading. Traders set up profile pages on the platform on which they disclose their identity and describe themselves and their investment strategy. The profile pages also show the traders' current portfolio holdings, trading history, and past portfolio performance. One typically sees either the funds of followers or the number of

\footnotetext{
${ }^{5}$ See, e.g., "FOMO, social media driving millennials' investing decisions", Bloomberg News, October 10, 2018; "Cashing in on the crypto followers", Financial Times, March 28, 2018; "The 10 financial technology companies to watch", Financial Times, November 16, 2016; "Retail traders wield social media for investing fame", Wall Street Journal, April 21, 2015; "Social trading takes off for the masses", Financial Times, November 5, 2014; "UK's financial regulator warns on copy trading", Financial Times, March 10, 2014; "Social trading targets savvy retail investors", Financial Times, June 22, 2013.
} 
followers that replicate the shared investment strategy. Traders can communicate with followers by posting comments on their profile pages or by sending private messages. Platform operators typically check whether the information shared on profile pages is consistent with legal regulations. Finally, platforms remunerate traders either based on the funds of followers or the number of followers that replicate the shared portfolio. Figure 1 provides a sample profile page of a shared investment strategy.

Followers gather information by visiting traders' profile pages. To do so, followers typically have to register with the platform. In addition, to replicate investment ideas of traders, followers need a real money brokerage account that is linked to the platform. The replication of trading decisions usually takes place in real time. While some social trading platforms allow investors to copy single transactions of traders, the predominant form of social trading is the replication of entire investment strategies. The basis for actual returns received by followers is the returns after transaction costs and fees charged by the platform and the partnering brokerage houses.

Our data come from a leading European social trading platform. The investigation period starts in January 2013 and ends in December 2014. We have information on all portfolios of traders that followers can replicate in their own accounts. This results in a sample of 2,161 portfolios managed by 1,314 traders and 475,288 portfolio-day observations. As of December 2014, 2,022 portfolios are still alive and 139 portfolios are defunct. In January 2013, our sample starts with 220 portfolios. Thus, the platform has experienced strong growth over our investigation period. The amount of money invested by followers increases from EUR 6.2 million in January 2013 to EUR 52.9 million in December 2014. Panels A and B of Figure 2 graphically illustrate the growth in the number of portfolios as well as the growth in follower funds over our sample period.

Although investigating the reaction of individual investors to investment-related Internet postings by looking at a social trading platform has several advantages, the main limitation of our study is that all information we use comes from one platform only. Therefore, it is a valid question whether the platform and its users are representative. However, investment-related online communities are relatively similar across different providers. In particular, all of them are characterized by low barriers to entry, thereby attracting rather uninformed traders and followers. Therefore, we see no obvious reason that would make us believe that traders and followers on our platform are 
different from traders and followers on other platforms in any fundamental way.

\subsection{Comment characteristics}

On our platform, traders can communicate with followers by posting comments on their profile pages. This platform does not allow users to send each other private messages. To understand the nature of the posted comments, it is helpful to look at examples. When traders post comments, they classify them as either general or firm-specific. Panels A and B of Figure 3 provide six fairly typical examples of comments published on the platform, of which three are general comments and the other three are firm-specific comments. Some of the posts are backward-looking, providing an explanation for the past performance of the portfolio or a specific security. Others are forward-looking, containing a predicted price change of the portfolio or a specific security and some explanations for the prediction. We drop 5,317 comments that contain fewer than five words as these comments tend not to be informative. ${ }^{6}$ This leaves us with a sample of 29,204 comments.

Our main independent variables of interest capture different aspects of the postings of traders. We create an indicator variable that equals one on days on which traders post at least one comment on their profile page, and zero otherwise. We also count the number of comments posted on days on which traders communicate. To measure the overall length of comments, we compute the number of words per comment. When there are multiple comments on a day, we calculate the average number of words across comments. To extract traders' opinions from comments, we build on prior research, which suggests that the frequency of positive words and the frequency of negative words used in a text measures the tone of the text (e.g., Tetlock, 2007; Kothari et al., 2009; Feldman et al., 2010; Loughran and McDonald, 2011; Engelberg et al., 2012; Chen et al., 2014; Hillert et al., 2014; Huang et al., 2014; Hillert et al., 2016). As most of our comments are not in English, we cannot employ the widely used Loughran and McDonald (2011) word lists that were specifically designed for financial matters. ${ }^{7}$ Instead, we rely on positive and negative word lists based on the Harvard IV-4 dictionary (Remus et al., 2010). These word lists were developed to measure positive and negative emotions in a general context. However, the Harvard IV-4 dictionary has also been applied in a finance context

\footnotetext{
${ }^{6}$ When replicating our analyses including all comments, we obtain results that are largely unchanged.

${ }^{7}$ The Loughran and McDonald (2011) dictionary is constructed based on textual analysis of 10-K filings. Traders on our platform certainly use a different wording than that used in $10-\mathrm{K}$ filings. Thus, it is not entirely clear whether the word lists of Loughran and McDonald (2011) would be suitable in our setting.
} 
in previous research (e.g., Tetlock, 2007; Kothari et al., 2009; Feldman et al., 2010; Engelberg et al., 2012; Hillert et al., 2016). The two word lists comprise 1,818 positive words and 1,650 negative words. Table IA1 in the Internet Appendix reports the 25 positive words and the 25 negative words that appear most frequently in traders' postings. The five most commonly used positive words are "new", "good", "up-to-date", "strong", and "gain". The most frequently used negative words are "small", "unfortunately", "end", "tight", and "short". In the sample comments provided in Figure 3 , we underline words that are included in our dictionary. The tone measure is then constructed as the sum of the number of positive (negative) words in a comment divided by the sum of the total number of words in the comment. When a trader posts more than one comment per day, we compute the average tone across comments.

Panel A of Table 1 provides descriptive statistics on our posting metrics. On average, traders post comments on $5.3 \%$ of all days. For 1,077 portfolios, we observe at least one comment during our investigation period, while traders managing the remaining 1,084 portfolios do not post comments at all. On those days on which traders communicate, they post an average of 1.5 comments. Explanations provided in comments tend to be rather short. The average (median) length of a comment is 36 (20) words. This is consistent with Antweiler and Frank (2004), who report that the number of words in messages posted on Yahoo! Finance and Raging Bull is typically between 20 and 50. The average fraction of positive and negative words used in comments is $5.1 \%$ and $1.7 \%$, respectively. The percentage of negative words is consistent with Chen et al. (2014). Using the dictionary of Loughran and McDonald (2011), they report that the average fraction of negative words in comments posted on Seeking Alpha is $1.8 \%{ }^{8}$ The fact that the percentage of positive words is much higher than the percentage of negative words provides first suggestive evidence that the postings of traders are biased toward positive outcomes.

\subsection{Follower characteristics}

Our platform enables followers to link their real money brokerage accounts to the platform. Once an investor decides to follow a trader, the trader's investment decisions are proportionately replicated in the follower's portfolio. In total, our sample includes 43,676 transactions executed by followers

\footnotetext{
${ }^{8}$ Chen et al. (2014) do not report the fraction of positive words in comments.
} 
into and out of trading strategies, of which 28,744 are investments and 14,932 are withdrawals.

Our main dependent variable captures the transactions of followers. On each day, we compute the net investments of followers in shared investment ideas of traders. ${ }^{9}$ To make our data more normally distributed, we follow previous research and make use of the inverse hyperbolic sine transformation (e.g., Burbidge et al., 1988; Kale et al., 2009; Karlan et al., 2016). Taking the inverse hyperbolic sine is an alternative to a log-transformation when a variable takes on zero or negative values. ${ }^{10}$

Panel B of Table 1 presents descriptive statistics on transactions of followers. The average (median) trade size is EUR 5,360 (EUR 2,237). With an average trade size of EUR 6,124 withdrawals tend to be larger than investments (EUR 4,961). The size of transactions of followers suggests that social trading platforms mainly attract retail investors. Barber et al. (2009) argue that trades that are smaller than USD 5,000 are individual investor trades. There is a handful of very large investments of up to EUR 300,000, indicating that there are a few institutional players or very wealthy individuals that replicate the shared investment strategies. Overall, transactions of followers into and out of shared portfolios amount to more than EUR 234 million over our investigation period. Daily net investments of followers are positive on average and amount to EUR 106. This is not surprising given the strong growth of the platform over our sample period. On average, followers invest EUR 261 per day and they withdraw EUR 155 per day.

\subsection{Performance characteristics}

To measure the performance of traders' portfolios, we compute daily raw returns and daily alphas. We determine the portfolio performance net of bid-ask spreads and fees charged by the platform. ${ }^{11}$ As traders invest $90 \%$ of their non-cash portfolio holdings in equities, we employ a standard fourfactor equity asset pricing model to determine abnormal returns of portfolios. The model contains an equity market factor as well as the investment style factors of Fama and French (1993) and

\footnotetext{
${ }^{9}$ The mutual fund literature typically computes net flows as the percentage growth of a fund. This is not a suitable measure in our setting as most portfolios in our sample are created during our investigation period and thus they either do not have any followers at all or only very few followers. In these cases, percentage growth is either not defined or inflated.

${ }^{10}$ Alternatively, we could transform all observations by adding a constant equal to the absolute value of the minimum net investment to each observation. For this transformation, our results are qualitatively similar to the reported results.

${ }^{11}$ We do not observe transaction costs and fees charged by the partnering brokerage houses.
} 
Carhart (1997). We construct factors using MSCI indices as these indices are investible for retail investors. Since two-thirds of the stock holdings in portfolios are invested in European stocks, we use European MSCI indices. We employ the MSCI Europe Index as proxy for the market. The size factor (SMB) is approximated by the difference in daily returns between the MSCI Europe Small Cap Index and the MSCI Europe Index. The value factor (HML) is approximated by the return difference between the MSCI Europe Value Index and the MSCI Europe Growth Index. In addition, we use the MSCI Europe Momentum Index as a proxy for the momentum factor. The risk-free rate is captured by daily returns on the J.P. Morgan 3 Month Euro Cash Index. Data on indices are obtained from Thomson Reuters Datastream. To determine daily alphas of portfolios, we estimate factor exposures over 6-month rolling windows from t-126 to t-1. Alphas are then calculated as the difference between daily excess returns of portfolios and excess returns predicted by the estimated factor loadings.

Panel C of Table 1 provides information on the distribution of returns and alphas in our sample. The average (median) annualized return of portfolios amounts to -5.3\% (4.4\%). Moreover, the average (median) alpha is $-9.8 \%$ p.a. (-2.8\% p.a.). Thus, portfolios in our sample tend to underperform common benchmarks. ${ }^{12}$

\subsection{Portfolio and trader characteristics}

Our dataset also includes information on various portfolio and trader characteristics. In Panel D of Table 1, we present summary statistics on portfolio characteristics. To determine the number of followers of a portfolio, we count the number of follower transactions over time. Similarly, to compute the amount of money followers have allocated to a portfolio of a trader, we sum up net investments over time. The average portfolio in our sample is followed by five individuals who have invested EUR 22,563. However, there is substantial variation in the number of followers and in funds of followers across different portfolios. There are 1,054 portfolios that do not attract any followers during our investigation period, whereas the most popular portfolio in terms of number of followers has almost 1,200 followers on average and followers have allocated close to EUR 7 million on average over our sample period to the most popular portfolio in terms of follower funds. We

\footnotetext{
${ }^{12}$ The average annualized gross return (alpha) of portfolios is $-3.3 \%(-8.0 \%)$, indicating that bid-ask spreads and fees charged by the platform amount to about $2 \%$ p.a.
} 
define the age of a portfolio as the number of calendar days since the creation of the portfolio on the platform. In December 2014, the average portfolio is 324 days old. Moreover, we create a dummy variable that equals one for traders who have their own money invested in their trading strategy, and zero otherwise. The platform requires traders to allocate several thousand euros to their portfolios to be flagged as real money accounts. According to this classification, about $9.3 \%$ of all portfolios in our sample are classified as real money portfolios and the remaining portfolios are virtual portfolios.

On our platform, the investment universe that traders can pick securities from consists of stocks, funds, and derivatives. The average portfolio contains 12 different securities. More than half of the average portfolio is invested in stocks, of which approximately two-thirds are held in European stocks and one-third in non-European stocks. About one-fifth of the mean portfolio is held in mutual funds and exchange-traded funds, of which about $70 \%$ are equity funds. Only about $2.3 \%$ of portfolio holdings are allocated to derivative instruments. Moreover, traders hold a substantial fraction of $22.5 \%$ of their portfolios in cash. ${ }^{13}$ The remaining $3.7 \%$ of the average portfolio are held in securities we cannot identify. On average, traders place more than one trade per day. Daily turnover is defined as the average of the value of all purchases and the value of all sales executed on a specific day divided by the value of the trader's portfolio at the beginning of the day. The mean daily turnover of portfolios is $3.6 \%$. Hence, traders turn over their portfolios about nine times per year on average, implying that they tend to trade excessively. For comparison, in the discount brokerage dataset of Barber and Odean (2000), the average household turns over $75 \%$ of its portfolio annually. However, it is not surprising that traders on this social trading platform trade more actively given that the only transaction costs the platform charges when traders execute transactions are bid-ask spreads. ${ }^{14}$ Moreover, most of these traders do not have their own money at stake. As the distribution of these variables is heavily skewed, we winsorize the number of trades and the turnover at the $99 \%$ level to eliminate the effect of outliers. For the same reason, we also winsorize the number of securities in traders' portfolios.

\footnotetext{
${ }^{13}$ Traders are generally not able to use leverage. However, the deduction of fees from traders' accounts might result in negative cash positions.

${ }^{14}$ In the dataset of Barber and Odean (2000), commissions amount to $2.1 \%$ for purchases and $3.1 \%$ for sales and thus they are substantially higher than bid-ask spreads, which are $0.3 \%$ for purchases and $0.7 \%$ for sales. Our platform does not charge any commissions when traders execute transactions.
} 
Finally, Panel E of Table 1 summarizes the characteristics of traders. Only $2.2 \%$ of all traders are professional money managers. The platform verifies whether these traders are indeed professional money management firms. Thus, users sharing investment ideas in this online community are mainly individual investors. When setting up their profile page, traders indicate their years of trading experience. We classify traders as experienced if they have more than three years of trading experience. According to this classification, over $93 \%$ of traders are experienced. Furthermore, only $2.1 \%$ of all traders are female. Finally, traders handle about 1.6 portfolios on average over our investigation period. The Appendix provides detailed descriptions of all variables used throughout the study.

\subsection{Determinants of comments}

A potential concern with our analysis is that days on which traders post comments and days on which traders do not communicate might be different along dimensions correlated with followers' investment behavior. To shed light on this potential problem, we investigate the determinants of comment posting and the determinants of comment tone. We conduct multivariate analyses and use the different comment characteristics as dependent variables and relate them to performance, follower, portfolio, and trader characteristics. All time-varying explanatory variables are lagged by at least one day to address potential reverse causality concerns. Moreover, we include day fixed effects to control for the overall market environment. Standard errors are clustered at the portfolio level.

Results are presented in Table IA2 in the Internet Appendix. In Column 1, the dependent variable is the indicator variable that is equal to one on days on which traders post at least one comment, and zero otherwise. In Columns 2 to 5, we restrict the sample to days with at least one comment posted by traders. The logarithm of the number of comments per day is the dependent variable in Column 2. We use the logarithm of the number of words per comment as our dependent variable in Column 3. The fraction of positive words and the fraction of negative words are used as dependent variables in Columns 4 and 5. Coefficient estimates in Column 1 show that traders are more likely to post comments when their portfolio performed well. They are also more likely to communicate when they have many followers, have joined the platform only recently, have their 
own money at stake, hold many securities in their portfolio, trade frequently, and are professionals. Results are similar when we examine the determinants of the number of comments posted on days with at least one comment (Column 2). In Column 3, we show that comments tend to be longer after more negative portfolio returns, for more popular strategies in terms of follower funds, and for female traders. In Column 4, we document that traders post more optimistic comments after good returns. In contrast, when focusing on the fraction of negative words in Column 5, we find no significant relation between past returns and negativity. This provides further evidence that traders are more reluctant to talk about failure than to talk about success. Looking at the other explanatory variables in Columns 4 and 5 that display a significant relation with comment tone, we find that traders of less popular trading strategies and traders who manage fewer portfolios communicate more optimistically. In addition, traders who do not have their own money at stake, traders who trade more, and male traders tend to use more negative words in their posts.

Overall, we find that there are significant differences between days on which traders post comments and days on which traders do not communicate. Moreover, comment tone also varies systematically across performance, followers, portfolio, and trader characteristics. This suggests that we have to control for these factors when investigating the influence of comments and comment tone on the investment behavior of followers.

\section{Empirical analysis}

Our unique dataset allows us to perform three sets of novel tests: First, we analyze the link between comments posted by traders and investment decisions of followers (Section 3.1). We go on to examine the informational value of the posts of traders (Section 3.2). We then investigate how our findings differ across followers (Section 3.3). Finally, we perform an experiment to corroborate our findings from the field study (Section 3.4).

\subsection{Comments and trades of followers}

We start by analyzing the relation between postings of traders and the trading behavior of followers. The only way for followers to gather information about a portfolio of a trader is by visiting the 
trader's profile page, where they immediately see the trader's comments. Hence, it is highly likely that comments influence followers' investment decisions. To analyze followers' trading behavior after the posting of comments, we run panel regressions and regress today's net investments of followers in a shared trading strategy on a dummy variable that equals one if a trader posted a comment yesterday, and zero otherwise. Specifically, we use the inverse hyperbolic sine of daily net investments of followers as dependent variable. We include the full set of performance, follower, portfolio, and trader characteristics as controls. These variables should capture all information that is available on traders' profile pages. Since information on shared portfolios is not available anywhere else, our set of variables likely includes the most important drivers of followers' investment decisions. All time-varying explanatory variables are lagged by at least one day. In our most robust specification, we additionally include different fixed effects. We include portfolio fixed effects to account for all portfolio and trader characteristics that remain constant over time. This is equivalent to examining the link between comment posting and followers' investment decisions in a withinportfolio setting. To control for the overall performance of the market as well as time trends in communication, we include day fixed effects. Standard errors are clustered at the portfolio level.

Results are reported in Table 2. In Column 1, we run the regression without control variables. In Column 2, we add the full set of control variables. In Column 3, we additionally include portfolio and day fixed effects. If postings attract new followers or prevent existing followers from withdrawing, the coefficient on the comment dummy should be positive. If postings lead to fewer investments or more withdrawals of followers, we expect the coefficient estimate to be negative. If postings do not affect followers' investment decisions or if they have a similar impact on investments and withdrawals of followers, we should not find any effect. However, we document that the posting of comments is associated with an increase in net investments of followers. The effect is statistically significant at least at the $5 \%$ level. In the most robust specification in Column 3 , we find that after the posting of comments net investments of followers increase by $6.0 \%$ compared to the average daily net investments for the same portfolio. This suggests that the soft information transmitted through comments posted on traders' profile pages matters for investment decisions of followers.

Our findings are consistent with summary statistics on page views provided by our social trading platform. According to these statistics, about one-third of all clicks of profile page visitors are clicks 
on traders' comments to see the comments in full, another third are clicks on the current portfolio holdings of traders to see additional details, and the remaining third are clicks on other parts of profile pages such as recent transactions. Hence, posted comments seem to be of similar importance as portfolio holdings and more important than the trading history. This lends further support to the conjecture that the significant comment-follower relationship is driven by followers trading on comments. ${ }^{15}$

With respect to the control variables in Columns 2 and 3 of Table 2, we find all coefficients on past performance to be positive (except for the coefficients on the return four days ago and the return since inception) and many of them to be statistically significant, indicating that followers turn to portfolios with positive past returns. The effects are also economically meaningful. For example, the magnitude of the coefficient on the past 1-month return in Column 3 suggests that a one standard deviation increase in the past 1-month return increases today's net investment of followers by $3.8 \%$ compared to the average daily net investments for the same portfolio. Coefficients on past net investments of followers are also all positive and significant, implying that if a trading strategy attracted new followers recently this is likely to continue. The coefficient estimate on the past 1-month net investments indicates that a one standard deviation increase in the past 1-month net investments increases today's net investment of followers by $4.0 \%$ compared to the average daily net investments for the same trading strategy. In addition, popular trading strategies in terms of follower funds tend to attract fewer followers than less popular trading strategies. Furthermore, the negative and significant coefficient on portfolio age suggests that older portfolios attract fewer followers than younger portfolios. Results regarding real money accounts of traders are less conclusive. While the coefficient on the real money account dummy variable is positive and significant in Column 2, it turns negative and significant in our within-portfolio analysis in Column 3. Finally, the positive and significant coefficient on the turnover variable suggests that portfolios that are turned over frequently attract substantially more followers.

Thus far, we have focused on net investments of followers. The documented effect could be driven by comments attracting new followers or by traders' being able to prevent existing followers from withdrawing money. To disentangle these two mechanisms, we re-estimate our baseline

\footnotetext{
${ }^{15}$ Linking transactions of followers with their page views is not possible in our setting as the platform administers the profile pages, while partnering brokerage firms handle the transactions of followers.
} 
specification from Column 3 of Table 2 separately for purchases and sales of followers.

Results are presented in Table 3. We do not tabulate coefficients on the control variables for space reasons. ${ }^{16}$ In Column 1, we find the relationship between postings of traders and investments of followers to be positive and highly statistically significant (t-statistic of 4.96). Interestingly, the coefficient estimate in Column 2 is also positive and significant at the $5 \%$ level, suggesting that comments not only attract new followers but also motivate some followers to walk away. The net effect is positive as investments increase by $11.6 \%$ after the posting of comments, whereas withdrawals increase by $4.1 \%$ only.

Next, we examine the comment-follower relation in the longer run. Comments remain on the profile pages of traders after they are published. ${ }^{17}$ Thus, it might well be that they do not only attract followers immediately after they are posted but also in the longer run. Alternatively, it could be the case that the documented effect reverses after some time. To shed light on the longer-term behavior of followers, we turn to a longer-term analysis over several weeks. Specifically, for the eight weeks after the posting of a comment, we compute average daily net investments of followers for each week and rerun our main regression from Column 3 of Table 2.

Regression estimates are reported in Table 4. For space reasons, we again only report the coefficient on the lagged comment dummy variable. ${ }^{18}$ Results in Columns 1 to 3 show significantly higher net investments of followers within the first three weeks after the posting of a comment. Daily net investments are $15.1 \%$ higher in week 1, $7.6 \%$ higher in week 2 , and $8.6 \%$ higher in week 3 relative to the average daily net investments for the same portfolio. After week 3 , we find insignificant coefficient estimates. In weeks 7 and 8, the coefficient estimates on the comment dummy turn from positive to negative but they still lack statistical significance. Thus, there are only some weak signs of a reversal over the longer run, suggesting that the follower reaction is relatively persistent.

The longer-term dynamics of the relation between comments of traders and the trading behavior

\footnotetext{
${ }^{16}$ The full set of coefficient estimates is provided in Table IA3 in the Internet Appendix.

${ }^{17}$ Although traders on this platform cannot alter posted comments, they can delete comments from their profile pages. To investigate whether traders frequently drop comments, we randomly select 50 portfolios and collect posted comments at two points in time with a gap of approximately six months. We do not find a single trader that has deleted comments from the profile page. Alternatively, the platform can also delete comments that violate terms and conditions. However, this happens rarely and these comments are typically deleted shortly after their publication. Thus, deletion of selected comments ex post should not be a concern in our analysis.

${ }^{18}$ Table IA4 in the Internet Appendix shows all coefficient estimates.
} 
of followers are graphically illustrated in Figure 4. We plot average daily net investments for each week around the posting of a comment beginning four weeks prior to the posting and ending eight weeks after the posting. Average daily net investments are demeaned by portfolio and by day. The effect of demeaning is comparable to the effect of including portfolio fixed effects and day fixed effects in a regression. To better isolate the impact of comments on investment decisions of followers, we drop all comments that have confounding comments in the prior four weeks. This leaves us with 2,398 portfolio-day observations with at least one comment ( $12.5 \%$ of the initial sample). We find that net investments of followers fluctuate around zero in the weeks before the posting. They turn strongly positive and significant in the three weeks after the posting of a comment. Thereafter, net investments of followers are again substantially lower.

To dig deeper, we also investigate the association between other comment characteristics and the trading behavior of followers. Rather than regressing daily net investment of followers on the lagged comment dummy, we focus on days with at least one comment published on the preceding day and use the logarithm of the number of comments, the logarithm of the length of comments, and comment tone as main explanatory variables. Explanatory variables are lagged by one day. We again include the full set of control variables as well as portfolio and time fixed effects in all our regressions. Standard errors are clustered at the portfolio level.

Results are presented in Table 5. For space reasons, we again only tabulate coefficient estimates on comment characteristics. ${ }^{19}$ In Column 1, we relate followers' investment behavior to the posting frequency on days with at least one comment. The positive coefficient estimate on the number of comments suggests that followers trade more when traders post more. However, the effect is not statistically significant at conventional levels (t-statistic of 1.05).

We then analyze whether the follower reaction varies with the length of comments. Thus, in Column 2, the logarithm of the number of words per comment serves as our main independent variable. The coefficient estimate on this variable is also positive, indicating that net investments are higher after longer comments. However, this result is again not statistically significant (tstatistic of 0.56).

In Columns 3 and 4 of Table 5, we investigate the role of comment tone. We find that the

\footnotetext{
${ }^{19}$ Table IA5 in the Internet Appendix reports coefficient estimates on the controls.
} 
coefficient estimate on the fraction of positive words is positive and statistically significant at the $5 \%$ level, suggesting that followers are more willing to replicate a shared portfolio after the posting of more optimistic comments. A one standard deviation increase in the fraction of positive words is associated with an increase in net investments of followers by $4.3 \%$. Moreover, the relation between negativity and net investments of followers is negative. However, this effect is not statistically significant (t-statistic of 1.01). One potential explanation for why the effect is stronger for positivity than for negativity is that withdrawing money after negative comments is more restricted than investing money after positive comments because followers cannot take short positions in shared investment strategies and thus only the typically few investment strategies which they follow are candidates for withdrawals. Another possible explanation is that comments with a more positive tone are about five times more frequent than comments with a more negative tone.

Finally, in Column 5, we include all comment characteristics simultaneously. This yields inferences that are qualitatively similar. We still document a positive and significant relation between traders' optimism and followers' net investments (t-statistic of 1.96).

Results in Table IA2 in the Internet Appendix suggest that there are significant differences between days on which traders post comments and days on which traders do not communicate. In an alternative test to account for the fact that the posting of comments is not random but driven by factors that are also relevant to followers' investment decisions, we apply propensity score matching. To do so, we use the coefficient estimates from the logit regression in Column 1 of Table IA2 to generate a propensity score for each observation. We then employ these propensity scores to match days on which traders post comments with days on which traders do not post any comments using the nearest-neighbor matching method with replacement. This matching results in the pairing of 19,004 days with comments with 18,036 days without any comments. We then rerun the logit regression from Column 1 of Table IA2 for the matched sample. Results are presented in Table IA6 in the Internet Appendix. In the matched sample, all coefficient estimates turn statistically insignificant, except for the coefficients on the portfolio return two days ago and the past 1-month portfolio return. This suggests that days on which traders post comments and days on which traders do not communicate are now similar across observable dimensions. We then rerun the main regression specifications from Tables 2 to 4 using the matched sample. Results are reported in 
Table 6. The coefficient on the lagged comment dummy variable is insignificant in Columns 1 and 3 , when using daily net investments and daily withdrawals as dependent variables. However, the coefficient remains highly statistically significant and economically meaningful in Columns 2 and 4, when focusing on daily investments and average daily net investments in the week after the posting of a comment (t-statistics of 2.56 and 3.46, respectively). Thus, we again find strong evidence that followers increasingly replicate shared portfolios of traders after the posting of comments.

We conduct a battery of additional tests. First, to address the concern that traders post comments when they make changes to their portfolios and that these portfolio changes are the main drivers of followers' trading behavior as opposed to the comments themselves, we drop all comments with confounding portfolio changes and rerun our analyses. Second, it could be the case that comments of traders and investment decisions of followers reflect news that both traders and followers observe directly. To address this problem, we obtain business press data from RavenPack and eliminate all comments with confounding news on one of the portfolio holdings. Moreover, in an alternative test to alleviate the concern that our results are driven by confounding firm-specific news, we reproduce our analyses using only general comments. While firm-specific comments might be affected by corporate news announcements, general comments tend to talk about portfolios more broadly. Finally, we examine whether our results are driven by a few very popular investment strategies shared on our social trading platform. To do so, we exclude the most popular $5 \%$ of portfolios in terms of follower funds and rerun our analyses. The details of these tests are described in the Internet Appendix. Results of these additional stability checks are presented in Tables IA7 to IA10 in the Internet Appendix. Across all tests, we find a significant relation between comments of traders and the trading behavior of followers.

In summary, we document a robust link between comments posted in an investment-related online social network and the investment behavior of followers. The trading activity of followers is not only elevated immediately after comment postings but the effect lasts for up to three weeks.

If comments of traders indeed attract new followers, it is a valid question why comments have not been exploited by traders to a greater extent so far. We can only speculate about potential explanations. The platform asks traders to give a fair and truthful picture of the shared investment strategy, which might prevent traders from posting more frequently and more optimistically. It 
could also be the case that traders fear that too frequent commenting decreases the impact of comments. Alternatively, traders might simply not be aware of the effect of comments on investment decisions of followers.

\subsection{The predictive power of comments for future performance}

In this section, we investigate whether comments convey valuable information that helps followers identify traders with superior skills. We first test whether comments posted by traders have predictive power for the future performance of portfolios. To do so, we regress daily portfolio returns and daily portfolio alphas from our four-factor model on our five communication metrics. Comment characteristics are lagged by one trading day. The same set of control variables as in all previous analyses are included in every regression but not reported. We again also include portfolio fixed effects and day fixed effects in all specifications. As before, standard errors are clustered at the portfolio level.

Results are presented in Table 7. In Columns 1 to 6 , we use daily portfolio returns as dependent variable and in Columns 7 to 12 daily portfolio alphas. Coefficient estimates for the impact of comments on future performance are all insignificant except for Columns 4 and 6 . In Columns 4 and 6 , the coefficient on the fraction of positive words is positive and statistically significant, suggesting that portfolios indeed deliver superior raw returns after the posting of more positive comments. However, when looking at the more meaningful results based on the four-factor model in Columns 10 and 12, the coefficient on positivity turns insignificant. This implies that comments contain little predictive value.

To assess the robustness of our results, we repeat the analysis from Table 7 for a different horizon and using alternative factor models. Results of these tests are shown in Table IA11 in the Internet Appendix. In Columns 1 and 2, we use 1-month cumulative abnormal returns (CARs) as performance measure rather than 1-day returns and 1-day alphas. In Columns 3 and 4, we rerun the analysis using alphas from a four-factor model that uses MSCI World indices rather MSCI Europe indices. In Columns 5 and 6, we employ alphas from a single-factor CAPM. Finally, in Columns 7 and 8, we use alphas from a six-factor model that additionally includes a call option and a put option factor to account for the non-linear payoff profiles that result from the traders' use 
of derivative instruments. The two option factors are constructed as in Agarwal and Naik (2004) using at-the-money European call and put options on the Euro Stoxx 50. There is no evidence that comments have predictive power for the future performance of shared portfolios.

So far, the analysis suggests that followers trade on comments of traders, even though we do not find any predictive power of comment characteristics. However, trading on comments could still be beneficial for followers if the comments that induce followers to trade contain valuable information that we do not capture with our comment characteristics. Therefore, we next examine the performance of trades of followers that are likely affected by comments and compare it to the performance of trades of followers that are likely not affected by comments. To do so, we classify trades of followers executed on the day after the posting of a comment as influenced by the comment and trades of followers executed on all other days as not influenced by comments. For each individual portfolio of a trader, we sum up these two types of transactions over time. This provides us with the amount of money followers have allocated to a portfolio of a trader immediately after the posting of comments and the amount of money followers have allocated to a portfolio of a trader at any other point in time. We then build two aggregate calendar-time portfolios consisting of all individual portfolios of traders. In the first aggregate calendar-time portfolio, individual portfolios of traders are weighted by the amount of money followers have allocated to the portfolios after the posting of comments and in the second aggregate calendar-time portfolio, individual portfolios are weighted by the amount of money followers have allocated to the portfolios on all other days. This yields two time series of daily raw returns from January 2013 to December 2014.

Figure 5 shows graphically the return of transactions of followers executed immediately after the posting of comments and the return of transactions of followers executed on all other days. The figure also presents the return of the MSCI Europe Index and the return of the MSCI World Index. Trades of followers executed on the day after the posting of a comment generate an average raw return of $1.3 \%$ and trades of followers executed at any other point in time earn an average raw return of $6.5 \%$ from January 2013 to December 2014. This is substantially below the $25.1 \%$ generated by the MSCI Europe Index and the $42.8 \%$ generated by the MSCI World Index over the same time period. This provides first evidence that trades of followers executed after the posting of comments underperform other trades as well as common benchmarks. 
We also examine the performance of transactions of followers in a more formal way. Table 8 reports alphas and factor loadings of the two portfolios. We again employ our four-factor model. In Column 1, we present results for investments of followers made on the day after the posting of a comment. The annualized alpha of this portfolio amounts to $-7.7 \%$. In Column 2, the annualized alpha of the portfolio of investments of followers made on all other days is $-6.0 \%$. Hence, both portfolios underperform common benchmarks. However, both estimates are not statistically significant at conventional levels. The negative alpha of the difference portfolio reported in Column 3 suggests that comments do not help followers identify portfolios that deliver superior performance. With respect to the factor loadings, we find that both portfolios load positively on the market factor and the investment style factors of Fama and French (1993) and Carhart (1997).

Next, we repeat the analysis from Table 8 using an alternative classification of transactions of followers potentially affected by comments of traders and using alternative factor models. Results of these robustness checks are reported in Table IA12 in the Internet Appendix. In Columns 1 to 3, we classify trades of followers as affected by comments if they take place any time within three weeks after the posting of a comment. In Columns 4 to 6 , we apply a four-factor model based on MSCI World indices rather than a four-factor model based on MSCI Europe indices. In Columns 7 to 9, we use a single-factor CAPM. Finally, in Columns 10 to 12, we report results for a six-factor model that additionally includes a call option and a put option factor. In all these tests, we find that trades of followers executed after the posting of comments and trades of followers executed on all other days deliver about the same performance. Alphas of both portfolios are always negative. However, they are not statistically significant, except for Columns 4 and 5 when applying the four-factor model based on MSCI World indices. In Columns 4 and 5, we find the annualized alpha of investments of followers made after the posting of comments to amount to $-13.2 \%$ and the annualized alpha of investments of followers made on all other days to be $-10.6 \%$. Both estimates are significant at the $5 \%$ level.

Taken together, the findings in this section suggest that the postings on our platform do not help followers uncover portfolios of traders that deliver superior performance. Moreover, there is no evidence that social trading strategies add value vis-à-vis common benchmarks, if anything they underperform common benchmarks. 
Of course, we do not know what followers would have done if they had not traded on comments. As benchmarks for the performance of social trading strategies we use the returns on MSCI indices. MSCI indices are useful benchmarks because they correspond to simple passive investment strategies. Moreover, they are feasible investment strategies even for small investors as many mutual fund firms offer low-cost index funds and index ETFs that replicate the performance of MSCI indices. However, it is possible that followers would not have invested passively in the absence of comments and that they might have performed even worse if they had not followed the comments.

\subsection{Which followers drive results?}

Next, we examine heterogeneity in the relation between the posting of comments and the trading behavior of followers. As we do not observe any follower characteristics directly, we use trade size to categorize followers. Previous research shows that large trades tend to be executed by (more sophisticated) professional investors, while small trades tend to be carried out by (less sophisticated) individual investors (e.g., Lee and Radhakrishna, 2000; Malmendier and Shanthikumar, 2007; Mikhail et al., 2007; Hvidkjaer, 2008; Barber et al., 2009; Peress and Schmidt, 2020). In our descriptive statistics, we report the average (median) trade size in our sample to be EUR 5,360 (EUR 2,237). Thus, we use EUR 5,000 (EUR 2,500) as cutoff point and classify transactions that are below this threshold as small trades and transactions above or equal to this threshold as large trades. To investigate whether results differ across followers, we rerun our baseline specification from Column 3 of Table 2 separately for small and large trades.

Results of this analysis are reported in Table 9. In Columns 1 and 2 (Columns 3 and 4), we present coefficient estimates from the regressions using EUR 5,000 (EUR 2,500) as cutoff point. The small trades we focus on in Column 1 only account for about one quarter of the overall transaction volume of followers. Nevertheless, we find a strong comment-follower relation. In contrast, when focusing on large trades in Column 2, the coefficient estimate on the comment dummy is neither statistically nor economically meaningful. This suggests that our findings are indeed driven by small investors. In Column 3, when using EUR 2,500 as cutoff point, small trades constitute only $11.7 \%$ of the total transaction volume but the coefficient estimate on the comment dummy variable

is still about twice as large as the coefficient estimate on the comment dummy in Column 4, where 
we restrict our sample to large trades. Consistently, the coefficient estimate on the lagged comment dummy in Column 3 is highly statistically significant (t-statistic of 2.67), while the coefficient estimate is not statistically significant at conventional levels in Column 4 (t-statistic of 0.86). Thus, our results are robust to variations in cutoffs.

In summary, we show that the association between comments of traders and the trading behavior of followers is mainly driven by small investors that are often considered to be unsophisticated market participants. This is consistent with our story in the previous sections that followers trade on comments, even though comments do not predict future performance.

\subsection{Experimental analysis}

Although the analyses in the previous sections suggest that alternative explanations are unlikely to drive the relation between comments posted by traders and the transactions of followers, we cannot rule out that there is an omitted variable that affects our findings. Thus, to better identify a causal effect of traders' comments on investment decisions of followers, we conduct an experiment.

In this experiment, we provided subjects with two profile pages from our social trading platform. The two profile pages are relatively similar across all observable dimensions. We then created a positive (negative) comment revealing the trader's opinion about the future performance of the shared portfolio: "The current market environment is favorable (unfavorable) for my trading strategy. Thus, I think that it will work well (poorly) in the near future and will generate above (below) average returns." This design allows us to examine whether subjects' reactions to positive and negative comments are symmetric. We randomly displayed either the positive comment or the negative comment on one of the two profile pages. Subjects then had to decide which trading strategy they wanted to follow. We performed the experiment on 800 subjects recruited through Clickworker, a European online marketplace similar to the U.S. online marketplace Amazon Mechanical Turk. ${ }^{20}$ Of the 800 subjects, 400 saw the positive comment and the other 400 saw the negative comment. A potential concern with online marketplaces is that subjects may not properly complete the tasks. ${ }^{21}$

\footnotetext{
${ }^{20}$ Both Amazon Mechanical Turk and Clickworker are increasingly used in finance research (e.g., D'Acunto, 2018; D'Acunto, Prokopczuck, and Weber, 2019; Hartzmark and Sussman, 2019; Lian et al., 2019).

${ }^{21}$ Experimental research shows that this concern is not warranted. Existing studies find that subjects recruited through online marketplaces tend to perform similarly on tasks, better in attention checks, and are usually more diverse than traditional subject pools recruited through labs (e.g., Casler et al, 2013; Paolacci and Chandler, 2014; Hauser and Schwarz, 2016).
} 
To address this concern, we tracked the time it took subjects to complete the experiment. ${ }^{22}$ Furthermore, we added implausible options to some questions and verified that they were not picked. Subjects spent on average 11.0 minutes completing the experiment. They received a performanceunrelated participation fee of EUR 2.5. Moreover, to incentivize subjects to think carefully about their investment decision, we paid 100 randomly selected subjects a performance-related bonus of either EUR 10 or EUR 11 depending on which portfolio they chose. The performance-related bonus was calculated based on simulations of the one-year return of the two portfolios. Additional information on the experimental design is provided in the Internet Appendix.

Roughly $45 \%$ of the subjects in our sample are female. The majority of subjects $(70.0 \%)$ are in the age range of 18 to 39 . About $40.4 \%$ report that they have a college education and $8.3 \%$ state that they have worked in the financial industry. In addition, $47.7 \%$ have invested in stocks or equity funds and more than one-fifth of subjects report that they have invested in investment ideas shared on the Internet. We measure subjects' financial literacy by counting the number of correctly answered questions in the test proposed by Fernandes et al. (2014). On average, subjects answered correctly 7.7 questions out of 12 . More details on subject characteristics are provided in Table IA13 in the Internet Appendix.

How do these subject characteristics compare with characteristics of users on the social trading platform? In 2013, our social trading platform conducted a survey among approximately 600 users. According to this survey, about $58 \%$ of users are in the age range of 18 to 39 . In addition, $44 \%$ report that they have a college education and $17 \%$ claim that they work in the financial industry. Hence, subjects in the experiment are slightly younger, similar in terms of education, and somewhat less likely to work in the financial industry compared to users of the social trading platform.

Results of our experimental analysis are presented in Table 10. We compare differences in the fraction of subjects that decide to follow a trader if they see a positive comment or a negative comment. If subjects ignore the comment, we should not find any effect of comments on the chosen trading strategy. In contrast, if subjects base their investment decision on comments, we expect to observe a difference in the likelihood that they will follow a trader. Results show that $54.3 \%$ of subjects decide to follow a trader if they see a positive comment on that trader's profile

\footnotetext{
${ }^{22}$ We anticipated that the experiment would take approximately 10 minutes to complete. The minimum time was set to 3 minutes and the maximum time to 30 minutes.
} 
page and only $37.5 \%$ of subjects decide to follow if they see a negative comment. Both fractions are significantly different from $50 \%$ (t-statistics of 1.70 and 5.16, respectively). ${ }^{23}$ The difference amounts to 16.8 percentage points and is also highly statistically significant (t-statistic of 4.82 ). The difference is even larger (20.0 percentage points) when we focus on subjects that have invested in ideas shared on the web.

To shed further light on whether the sophistication of subjects affects their reaction to comments, we split our sample into more sophisticated and less sophisticated subjects. First, we split the subject pool into subjects that have a college education and subjects that do not have a college education. Results suggest that the difference in the fraction of subjects that decide to follow if they see a positive comment or a negative comment is about $61.9 \%$ larger for subjects without a college education compared to subjects with a college education. Second, we assign subjects to terciles based on their financial literacy score. Again, the effect is about $62.0 \%$ stronger for the least financially literate subjects in tercile 1 compared to the most financially literate subjects in tercile 3 .

Overall, our experimental evidence confirms the empirical evidence from previous sections. We find a strong impact of comments on the investment decision of subjects, even though comments only reveal the trader's opinion about the future prospects of the shared trading strategy without further substantiating it. Moreover, we document that less sophisticated individuals are more likely to rely on postings than more sophisticated individuals.

Even though we try to make the experimental setting as realistic as possible, there are of course differences between the experiment and the real-world setting. First, there are no restrictions to investments and withdrawals in the experiment. In contrast, on the platform, withdrawing money is more restricted than investing money because followers do not take short positions in shared investment strategies and thus only the typically few investment strategies which they follow are candidates for withdrawals. Second, while half of the subjects in the experiment see a positive comment, the other half see a negative comment. In contrast, in our field data, comments with a

\footnotetext{
${ }^{23}$ Psychological research argues that people generally react more strongly to negative news than to positive news (e.g., Baumeister et al., 2001). Furthermore, behavioral economics suggests that investors tend to be loss averse, which likely results in them being more sensitive to negative information about their investments than to positive (e.g., Kahneman and Tversky, 1979). These are possible explanations for why we find negative comments to have a stronger impact on subjects' decision-making than positive comments.
} 
more positive tone are about five times more frequent than comments with a more negative tone. Moreover, one rarely sees negative comments on the platform that are as pessimistic as the negative comment in the experiment. These differences between the experimental analysis and our field study might explain why we find that negative comments are more influential than positive comments in the experiment. In contrast, in our field study, we document that the relation between the positivity of comments and the trading behavior of followers has about the same economic magnitude as the relation between the negativity of comments and followers' behavior (although with opposite sign), but the relation for positivity is statistically stronger than the relation for negativity.

\section{Conclusion}

Investment-related online communities have become very popular in recent years. This paper investigates whether individual investors trade on comments posted in these communities. We find strong evidence that followers' investment decisions are related to the comments of traders. However, our analysis shows that postings do not help followers identify portfolios of traders that outperform in the future. In a cross-sectional test, we find that the comment-follower relation is strongest for small investors that are typically considered to be unsophisticated. Experimental evidence confirms that postings affect individuals' decision-making and that the effect of postings is stronger among the less financially literate. Overall, this paper suggests that it is primarily unsophisticated individuals who rely on the opinions of others shared on the web when making investment decisions, but there is not much evidence that online postings help those unsophisticated individuals improve their investment quality. 


\section{References}

Agarwal, V., and N.Y. Naik, 2004, Risk and portfolio decisions involving hedge funds, Review of Financial Studies 17, 63-98.

Antweiler, W., and M.Z. Frank, 2004, Is all that talk just noise? The information content of Internet stock message boards, Journal of Finance 59, 1259-1294.

Avery, C.N., J.A. Chevalier, and R.J. Zeckhauser, 2016, The "CAPS" prediction system and stock market returns, Review of Finance 20, 1363-1381.

BaFin, 2015, Wertpapiergeschäfte - Was Sie als Anleger beachten sollten, https://www . bafin.de/ DE/Verbraucher/GeldanlageWertpapiere/Wertpapiergeschaefte/wertpapiergeschaefte_ node.html.

Barber, B.M., and T. Odean, 2000, Trading is hazardous to your wealth: The common stock investment performance of individual investors, Journal of Finance 55, 773-806.

Barber, B.M., and T. Odean, 2001, Boys will be boys: Gender, overconfidence, and common stock investment, Quarterly Journal of Economics 116, 261-292.

Barber, B.M., and T. Odean, 2002, Online investors: Do the slow die first?, Review of Financial Studies 15, 455-487.

Barber, B.M., T. Odean, and N. Zhu, 2009, Do retail traders move markets?, Review of Financial Studies 22, 151-186.

Barrot, J.-N., R. Kaniel, and D. Sraer, 2016, Are retail traders compensated for providing liquidity?, Journal of Financial Economics 120, 146-168.

Baumeister, R.F., E. Bratslavsky, C. Finkenauer, and K.D. Vohs, 2001, Bad is stronger than good, Review of General Psychology 5, 323-370.

Burbidge, J.B., L. Magee, and A.L. Robb, 1988, Alternative transformations to handle extreme values of the dependent variable, Journal of the American Statistical Association 83, 123-127.

Carhart, M.M., 1997, On persistence in mutual fund performance, Journal of Finance 52, 57-82.

Casler, K., L. Bickel, and E. Hackett, 2013, Separate but equal? A comparison of participants and data gathered via Amazon's MTurk, social media, and face-to-face behavioral testing, Computers in Human Behavior 29, 2156-2160.

Chen, H., D. Prabuddha, Y.J. Hu, and B.-H. Hwang, 2014, Wisdom of crowds: The value of stock opinions transmitted through social media, Review of Financial Studies 27, 1367-1403.

Crawford, S.S., R.G. Wesley, and A.E. Kern, 2017, Why do fund managers identify and share profitable ideas?, Journal of Financial and Quantitative Analysis 52, 1903-1926.

D'Acunto, F., 2018, Identity and choice under risk, Working Paper, Boston College.

D'Acunto, F., N. Prabhala, and A.G. Rossi, 2019, The promises and pitfalls of robo-advising, Review of Financial Studies 32, 1983-2020.

D'Acunto, F., M. Prokopczuck, and M. Weber, 2019, Historical antisemitism, ethnic specialization, and financial development, Review of Economic Studies 86, 1170-1206.

Das, S.R., and M.Y. Chen, 2007, Yahoo! for Amazon: Sentiment extraction from small talk on the web, Management Science 53, 1375-1388.

Dewally, M., 2003, Internet investment advice: Investing with a rock of salt, Financial Analyst Journal 59, 65-77.

Engelberg, J., A.V. Reed, M.C. Ringgenber, 2012, How are shorts informed? Short sellers, news, and information processing, Journal of Financial Economics 105, 260-278. 
Fama, E.F., and K.R. French, 1993, Common risk factors in the returns on stocks and bonds, Journal of Financial Economics 33, 3-56.

FCA, 2018, FCA warns of increased risk of online investment fraud, as investors lose $£ 87 \mathrm{k}$ a day to binary options scams, https://www.fca.org.uk/news/press-releases/ fca-warns-increased-risk-online-investment-fraud-investors-scamsmart.

Feldman, R., S. Govindaraj, J. Livnat, and B. Segal, 2010, Management's tone change, post earnings announcement drift and accruals, Review of Accounting Studies 15, 915-953.

Fernandes, D., J.G. Lynch, and R.G. Netemeyer, 2014, Financial literacy, financial education, and downstream financial behaviors, Management Science 60, 1861-1883.

Foerster, S., J.T. Linnainmaa, B.T. Melzer, and A. Previtero, 2017, Retail financial advice: Does one size fit all?, Journal of Finance 72, 1441-1482.

Grinblatt, M., and M. Keloharju, 2009, Sensation seeking, overconfidence, and trading activity, Journal of Finance 64, 549-578.

Hackethal, A., M. Haliassos, and T. Jappelli, 2012, Financial advisors: A case of babysitters? Journal of Banking and Finance 36, 509-524.

Hartzmark, S.M., and A. Sussman, 2019, Do investors value sustainability? A natural experiment examining ranking and fund flows, Journal of Finance 74, 2789-2837.

Hauser, D.J., and N. Schwarz, 2016, Attentive Turkers: MTurk participants perform better on online attention checks than do subject pool participants, Behavior Research Methods 48, 400-407.

Heimer, R.Z., 2016, Peer pressure: Social interaction and the disposition effect, Review of Financial Studies 29, 3177-3209.

Heimer, R.Z., and D. Simon, 2015, Facebook finance: How social interaction propagates active investing, Working Paper, Federal Reserve Bank of Cleveland.

Heimer, R.Z., and A. Simsek, 2019, Should retail investors' leverage be limited?, Journal of Financial Economics 132, 1-21.

Hillert, A., H. Jacobs, and S. Müller, 2014, Media makes momentum, Review of Financial Studies $27,3467-3501$.

Hillert, A., A. Niessen-Ruenzi, and S. Ruenzi, 2016, Mutual fund shareholder letters: Flows, performance, and managerial behavior, Working Paper, University of Mannheim.

Hoechle, D., S. Ruenzi, N. Schaub, and M. Schmid, 2018, Financial advice and bank profits, Review of Financial Studies 31, 4447-4492.

Huang, A.H., A.Y. Zang, and R. Zheng, 2014, Evidence on the information content of text in analyst reports, Accounting Review 89, 2151-2180.

Hvidkjaer, S., 2008, Small trades and the cross-section of stock returns, Review of Financial Studies $21,1123-1151$.

Kale, J.R.K., E. Reis, and A. Venkateswaran, 2009, Rank-order tournaments and incentive alignment: The effect on firm performance, Journal of Finance 64, 1479-1512.

Kahneman, D., and A. Tversky, 1979, Prospect theory: An analysis of decision under risk, Econometrica 47, 263-291.

Kaniel, R., G. Saar, and S. Titman, 2008, Individual investor trading and stock returns, Journal of Finance 63, 273-310.

Karlan, D., M. McConnell, S. Mullainathan, and J. Zinman, 2016, Getting to the top of mind: How reminders increase saving, Management Science 62, 3393-3411.

Kelley, E.K., and P.C. Tetlock, 2013, How wise are crowds? Insights from retail orders and stock 
returns, Journal of Finance 68, 1229-1265.

Kelley, E.K., and P.C. Tetlock, 2017, Retail short selling and stock returns, Review of Financial Studies 30, 801-834.

Kim, S.-H., and D. Kim, 2014, Investor sentiment from internet message postings and the predictability of stock returns, Journal of Economic Behavior and Organization 107, 708-729.

Kothari, S.P., X. Li, J.E. Short, 2009, The effect of disclosures by management, analysts, and business press on cost of capital, return volatility, and analyst forecasts: A study using content analysis, Accounting Review 84, 1639-1670.

Lee, C.M.C., and B. Radhakrishna, 2000, Inferring investor behavior: Evidence from TORQ data, Journal of Financial Markets 3, 83-111.

Lian, C., Y. Ma, and C. Wang, 2019, Low interest rates and risk taking: Evidence from individual investment decisions, Review of Financial Studies 32, 2107-2148.

Loughran, T., and B. McDonald, 2011, When is a liability not a liability? Textual analysis, dictionaries, and 10-Ks, Journal of Finance 66, 35-65.

Mikhail, M.B., B.R. Walther, and R.H. Willis, 2007, When security analysts talk, who listens?, Accounting Review 82, 1227-1253.

Malmendier, U., and D. Shanthikumar, 2007, Are small investors naïve about incentives?, Journal of Financial Economics 85, 457-489.

Odean, T., 1999, Do investors trade too much?, American Economic Review 89, 1279-1298

Paolacci, G., and J. Chandler, 2014, Inside the Turk: Understanding Mechanical Turk as a participant pool, Current Directions in Psychological Science 23, 184-188.

Peress, J., and D. Schmidt, 2020, Glued to the TV: Distracted noise traders and stock market liquidity, Journal of Finance 75, 1083-1133.

Remus, R., U. Quasthoff, and G. Heyer, 2010, SentiWS - a publicly available German-language resource for sentiment analysis, Proceedings of the 7th International Language Resources and Evaluation, 1168-1171.

SEC, 2001, Investor alert: Stock market fraud "survivor" checklist, https://www.sec.gov/ reportspubs/investor-publications/investorpubsfraudsurvivorhtm.html.

SEC, 2007, Avoiding Internet investment scams: Tips for investors, https://www.sec.gov/ reportspubs/investor-publications/investorpubsscamshtm.html.

SEC, 2011, Internet fraud, https://www.sec.gov/reportspubs/investor-publications/ investorpubscyberfraudhtm.html.

SEC, 2015, Updated investor alert: Social media and investing - Stock rumors, https ://www . sec . gov/oiea/investor-alerts-bulletins/ia_rumors.html.

SEC, 2016, Updated investor alert: Fraudulent stock promotions, https://www.sec.gov/oiea/ investor-alerts-bulletins/ia_promotions.html.

SEC, 2017a, SEC: Payments for bullish articles on stocks must be disclosed to investors, https: //www.sec.gov/news/press-release/2017-79.

SEC, 2017b, Investor alert: Beware of stock recommendations on investment research websites, https://www.sec.gov/oiea/investor-alerts-and-bulletins/iastockrecommendations.

Tetlock, P.C., 2007, Giving content to investor sentiment: The role of media in the stock market, Journal of Finance 62, 1139-1168.

Tumarkin, R., and R.F. Whitelaw, 2001, News or noise? Internet postings and stock prices, Financial Analyst Journal 57, 41-51. 


\section{Tables}

\section{Table 1: Descriptive statistics}

This table presents descriptive statistics on comment characteristics (Panel A), follower characteristics (Panel B), performance characteristics (Panel C), portfolio characteristics (Panel D), and trader characteristics (Panel E). For time-varying variables, either end-of-period values (Age) or averages over the sample period from January 2013 to December 2014 are reported (all other time-varying variables). The Appendix provides detailed descriptions of all variables used throughout the study.

\begin{tabular}{|c|c|c|c|c|c|c|}
\hline & Mean & Minimum & Median & Maximum & $\begin{array}{l}\text { Standard } \\
\text { deviation }\end{array}$ & $\mathrm{N}$ \\
\hline \multicolumn{7}{|c|}{ Panel A: Comment characteristics } \\
\hline Comment (d) & 0.053 & 0.000 & 0.000 & 1.000 & 0.112 & 2,161 \\
\hline \# comments & 1.48 & 1.00 & 1.25 & 12.60 & 0.76 & 1,077 \\
\hline \# words per comment & 35.79 & 5.00 & 20.00 & $1,641.00$ & 52.93 & 29,204 \\
\hline$\%$ positive words & 5.07 & 0.00 & 4.00 & 50.00 & 5.56 & 29,204 \\
\hline$\%$ negative words & 1.74 & 0.00 & 0.00 & 40.00 & 3.44 & 29,204 \\
\hline \multicolumn{7}{|c|}{ Panel B: Follower characteristics } \\
\hline Trade size (EUR) & $5,359.56$ & 0.01 & $2,236.56$ & $324,586.72$ & $11,265.75$ & 43,676 \\
\hline Net investments (EUR) & 105.87 & $-27,796.70$ & 0.00 & $23,211.87$ & $1,056.86$ & 2,161 \\
\hline \multicolumn{7}{|c|}{ Panel C: Performance characteristics } \\
\hline Return (\%) & -0.021 & -11.332 & 0.017 & 3.899 & 0.452 & 1,930 \\
\hline Alpha $(\%)$ & -0.041 & -12.424 & -0.011 & 15.828 & 0.649 & 1,930 \\
\hline \multicolumn{7}{|c|}{ Panel D: Portfolio characteristics } \\
\hline \# followers & 5.31 & 0.00 & 0.04 & $1,165.73$ & 41.76 & 2,161 \\
\hline Funds of followers (EUR) & 22,563 & 0 & 26 & $6,828,934$ & 205,570 & 2,161 \\
\hline Age (days) & 324.43 & 1.00 & 238.00 & 886.00 & 250.87 & 2,161 \\
\hline Real money account (d) & 0.093 & 0.000 & 0.000 & 1.000 & 0.291 & 2,161 \\
\hline \# securities & 12.41 & 0.00 & 8.95 & 71.00 & 13.07 & 2,161 \\
\hline$\%$ stocks & 53.25 & 0.00 & 61.09 & 105.56 & 37.62 & 2,149 \\
\hline$\%$ funds & 18.34 & 0.00 & 0.55 & 104.89 & 29.76 & 2,149 \\
\hline$\%$ derivatives & 2.25 & 0.00 & 0.00 & 100.19 & 9.53 & 2,149 \\
\hline$\%$ cash & 22.48 & -6.70 & 12.30 & 100.00 & 25.01 & 2,149 \\
\hline \# trades & 1.22 & 0.00 & 0.34 & 18.00 & 2.31 & 2,161 \\
\hline Turnover (\%) & 3.64 & 0.00 & 0.88 & 75.88 & 7.88 & 2,161 \\
\hline \multicolumn{7}{|c|}{ Panel E: Trader characteristics } \\
\hline Professional (d) & 0.022 & 0.000 & 0.000 & 1.000 & 0.147 & 1,314 \\
\hline Experienced (d) & 0.934 & 0.000 & 1.000 & 1.000 & 0.249 & 1,314 \\
\hline Female (d) & 0.021 & 0.000 & 0.000 & 1.000 & 0.144 & 1,314 \\
\hline \# portfolios & 1.61 & 1.00 & 1.00 & 9.21 & 1.13 & 1,314 \\
\hline
\end{tabular}




\section{Table 2: Comments and trades of followers}

This table presents the results from panel regressions with portfolio and day fixed effects. The dependent variable is the inverse hyperbolic sine of daily net investments of followers. The Appendix provides detailed descriptions of all variables used throughout the study. Standard errors are clustered at the portfolio level. t-statistics are provided in parentheses. $* * *, * *, *$ denote statistical significance at the $1 \%, 5 \%, 10 \%$ level.

\begin{tabular}{|c|c|c|c|}
\hline & \multicolumn{3}{|c|}{ Log(net investments) } \\
\hline & $(1)$ & $(2)$ & $(3)$ \\
\hline Comment $(\mathrm{d})_{\mathrm{t}-1}$ & $\begin{array}{c}0.309^{* * *} \\
(6.00)\end{array}$ & $\begin{array}{c}0.073^{* * *} \\
(2.99)\end{array}$ & $\begin{array}{c}0.060^{* *} \\
(1.97)\end{array}$ \\
\hline Return $(\%)_{t-1}$ & & $\begin{array}{c}0.008^{* * *} \\
(3.66)\end{array}$ & $\begin{array}{l}0.007 * * * \\
(2.97)\end{array}$ \\
\hline Return $(\%)_{\mathrm{t}-2}$ & & $\begin{array}{c}0.006^{* * *} \\
(3.63)\end{array}$ & $\begin{array}{l}0.006^{* * *} \\
(3.41)\end{array}$ \\
\hline Return $(\%)_{\mathrm{t}-3}$ & & $\begin{array}{l}0.002 \\
(1.46)\end{array}$ & $\begin{array}{l}0.002 \\
(1.34)\end{array}$ \\
\hline Return $(\%)_{\mathrm{t}-4}$ & & $\begin{array}{c}-0.003^{*} \\
(-1.89)\end{array}$ & $\begin{array}{c}-0.003^{*} \\
(-1.83)\end{array}$ \\
\hline Return $(\%)_{\mathrm{t}-5}$ & & $\begin{array}{l}0.000 \\
(0.04)\end{array}$ & $\begin{array}{l}0.000 \\
(0.12)\end{array}$ \\
\hline Past 1-month return $(\%)_{\mathrm{t}-1}$ & & $\begin{array}{c}0.003^{* * *} \\
(3.35)\end{array}$ & $\begin{array}{c}0.004^{* * *} \\
(2.87)\end{array}$ \\
\hline Past 3-month return $(\%)_{\mathrm{t}-1}$ & & $\begin{array}{c}0.001^{* * *} \\
(3.71)\end{array}$ & $\begin{array}{c}0.001^{* * *} \\
(4.91)\end{array}$ \\
\hline Past 6-month return $(\%)_{\mathrm{t}-1}$ & & $\begin{array}{l}0.000 \\
(0.68)\end{array}$ & $\begin{array}{l}0.001 \\
(0.67)\end{array}$ \\
\hline Past 1-year return $(\%)_{\mathrm{t}-1}$ & & $\begin{array}{l}0.000 \\
(0.94)\end{array}$ & $\begin{array}{l}0.000 \\
(0.32)\end{array}$ \\
\hline Return since inception $(\%)_{\mathrm{t}-1}$ & & $\begin{array}{l}-0.000 \\
(-0.45)\end{array}$ & $\begin{array}{l}0.000 \\
(0.14)\end{array}$ \\
\hline $\log (\text { net investments })_{\mathrm{t}-1}$ & & $\begin{array}{c}0.143^{* * *} \\
(18.20)\end{array}$ & $\begin{array}{c}0.136^{* * *} \\
(17.00)\end{array}$ \\
\hline $\log (\text { net investments })_{\mathrm{t}-2}$ & & $\begin{array}{c}0.115^{* * *} \\
(20.93)\end{array}$ & $\begin{array}{c}0.109^{* * *} \\
(18.80)\end{array}$ \\
\hline $\log (\text { net investments) })_{\text {-3 }}$ & & $\begin{array}{c}0.096^{* * *} \\
(15.36)\end{array}$ & $\begin{array}{c}0.090^{* * * *} \\
(13.77)\end{array}$ \\
\hline $\log (\text { net investments })_{\mathrm{t}-4}$ & & $\begin{array}{c}0.086^{* * *} \\
(12.11)\end{array}$ & $\begin{array}{c}0.080 * * * \\
(10.99)\end{array}$ \\
\hline $\log (\text { net investments })_{t-5}$ & & $\begin{array}{c}0.091^{* * *} \\
(13.24)\end{array}$ & $\begin{array}{c}0.085^{* * *} \\
(12.45)\end{array}$ \\
\hline $\log (\text { past } 1 \text {-month net investments })_{\mathrm{t}-1}$ & & $\begin{array}{c}0.010^{* * *} \\
(4.37)\end{array}$ & $\begin{array}{c}0.010^{* * *} \\
(4.43)\end{array}$ \\
\hline $\log$ (funds of followers) $\mathrm{t}-1$ & & $\begin{array}{c}-0.003^{* * *} \\
(-3.23)\end{array}$ & $\begin{array}{c}-0.039 * * * \\
(-14.04)\end{array}$ \\
\hline $\log ($ age $)$ & & $\begin{array}{c}-0.024^{* * *} \\
(-8.59)\end{array}$ & $\begin{array}{c}-0.023^{* *} \\
(-2.25)\end{array}$ \\
\hline Real money account $(\mathrm{d})_{\mathrm{t}-1}$ & & $\begin{array}{c}0.070^{* * *} \\
(2.78)\end{array}$ & $\begin{array}{c}-0.227^{* * *} \\
(-3.84)\end{array}$ \\
\hline \# securitiest $\mathrm{t}$ & & $\begin{array}{l}-0.000 \\
(-1.19)\end{array}$ & $\begin{array}{l}-0.001 \\
(-0.68)\end{array}$ \\
\hline Turnover $(\%)_{\mathrm{t}-1}$ & & $\begin{array}{c}0.002^{* * *} \\
(4.85)\end{array}$ & $\begin{array}{c}0.002^{* * *} \\
(4.51)\end{array}$ \\
\hline
\end{tabular}




\begin{tabular}{|c|c|c|c|}
\hline Professional (d) & & $\begin{array}{l}0.024 \\
(0.43)\end{array}$ & \\
\hline Experienced (d) & & $\begin{array}{l}0.005 \\
(0.31)\end{array}$ & \\
\hline Female (d) & & $\begin{array}{l}0.027 \\
(0.88)\end{array}$ & \\
\hline$\#$ portfolios $_{\mathrm{t}-1}$ & & $\begin{array}{l}-0.001 \\
(-0.83)\end{array}$ & $\begin{array}{l}-0.033 \\
(-1.02)\end{array}$ \\
\hline Constant & $\begin{array}{c}0.057^{* * * *} \\
(8.90)\end{array}$ & $\begin{array}{c}0.140^{* * *} \\
(7.13)\end{array}$ & \\
\hline Portfolio fixed effects & No & No & Yes \\
\hline Day fixed effects & No & No & Yes \\
\hline Adj. $R^{2}$ & 0.001 & 0.125 & 0.131 \\
\hline $\mathrm{N}$ & 475,288 & 475,288 & 475,288 \\
\hline
\end{tabular}




\section{Table 3: Comments, investments, and withdrawals}

This table presents the results from panel regressions with portfolio and day fixed effects. The dependent variable is either the inverse hyperbolic sine of daily investments of followers (Column 1) or the inverse hyperbolic sine of daily withdrawals of followers (Column 2). The variables Return (\%) ${ }_{t-1}$, Return $(\%)_{t-2}$, Return $(\%)_{t-3}$, Return (\%) $)_{t-4}$, Return $(\%)_{t-5}$, Past 1-month return $(\%)_{t-1}$, Past 3-month return (\%) $)_{t-1}$, Past 6-month return (\%) $)_{t-1}$, Past 1-year return (\%) $t_{t-1}$, Return since inception $(\%)_{t-1}, \log \left(\right.$ net investments) ${ }_{t-1}, \log (\text { net investments) })_{t-2}, \log (\text { net investments) })_{t-3}$, $\log (\text { net investments })_{t-4}, \log (\text { net investments })_{t-5}, \log (\text { past 1-month net investments })_{t-1}$, Log(funds of followers) $)_{t-1}$,

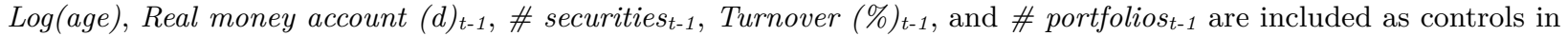
every regression but not reported (see Table IA3 in the Internet Appendix for coefficients on controls). The Appendix provides detailed descriptions of all variables used throughout the study. Standard errors are clustered at the portfolio level. t-statistics are provided in parentheses. ${ }^{* * *},{ }^{* *}, *^{*}$ denote statistical significance at the $1 \%, 5 \%, 10 \%$ level.

\begin{tabular}{lcc}
\hline & $\log ($ investments $)$ & $\log ($ withdrawals $)$ \\
\cline { 2 - 3 } & $(1)$ & $(2)$ \\
\hline Comment $(\mathrm{d})_{\mathrm{t}-1}$ & $0.116^{* * *}$ & $0.041^{* *}$ \\
& $(4.96)$ & $(2.36)$ \\
\hline Controls & Yes & Yes \\
Portfolio fixed effects & Yes & Yes \\
Day fixed effects & Yes & Yes \\
Adj. R ${ }^{2}$ & 0.390 & 0.318 \\
$\mathrm{~N}$ & 475,288 & 475,288 \\
\hline
\end{tabular}




\section{Table 4: Comments and trades of followers in the longer run}

This table presents the results from panel regressions with portfolio and day fixed effects. The dependent variable is the inverse hyperbolic sine of average daily net investments of followers. We compute average daily net investments for each week after the posting of a comment. The variables Return (\%) $t-1$, Return $(\%)_{t-2}$, Return $(\%)_{t-3}$, Return $(\%)_{t-4}$, Return $(\%)_{t-5}$, Past 1-month return $(\%)_{t-1}$, Past 3-month return $(\%)_{t-1}$, Past 6-month return (\%) $)_{t-1}$, Past 1-year return (\%) ${ }_{t-1}$,

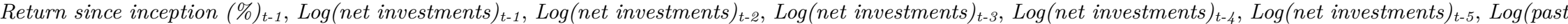
1-month net investments) $)_{t-1}, \log (\text { funds of followers })_{t-1}, \log ($ age $)$, Real money account $(d)_{t-1}$, \# securitiest-1, Turnover (\%) $)_{t-1}$, and \# portfoliost-1 are included as controls in every regression but not reported (see Table IA4 in the Internet Appendix for coefficients on controls). The Appendix provides detailed descriptions of all variables used throughout the study. Standard errors are clustered at the portfolio level. t-statistics are provided in parentheses. $* * *, * *, *$ denote statistical significance at the $1 \%, 5 \%, 10 \%$ level.

\begin{tabular}{|c|c|c|c|c|c|c|c|c|}
\hline & \multicolumn{8}{|c|}{ Log(net investments) } \\
\hline & $\begin{array}{c}\mathrm{t}, \mathrm{t}+4 \\
(\text { week 1) }\end{array}$ & $\begin{array}{l}\mathrm{t}+5, \mathrm{t}+9 \\
(\text { week } 2 \text { ) } \\
\end{array}$ & $\begin{array}{c}\mathrm{t}+10, \mathrm{t}+14 \\
(\text { week } 3)\end{array}$ & $\begin{array}{c}\mathrm{t}+15, \mathrm{t}+19 \\
(\text { week } 4)\end{array}$ & $\begin{array}{c}\mathrm{t}+20, \mathrm{t}+24 \\
(\text { week } 5)\end{array}$ & $\begin{array}{c}\mathrm{t}+25, \mathrm{t}+29 \\
(\text { week } 6) \\
\end{array}$ & $\begin{array}{c}\mathrm{t}+30, \mathrm{t}+34 \\
(\text { week } 7) \\
\end{array}$ & $\begin{array}{c}\mathrm{t}+35, \mathrm{t}+39 \\
(\text { week } 8)\end{array}$ \\
\hline & $(1)$ & $(2)$ & $(3)$ & $(4)$ & $(5)$ & $(6)$ & $(7)$ & $(8)$ \\
\hline Comment $(\mathrm{d})_{\mathrm{t}-1}$ & $\begin{array}{c}0.151^{* * *} \\
(3.98)\end{array}$ & $\begin{array}{l}0.076^{*} \\
(1.77)\end{array}$ & $\begin{array}{c}0.086^{*} \\
(1.80)\end{array}$ & $\begin{array}{c}0.058 \\
(1.09)\end{array}$ & $\begin{array}{l}0.030 \\
(0.61)\end{array}$ & $\begin{array}{l}0.022 \\
(0.45)\end{array}$ & $\begin{array}{l}-0.047 \\
(-0.94)\end{array}$ & $\begin{array}{l}-0.025 \\
(-0.59)\end{array}$ \\
\hline Controls & Yes & Yes & Yes & Yes & Yes & Yes & Yes & Yes \\
\hline Portfolio fixed effects & Yes & Yes & Yes & Yes & Yes & Yes & Yes & Yes \\
\hline Day fixed effects & Yes & Yes & Yes & Yes & Yes & Yes & Yes & Yes \\
\hline Adj. $R^{2}$ & 0.176 & 0.131 & 0.106 & 0.090 & 0.083 & 0.078 & 0.075 & 0.073 \\
\hline $\mathrm{N}$ & 466,652 & 456,136 & 445,893 & 435,659 & 425,586 & 415,857 & 406,156 & 396,478 \\
\hline
\end{tabular}


Table 5: Number of comments, length of comments, comment tone, and trades of followers

This table presents the results from panel regressions with portfolio and day fixed effects. The dependent variable is the inverse hyperbolic sine of daily net investments of followers. We restrict the sample to days with at least one comment posted on the preceding day. The variables Return $(\%)_{t-1}$, Return $(\%)_{t-2}$, Return $(\%)_{t-3}$, Return $(\%)_{t-4}$, Return $(\%)_{t-5}$, Past 1-month return (\%) ${ }_{t-1}$, Past 3-month return (\%) $)_{t-1}$, Past 6-month return (\%) ${ }_{t-1}$, Past 1-year return $(\%)_{t-1}$, Return since inception $(\%)_{t-1}$, Log (net investments $)_{t-1}$, Log (net investments $)_{t-2}$, Log $(\text { net investments) })_{t-3}$, $\log (\text { net investments })_{t-4}, \log (\text { net investments })_{t-5}, \log (\text { past 1-month net investments) })_{t-1}$, Log (funds of followers) ${ }_{t-1}$, Log(age), Real money account $(d)_{t-1}$, \# securities t-1 $_{1}$, Turnover $(\%)_{t-1}$, and \# portfoliost-1 are included as controls in every regression but not reported (see Table IA5 in the Internet Appendix for coefficients on controls). The Appendix provides detailed descriptions of all variables used throughout the study. Standard errors are clustered at the portfolio level. t-statistics are provided in parentheses. ${ }^{* * *}, * *, *$ denote statistical significance at the $1 \%, 5 \%, 10 \%$ level.

\begin{tabular}{|c|c|c|c|c|c|}
\hline & \multicolumn{5}{|c|}{$\log ($ net investments) } \\
\hline & $(1)$ & $(2)$ & $(3)$ & $(4)$ & $(5)$ \\
\hline $\log (\# \text { comments })_{\mathrm{t}-1}$ & $\begin{array}{c}0.086 \\
(1.05)\end{array}$ & & & & $\begin{array}{l}0.087 \\
(1.06)\end{array}$ \\
\hline $\log (\# \text { words per comment })_{\mathrm{t}-1}$ & & $\begin{array}{c}0.021 \\
(0.56)\end{array}$ & & & $\begin{array}{l}0.024 \\
(0.63)\end{array}$ \\
\hline$\%$ positive wordst-1 & & & $\begin{array}{c}0.009^{* *} \\
(2.05)\end{array}$ & & $\begin{array}{c}0.008^{*} \\
(1.96)\end{array}$ \\
\hline$\%$ negative wordst-1 & & & & $\begin{array}{l}-0.008 \\
(-1.01)\end{array}$ & $\begin{array}{l}-0.007 \\
(-0.87)\end{array}$ \\
\hline Controls & Yes & Yes & Yes & Yes & Yes \\
\hline Portfolio fixed effects & Yes & Yes & Yes & Yes & Yes \\
\hline Day fixed effects & Yes & Yes & Yes & Yes & Yes \\
\hline Adj. $R^{2}$ & 0.170 & 0.170 & 0.171 & 0.170 & 0.171 \\
\hline $\mathrm{N}$ & 19,190 & 19,190 & 19,190 & 19,190 & 19,190 \\
\hline
\end{tabular}




\section{Table 6: Comments and trades of followers - matched sample}

This table presents the results from panel regressions with portfolio and day fixed effects. The dependent variable is either the inverse hyperbolic sine of daily net investments of followers (Column 1), the inverse hyperbolic sine of daily investments of followers (Column 2), the inverse hyperbolic sine of daily withdrawals of followers (Column 3), or the inverse hyperbolic sine of average daily net investments of followers in the week after the posting of a comment (Column 4). We focus on a subsample after propensity score matching. The variables Return $(\%)_{t-1}$, Return $(\%)_{t-2}$, Return $(\%)_{t-3}$, Return $(\%)_{t-4}$, Return $(\%)_{t-5}$, Past 1-month return (\%) $)_{t-1}$, Past 3-month return $(\%)_{t-1}$, Past 6-month return (\%) $)_{-1}$, Past 1-year return $(\%)_{t-1}$, Return since inception $(\%)_{t-1}$, Log $(\text { net investments) })_{t-1}$,

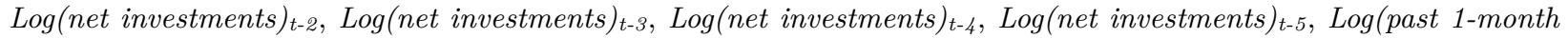
net investments $)_{t-1}, \log (\text { funds of followers })_{t-1}, \log ($ age $)$, Real money account $(d)_{t-1}$, \# securities $t_{-1}$, Turnover $(\%)_{t-1}$, and \# portfolios $t-1$ are included as controls in every regression but not reported. The Appendix provides detailed descriptions of all variables used throughout the study. Standard errors are clustered at the portfolio level. t-statistics are provided in parentheses. $* * *, * *, *$ denote statistical significance at the $1 \%, 5 \%, 10 \%$ level.

\begin{tabular}{lcccc}
\hline & $\begin{array}{c}\text { Log(net } \\
\text { investments) }\end{array}$ & Log(investments) & Log(withdrawals) & $\begin{array}{c}\text { Log(net } \\
\text { investments) } \\
\text { (week 1) }\end{array}$ \\
\cline { 2 - 5 } & $(1)$ & $(2)$ & $(3)$ & $(4)$ \\
\hline Comment (d)t-1 & 0.074 & $0.089^{* *}$ & 0.009 & $0.202^{* * *}$ \\
& $(1.34)$ & $(2.56)$ & Yes & $(3.46)$ \\
\hline Controls & Yes & Yes & Yes & Yes \\
Portfolio fixed effects & Yes & Yes & Yes & Yes \\
Day fixed effects & Yes & 0.484 & 0.383 & 0.224 \\
Adj. R & 0.152 & 37,848 & 37,848 & 37,140 \\
$\mathrm{~N}$ & 37,848 & & & \\
\hline
\end{tabular}




\section{Table 7: The predictive power of comments for future performance}

This table presents the results from panel regressions with portfolio and day fixed effects. The dependent variable is either the daily raw return of portfolios (Columns 1 to 6 ) or the daily alpha of portfolios (Columns 7 to 12). In Columns 2 to 6 and 8 to 12 , we restrict the sample to days with at least one comment posted on the preceding day. Daily alphas are calculated as the difference between daily excess returns and predicted excess returns using a four-factor model. The factor exposures used to predict excess returns are estimated over 6-month rolling windows from t- 126 to t-1. The four-factor model includes the MSCI Europe Index as proxy for the market, a SMB factor (return difference between the MSCI Europe Small Cap Index and the MSCI Europe Index), a HML factor (return difference between the MSCI Europe Value Index and the MSCI Europe Growth Index), and a momentum factor (MSCI Europe Momentum Index). Excess returns are in excess of the return on the J.P. Morgan 3 Month Euro Cash Index. The variables Return $(\%)_{t-1}$, Return $(\%)_{t-2}$, Return (\%) $)_{t-3}$, Return $(\%)_{t-4}$ Return $(\%)_{t-5}$, Past 1-month return $(\%)_{t-1}$, Past 3-month return $(\%)_{t-1}$, Past 6 -month return $(\%)_{t-1}$, Past 1-year return $(\%)_{t-1}$, Return since inception $(\%)_{t-1}$,

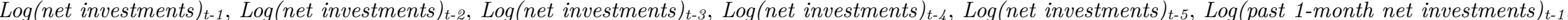
$\log (\text { funds of followers })_{t-1}, \log ($ age $)$, Real money account $(d)_{t-1}$, \# securities $t_{-1}$, Turnover $(\%)_{t-1}$, and \# portfoliost-1 are included as controls in every regression but not reported. The Appendix provides detailed descriptions of all variables used throughout the study. Standard errors are clustered at the portfolio level. t-statistics are provided in parentheses. ${ }^{* * *}, * *, *$ denote statistical significance at the $1 \%, 5 \%, 10 \%$ level.

\begin{tabular}{|c|c|c|c|c|c|c|c|c|c|c|c|c|}
\hline & \multicolumn{6}{|c|}{ Return (\%) } & \multicolumn{6}{|c|}{ Alpha $(\%)$} \\
\hline & $(1)$ & $(2)$ & $(3)$ & $(4)$ & $(5)$ & $(6)$ & $(7)$ & $(8)$ & $(9)$ & $(10)$ & $(11)$ & $(12)$ \\
\hline Comment $(d)_{t-1}$ & $\begin{array}{l}0.027 \\
(1.44)\end{array}$ & & & & & & $\begin{array}{l}0.002 \\
(0.11)\end{array}$ & & & & & \\
\hline $\log (\# \text { comments })_{\mathrm{t}-1}$ & & $\begin{array}{l}-0.046 \\
(-0.91)\end{array}$ & & & & $\begin{array}{l}-0.046 \\
(-0.89)\end{array}$ & & $\begin{array}{l}-0.051 \\
(-1.10)\end{array}$ & & & & $\begin{array}{l}-0.051 \\
(-1.09)\end{array}$ \\
\hline $\log (\# \text { words per comment })_{t-1}$ & & & $\begin{array}{l}0.021 \\
(0.98)\end{array}$ & & & $\begin{array}{l}0.021 \\
(1.00)\end{array}$ & & & $\begin{array}{l}0.019 \\
(0.86)\end{array}$ & & & $\begin{array}{l}0.019 \\
(0.86)\end{array}$ \\
\hline$\%$ positive words & & & & $\begin{array}{c}0.006^{* *} \\
(2.22)\end{array}$ & & $\begin{array}{c}0.006^{* *} \\
(2.23)\end{array}$ & & & & $\begin{array}{l}0.003 \\
(0.96)\end{array}$ & & $\begin{array}{l}0.003 \\
(1.00)\end{array}$ \\
\hline$\%$ negative words & & & & & $\begin{array}{l}-0.003 \\
(-0.60) \\
\end{array}$ & $\begin{array}{l}-0.002 \\
(-0.44) \\
\end{array}$ & & & & & $\begin{array}{l}0.001 \\
(0.35) \\
\end{array}$ & $\begin{array}{l}0.002 \\
(0.45) \\
\end{array}$ \\
\hline Controls & Yes & Yes & Yes & Yes & Yes & Yes & Yes & Yes & Yes & Yes & Yes & Yes \\
\hline Portfolio fixed effects & Yes & Yes & Yes & Yes & Yes & Yes & Yes & Yes & Yes & Yes & Yes & Yes \\
\hline Day fixed effects & Yes & Yes & Yes & Yes & Yes & Yes & Yes & Yes & Yes & Yes & Yes & Yes \\
\hline Adj. $R^{2}$ & 0.064 & 0.098 & 0.098 & 0.099 & 0.098 & 0.099 & 0.048 & 0.102 & 0.102 & 0.102 & 0.101 & 0.102 \\
\hline $\mathrm{N}$ & 475,288 & 19,190 & 19,190 & 19,190 & 19,190 & 19,190 & 412,819 & 15,364 & 15,364 & 15,364 & 15,364 & 15,364 \\
\hline
\end{tabular}




\section{Table 8: Performance of trades of followers}

This table presents the results from OLS regressions. The dependent variable is either the daily excess return of an aggregate calendar-time portfolio consisting of all individual portfolios of traders weighted based on investments of followers made on the day after the posting of a comment (Column 1), the daily excess return of an aggregate calendar-time portfolio consisting of all individual portfolios of traders weighted based on investments of followers made on all other days (Column 2), or the return difference between the two portfolios (Column 3). Daily alphas are estimated based on a four-factor model. The four-factor model includes the MSCI Europe Index as proxy for the market, a SMB factor (return difference between the MSCI Europe Small Cap Index and the MSCI Europe Index), a HML factor (return difference between the MSCI Europe Value Index and the MSCI Europe Growth Index), and a momentum factor (MSCI Europe Momentum Index). Excess returns are in excess of the return on the J.P. Morgan 3 Month Euro Cash Index. Standard errors are adjusted for heteroskedasticity. t-statistics are provided in parentheses. $* * *, * *, *$ denote statistical significance at the $1 \%, 5 \%, 10 \%$ level.

\begin{tabular}{|c|c|c|c|}
\hline & \multicolumn{3}{|c|}{ Excess return $(\%)$} \\
\hline & Trades after comments & Trades on all other days & Difference portfolio \\
\hline & $(1)$ & $(2)$ & $(3)$ \\
\hline Alpha (\%) & $\begin{array}{l}-0.032 \\
(-1.14)\end{array}$ & $\begin{array}{l}-0.025 \\
(-1.23)\end{array}$ & $\begin{array}{l}-0.007 \\
(-0.36)\end{array}$ \\
\hline Market excess return & $\begin{array}{c}0.555^{* * *} \\
(6.14)\end{array}$ & $\begin{array}{c}0.447^{* * *} \\
(6.98)\end{array}$ & $\begin{array}{l}0.107 \\
(1.42)\end{array}$ \\
\hline SMB & $\begin{array}{c}0.419^{* * *} \\
(5.36)\end{array}$ & $\begin{array}{c}0.320^{* * *} \\
(5.99)\end{array}$ & $\begin{array}{c}0.098^{*} \\
(1.70)\end{array}$ \\
\hline HML & $\begin{array}{c}0.421^{* * *} \\
(4.03)\end{array}$ & $\begin{array}{c}0.177^{* *} \\
(2.50)\end{array}$ & $\begin{array}{c}0.243^{* * *} \\
(3.13)\end{array}$ \\
\hline Momentum & $\begin{array}{c}0.105^{*} \\
(1.78)\end{array}$ & $\begin{array}{c}0.123^{* * *} \\
(2.62)\end{array}$ & $\begin{array}{l}-0.018 \\
(-0.37)\end{array}$ \\
\hline Adj. $R^{2}$ & 0.428 & 0.522 & 0.043 \\
\hline $\mathrm{N}$ & 506 & 506 & 506 \\
\hline
\end{tabular}




\section{Table 9: Which followers drive results?}

This table presents the results from panel regressions with portfolio and day fixed effects. The dependent variable is the inverse hyperbolic sine of daily net investments of followers. In Columns 1 and 3 (Columns 2 and 4 ), we restrict the sample to small (large) trades. We classify trades as small trades if they are smaller than EUR 5,000 (EUR 2,500) and as large trades if they are larger than or equal to EUR 5,000 (EUR 2,500). The variables Return $(\%)_{t-1}$, Return $(\%)_{t-2}$, Return $(\%)_{t-3}$, Return $(\%)_{t-4}$, Return $(\%)_{t-5}$, Past 1-month return (\%) $)_{t-1}$, Past 3-month return $(\%)_{t-1}$, Past 6-month return (\%) $)_{-1}$, Past 1-year return $(\%)_{t-1}$, Return since inception $(\%)_{t-1}$, Log $(\text { net investments) })_{t-1}$,

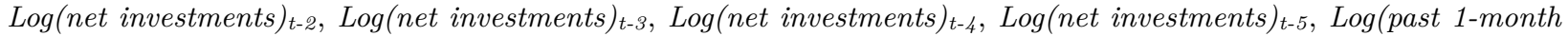
net investments $)_{t-1}, \log (\text { funds of followers })_{t-1}, \log ($ age $)$, Real money account $(d)_{t-1}$, \# securities $t_{t-1}$, Turnover $(\%)_{t-1}$, and \# portfolios p $-1_{1}$ are included as controls in every regression but not reported. The Appendix provides detailed descriptions of all variables used throughout the study. Standard errors are clustered at the portfolio level. t-statistics are provided in parentheses. ${ }^{* * *},{ }^{* *},{ }^{*}$ denote statistical significance at the $1 \%, 5 \%, 10 \%$ level.

\begin{tabular}{lcccc}
\hline & \multicolumn{4}{c}{ Log(net investments) } \\
\cline { 2 - 5 } & $\begin{array}{c}\text { Trade size }< \\
\text { EUR } 5,000\end{array}$ & $\begin{array}{c}\text { Trade size } \geq \\
\text { EUR 5,000 }\end{array}$ & $\begin{array}{c}\text { Trade size }< \\
\text { EUR 2,500 }\end{array}$ & $\begin{array}{c}\text { Trade size } \geq \\
\text { EUR 2,500 }\end{array}$ \\
\cline { 2 - 5 } & $(1)$ & $(2)$ & $(3)$ & $(4)$ \\
\hline Comment (d)t-1 & $0.059^{* *}$ & -0.001 & $0.054^{* * *}$ & 0.023 \\
& $(2.36)$ & $(-0.02)$ & $(2.67)$ & $(0.86)$ \\
\hline Portfolio fixed effects & Yes & Yes & Yes & Yes \\
Day fixed effects & Yes & Yes & 0.124 & 0.109 \\
Adj. R ${ }^{2}$ & 0.138 & 0.083 & 475,288 & 475,288 \\
$\mathrm{~N}$ & 475,288 & 475,288 & \\
\hline
\end{tabular}




\section{Table 10: Experimental analysis}

This table presents the fraction of subjects that decide to follow a trader if they see a positive comment or a negative comment on that trader's profile page. The Appendix provides detailed descriptions of all variables used throughout the study. Means of the subgroups are tested for equality using a standard t-test. ***, **, * denote statistical significance at the $1 \%, 5 \%, 10 \%$ level.

\begin{tabular}{|c|c|c|c|c|c|}
\hline & \multicolumn{2}{|c|}{$\%$ subjects that decide to follow } & \multirow[b]{2}{*}{ Difference } & \multirow[b]{2}{*}{ t-value } & \multirow[b]{2}{*}{$\mathrm{N}$} \\
\hline & $\begin{array}{c}\text { Positive } \\
\text { comment }\end{array}$ & $\begin{array}{l}\text { Negative } \\
\text { comment }\end{array}$ & & & \\
\hline All subjects & 54.25 & 37.50 & $16.75^{* * *}$ & 4.82 & 800 \\
\hline Invested in ideas shared online $(d)=1$ & 57.65 & 37.65 & $20.00^{* * *}$ & 2.65 & 170 \\
\hline Invested in ideas shared online $(d)=0$ & 53.33 & 37.46 & $15.87^{* * *}$ & 4.05 & 630 \\
\hline College education $(\mathrm{d})=1$ & 54.17 & 41.94 & $12.23^{* *}$ & 2.21 & 323 \\
\hline College education $(\mathrm{d})=0$ & 54.31 & 34.69 & $19.62^{* * *}$ & 4.39 & 477 \\
\hline \multicolumn{6}{|l|}{ Financial literacy (0-12) } \\
\hline High (tercile 3) & 50.91 & 37.04 & $13.87^{* *}$ & 2.07 & 218 \\
\hline Medium & 53.63 & 38.99 & $14.64^{* * *}$ & 2.71 & 338 \\
\hline Low (tercile 1) & 58.56 & 36.09 & $22.47^{* * *}$ & 3.58 & 244 \\
\hline
\end{tabular}




\section{Figures}

Figure 1: Sample profile page

This figure shows a sample profile page of a shared portfolio. We provide one possible translation of the profile page.

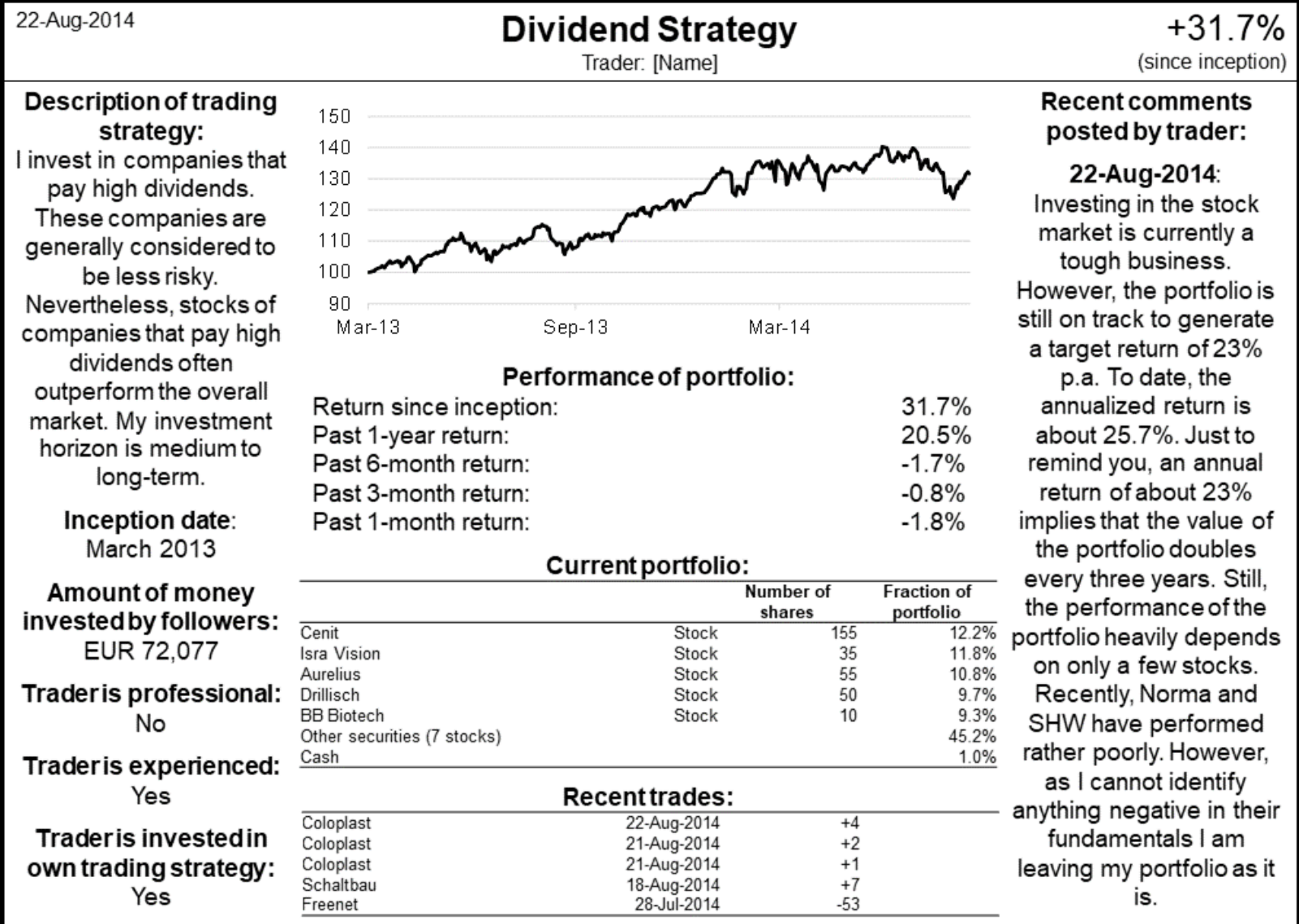


Figure 2: Number of portfolios and funds of followers

This figure shows the number of portfolios (Panel A) and funds of followers (Panel B) in our sample.

Panel A: Number of portfolios

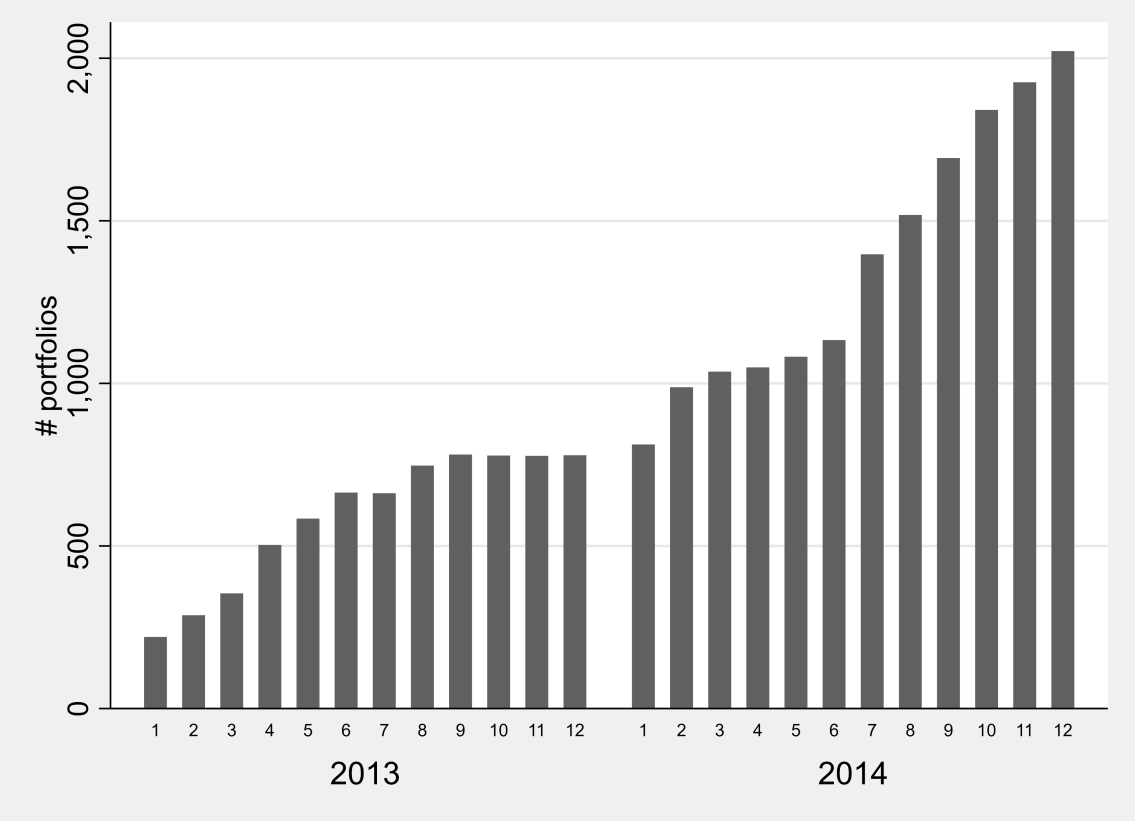

Panel B: Funds of followers

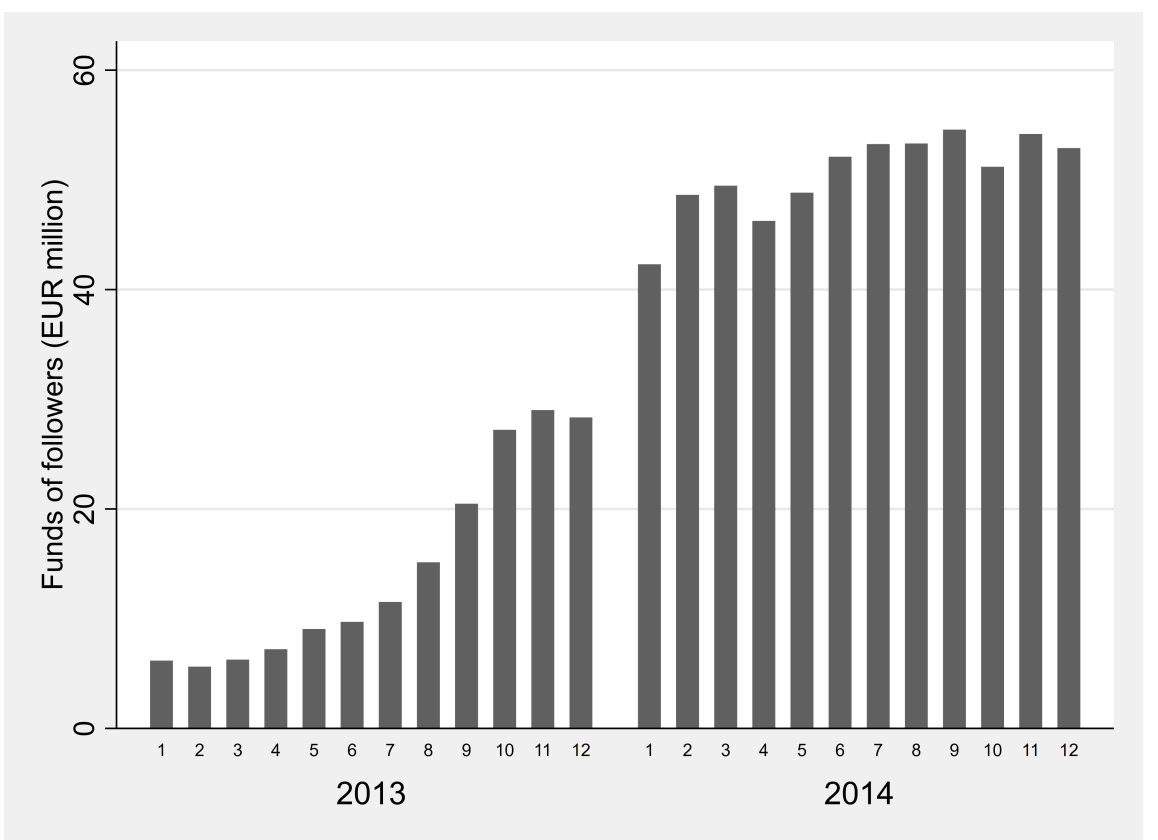




\section{Figure 3: Sample comments}

This figure shows six sample comments, of which three are general comments (Panel A) and the other three are firm-specific comments (Panel B). To identify positive and negative words in comments, we use word lists that are based on the Harvard IV-4 dictionary (Remus et al., 2010). Positive and negative words that are included in our dictionary are underlined. We provide one possible translation of comments.

\section{Panel A: General comments}

June 7, 2013:

Due to the protests in Turkey the performance of the Lyxor ETF Turkey deteriorated. However, as the overall economic environment has not changed, I'm keeping it as $5 \%$ of my portfolio.

June 5, 2014:

An exciting day lies ahead of us: This afternoon, the ECB will announce additional monetary policy measures. They may push the DAX above 10,000 points if the measures go beyond market expectations.

August 22, 2014:

Investing in the stock market is currently a tough business. However, the portfolio is still on track to generate a target return of $23 \% \mathrm{p} . \mathrm{a}$. To date, the annualized return is about $25.7 \%$. Just to remind you, an annual return of about $23 \%$ implies that the value of the portfolio doubles every three years. Still, the performance of the portfolio heavily depends on only a few stocks. Recently, Norma and SHW have performed rather poorly. However, as I cannot identify anything negative in their fundamentals I am leaving my portfolio as it is.

\section{Panel B: Firm-specific comments}

April 24, 2014, regarding GlaxoSmithKline (GB0009252882):

I'm selling GlaxoSmithKline with a gain of $2 \%$. Over the last couple of days, prices of major pharma stocks have increased substantially in the course of merger fantasies. I'm using this opportunity to exit.

March 19, 2013, regarding Apple (US0378331005):

Apple is expected to release good quarterly results.

October 29, 2014, regarding Cancom (DE0005419105):

Last night, Cancom reported extremely strong results: Revenues climbed by $46.5 \%$ to EUR 208.4 million in the third quarter and the earnings before interest, taxes, depreciation and amortization (EBITDA) rose by $93.8 \%$ to EUR 15.5 million, boosting the EBITDA margin to $7.4 \%$ from $5.6 \%$. In the first nine months of the year, Cancom reported a revenue increase of $39.7 \%$ to EUR $583.1 \mathrm{million}$ and the EBITDA rose by almost $65 \%$ to EUR 37.6 million. Given these great preliminary figures, I'm looking forward to the full report, which is going to be released on November 11 . In the past, I pointed out several times that this an excellent investment opportunity. I expect the stock to remain on a tear. 


\section{Figure 4: Comments and trades of followers in the longer run}

This figure shows the inverse hyperbolic sine of average daily net investments of followers around the posting of comments. We compute average daily net investments for each week beginning four weeks prior to the posting and ending eight weeks after the posting. Average daily net investments are demeaned by portfolio and by day. We drop comments if the trader posted another comment in the previous four weeks. We show point estimates together with $95 \%$ confidence intervals.

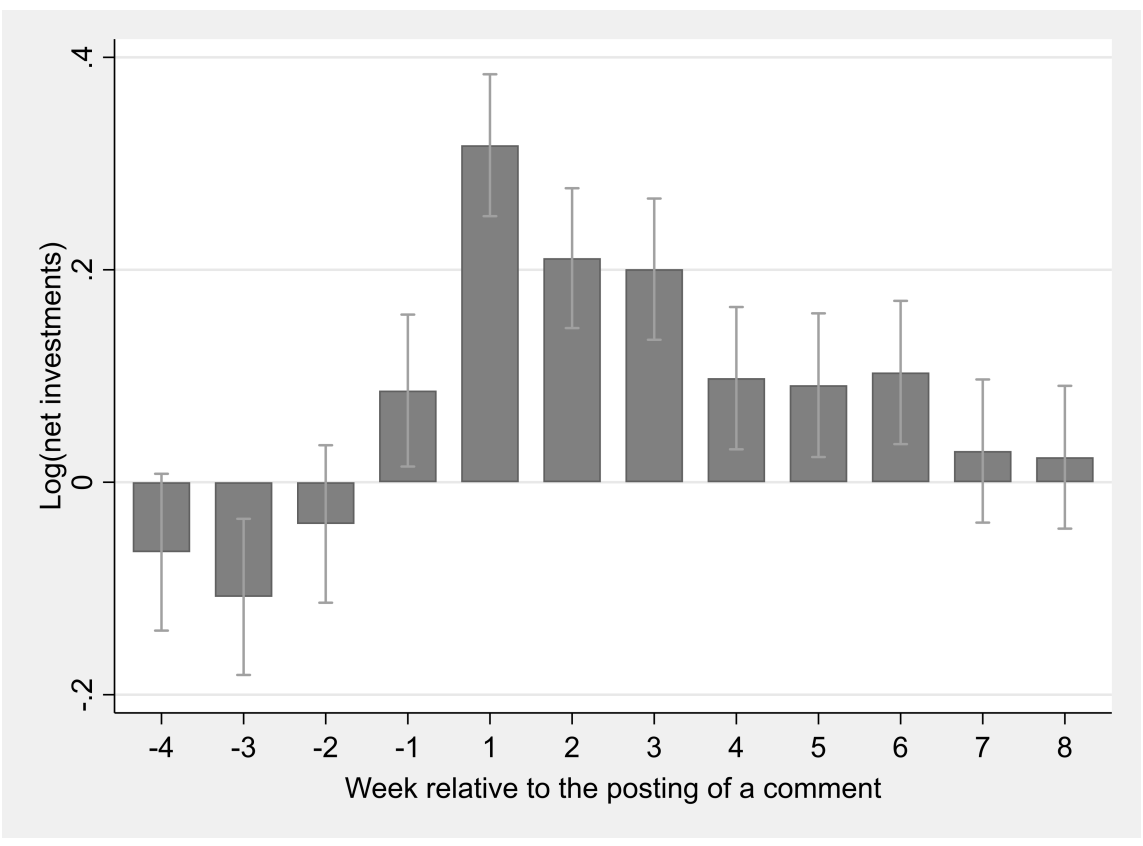




\section{Figure 5: Performance of trades of followers}

This figure shows the return of an aggregate calendar-time portfolio consisting of all individual portfolios of traders weighted based on investments of followers made on the day after the posting of a comment and the return of an aggregate calendar-time portfolio consisting of all individual portfolios of traders weighted based on investments of followers made on all other days. The figure also shows the return of the MSCI Europe (World) Index. Portfolios and indices are set to 100 on the first day of trading in January 2013.

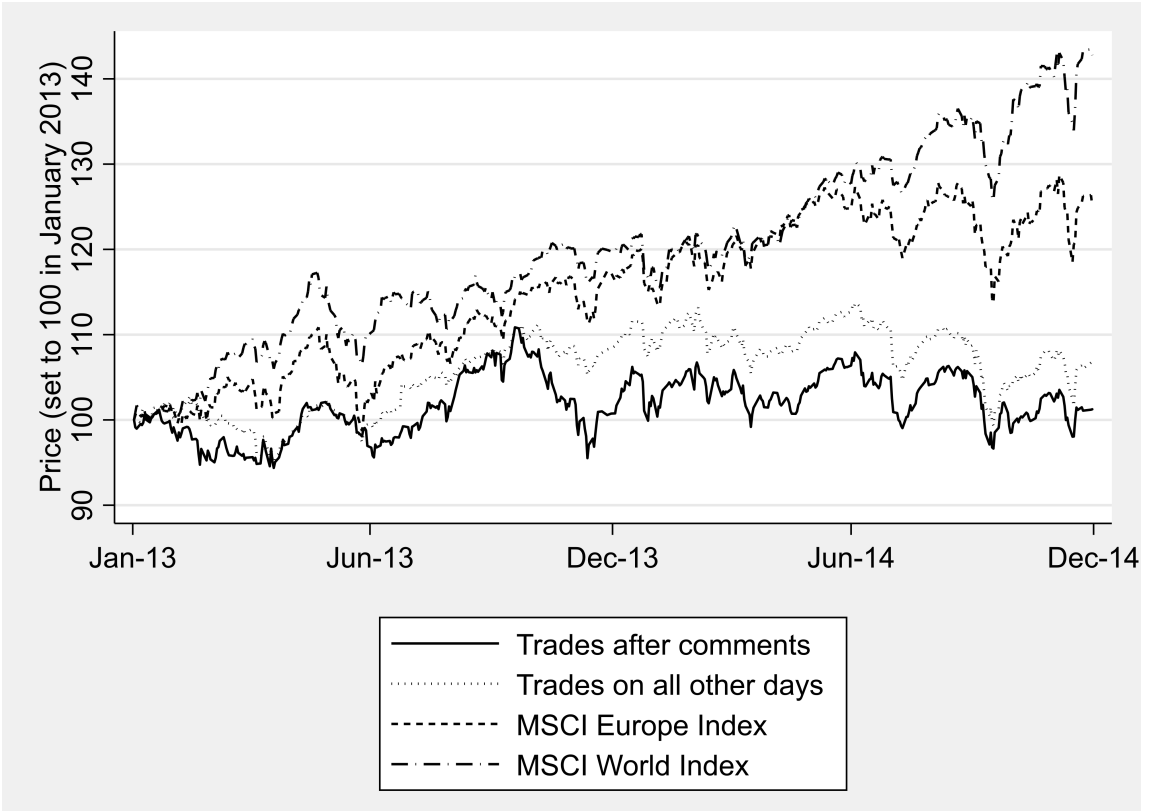




\section{Appendix: Variable descriptions}

This table defines the variables used throughout the study.

\begin{tabular}{|c|c|}
\hline Variable & Description \\
\hline \multicolumn{2}{|l|}{ Comment characteristics } \\
\hline Comment (d) & $\begin{array}{l}\text { Dummy variable that equals one on days on which traders post at least one } \\
\text { comment, and zero otherwise }\end{array}$ \\
\hline \# comments & Number of comments posted by the trader on a certain day \\
\hline $\log (\#$ comments $)$ & Ln(\# comments $)$ \\
\hline \# words per comment & Number of words per comment \\
\hline Log(\# words per comment) & Ln $(\#$ words per comment $)$ \\
\hline$\%$ positive words & Number of positive words per comment / Number of words per comment \\
\hline$\%$ negative words & Number of negative words per comment / Number of words per comment \\
\hline \multicolumn{2}{|l|}{ Follower characteristics } \\
\hline Trade size (EUR) & Trade size (in EUR) \\
\hline Investments (EUR) & Daily investments of followers who start replicating the trading strategy (in EUR) \\
\hline Log(investments) & Ln $\left(\right.$ Investments $\left.+\sqrt{\text { Investments }^{2}+1}\right)$ (inverse hyperbolic sine of Investments $)$ \\
\hline Withdrawals (EUR) & Daily withdrawals of followers who stop replicating the trading strategy (in EUR) \\
\hline $\log ($ net investments) & $\begin{array}{l}\text { Ln }(\text { Withdrawals }+\sqrt{\text { Withdrawals }}+1) \text { (inverse hyperbolic sine of } \\
\text { Withdrawals })\end{array}$ \\
\hline Net investments (EUR) & Investments - Withdrawals (in EUR) \\
\hline $\log ($ net investments) & $\begin{array}{l}\text { Ln }\left(\text { Net investments }+\sqrt{\text { Net investments }{ }^{2}+1}\right) \text { (inverse hyperbolic sine of } \\
\text { Net investments })\end{array}$ \\
\hline $\begin{array}{l}\text { Past 1-month net } \\
\text { investments (EUR) }\end{array}$ & Investments over the past month - Withdrawals over the past month (in EUR) \\
\hline $\begin{array}{l}\text { Log(past 1-month net } \\
\text { investments) }\end{array}$ & $\begin{array}{l}\text { Ln }\left(\text { Past 1-month net investments }+\sqrt{\text { Past } 1 \text {-month net investments }{ }^{2}+1}\right) \\
\text { (inverse hyperbolic sine of Past 1-month net investments) }\end{array}$ \\
\hline
\end{tabular}

Return (\%) Daily raw return of the portfolio net of transaction costs and fees charged by the platform

Alpha (\%)

Daily alpha of the portfolio net of transaction costs and fees charged by the platform. Daily alphas are calculated as the difference between daily excess returns and predicted excess returns using a four-factor model. The factor exposures used to predict excess returns are estimated over 6-month rolling windows from t-126 to t- 1 . The four-factor model includes the MSCI Europe Index as proxy for the market, a SMB factor (return difference between the MSCI Europe Small Cap Index and the MSCI Europe Index), a HML factor (return difference between the MSCI Europe Value Index and the MSCI Europe Growth Index), and a momentum factor (MSCI Europe Momentum Index). Excess returns are in excess of the return on the J.P. Morgan 3 Month Euro Cash Index

Past 1-month return (\%), Past 3-month return (\%), Past 6-month return (\%), Past 1-year return (\%), Return since inception (\%)
Raw return of the portfolio net of transaction costs and fees charged by the platform over the respective time period 
\# followers

Funds of followers (EUR)

$\log$ (funds of followers)

Age (days)

Log(age)

Real money account (d)

\# securities

$\%$ stocks, $\%$ funds,

$\%$ derivatives, $\%$ cash

\# trades

Turnover (\%)

\section{Trader characteristics}

Professional (d)

Experienced (d)

Female (d)

\# portfolios

Subject characteristics

Time (minutes)

Female (d)

Age (years)

College education (d)

Financial industry (d)

Invested in stocks or equity funds (d)

Invested in ideas shared online $(\mathrm{d})$

Financial literacy (0-12)
Number of followers who have allocated money to the trading strategy

Amount of money followers have allocated to the trading strategy (in EUR)

Ln(funds of followers)

Number of calendar days since the creation of the portfolio

Ln(age)

Dummy variable that equals one if the trader has a real money account, and zero otherwise

Number of securities in the trader's portfolio; winsorized at the $99 \%$ level

Value of the respective asset class in the trader's portfolio / Portfolio size

Number of trades in the trader's portfolio on a certain day; winsorized at the $99 \%$ level

$\frac{1}{2}$ (Value of all purchases executed in the trader's portfolio on a certain day + Value of all sales executed in the trader's portfolio on a certain day) / Portfolio size at the beginning of the day; winsorized at the $99 \%$ level

Dummy variable that equals one if the trader is a professional asset management firm as verified by the platform, and zero otherwise

Dummy variable that equals one for traders who have more than three years of trading experience, and zero otherwise

Dummy variable that equals one for female traders, and zero otherwise

Number of portfolios managed by the trader

Time it took subjects to complete the experiment (in minutes)

Dummy variable that equals one for female subjects, and zero otherwise

Age of the subject (in years)

Dummy variable that equals one for subjects who have a college education, and zero otherwise

Dummy variable that equals one for subjects who have worked in the financial industry, and zero otherwise; "Have you ever worked in the financial industry?" (answer: yes or no)

Dummy variable that equals one for subjects who have invested in stocks or equity funds, and zero otherwise; "Have you ever invested in stocks or equity funds?" (answer: yes or no)

Dummy variable that equals one for subjects who have invested in investment ideas shared on the Internet, and zero otherwise; "Have you ever invested in an investment idea that you found on the Internet?" (answer: yes or no)

Number of correct answers to 12 financial literacy questions from Fernandes et al. (2014). Item (8) from the original test was left out since the experiment was conducted in Europe and item (8) is a question related to 401(k) plans and therefore specific to the U.S. setting (score between 0 and 12) 


\title{
Internet Appendix to "Do Individual Investors Trade on Investment-related Internet Postings?"
}

\begin{abstract}
The Internet Appendix consists of three sections. Internet Appendix A contains additional tables. In Internet Appendix B, we discuss the robustness tests in Tables IA7 to IA10. Internet Appendix $\mathrm{C}$ provides additional information on the experiment.
\end{abstract}




\section{Appendix A: Additional tables}

Table IA1: Most frequently used positive and negative words

This table shows the 25 most frequently mentioned positive and negative words in traders' comments. To identify positive and negative words in comments, we use word lists that are based on the Harvard IV-4 dictionary (Remus et al., 2010). We provide one possible translation of words.

\begin{tabular}{|c|c|c|}
\hline Rank & Positive words & Negative words \\
\hline 1 & new & small \\
\hline 2 & good & unfortunately \\
\hline 3 & up-to-date & end \\
\hline 4 & strong & tight \\
\hline 5 & gain & short \\
\hline 6 & value & loss \\
\hline 7 & gains & risk \\
\hline 8 & correction & despite \\
\hline 9 & purchase & down \\
\hline 10 & easy & negative \\
\hline 11 & positive & smaller \\
\hline 12 & right & breakout \\
\hline 13 & favorable & low \\
\hline 14 & up & slow \\
\hline 15 & increase & reduce \\
\hline 16 & target & weak \\
\hline 17 & recovery & difficult \\
\hline 18 & better & weakness \\
\hline 19 & accomplished & poor \\
\hline 20 & share & decrease \\
\hline 21 & possible & crash \\
\hline 22 & nice & reduced \\
\hline 23 & great & little \\
\hline 24 & increased & weaker \\
\hline 25 & fast & downtrend \\
\hline
\end{tabular}


Table IA2: Determinants of comments

This table presents the results from a logit regression (Column 1) and OLS regressions with day fixed effects (Columns 2 to 5). The dependent variable is either a dummy variable that equals one on days on which traders post at least one comment, and zero otherwise (Column 1), the logarithm of the number of posted comments (Column 2), the logarithm of the number of words per comment (Column 3), the fraction of positive words per comment (Column 4), or the fraction of negative words per comment (Column 5). Column 1 shows marginal effects. In Columns 2 to 5 , we restrict the sample to days with at least one posted comment. The Appendix in the main paper provides detailed descriptions of all variables used throughout the study. Standard errors are clustered at the portfolio level. t-statistics are provided in parentheses. $* * *, * *, *$ denote statistical significance at the $1 \%, 5 \%, 10 \%$ level.

\begin{tabular}{|c|c|c|c|c|c|}
\hline & $\begin{array}{l}\text { Comment } \\
\text { (d) }\end{array}$ & $\begin{array}{c}\log (\# \\
\text { comments })\end{array}$ & $\begin{array}{c}\log (\# \\
\text { words per } \\
\text { comment) }\end{array}$ & $\begin{array}{c}\% \text { positive } \\
\text { words }\end{array}$ & $\begin{array}{c}\% \text { negative } \\
\text { words }\end{array}$ \\
\hline & $(1)$ & $(2)$ & $(3)$ & $(4)$ & $(5)$ \\
\hline Return $(\%)_{\mathrm{t}-1}$ & $\begin{array}{c}0.001^{* * * *} \\
(4.28)\end{array}$ & $\begin{array}{c}0.005^{* *} \\
(2.57)\end{array}$ & $\begin{array}{l}-0.007 \\
(-1.15)\end{array}$ & $\begin{array}{c}0.097^{* * * *} \\
(2.99)\end{array}$ & $\begin{array}{l}-0.016 \\
(-0.88)\end{array}$ \\
\hline Return $(\%)_{\mathrm{t}-2}$ & $\begin{array}{c}0.001^{* *} \\
(2.53)\end{array}$ & $\begin{array}{l}0.003 \\
(1.28)\end{array}$ & $\begin{array}{c}-0.015^{* * *} \\
(-2.61)\end{array}$ & $\begin{array}{c}0.084^{* *} \\
(2.43)\end{array}$ & $\begin{array}{l}-0.005 \\
(-0.29)\end{array}$ \\
\hline Return $(\%)_{\mathrm{t}-3}$ & $\begin{array}{c}0.001^{* * *} \\
(4.52)\end{array}$ & $\begin{array}{l}-0.001 \\
(-0.55)\end{array}$ & $\begin{array}{c}-0.014^{* *} \\
(-2.30)\end{array}$ & $\begin{array}{l}-0.004 \\
(-0.12)\end{array}$ & $\begin{array}{l}-0.011 \\
(-0.61)\end{array}$ \\
\hline Return $(\%)_{\mathrm{t}-4}$ & $\begin{array}{l}-0.000 \\
(-0.41)\end{array}$ & $\begin{array}{l}-0.001 \\
(-0.62)\end{array}$ & $\begin{array}{c}-0.015^{* * *} \\
(-2.59)\end{array}$ & $\begin{array}{c}-0.057^{*} \\
(-1.84)\end{array}$ & $\begin{array}{l}0.029 \\
(1.48)\end{array}$ \\
\hline Return $(\%)_{\mathrm{t}-5}$ & $\begin{array}{c}0.001^{* * *} \\
(2.96)\end{array}$ & $\begin{array}{l}0.002 \\
(0.96)\end{array}$ & $\begin{array}{l}-0.006 \\
(-0.99)\end{array}$ & $\begin{array}{l}0.031 \\
(1.07)\end{array}$ & $\begin{array}{l}-0.022 \\
(-0.97)\end{array}$ \\
\hline Past 1-month return $(\%)_{\mathrm{t}-1}$ & $\begin{array}{c}0.000 * * * \\
(3.50)\end{array}$ & $\begin{array}{l}0.000 \\
(0.58)\end{array}$ & $\begin{array}{c}-0.005^{* *} \\
(-2.28)\end{array}$ & $\begin{array}{c}0.021^{* *} \\
(2.19)\end{array}$ & $\begin{array}{l}-0.006 \\
(-1.11)\end{array}$ \\
\hline Past 3-month return $(\%)_{\mathrm{t}-1}$ & $\begin{array}{c}0.000^{* * *} \\
(3.80)\end{array}$ & $\begin{array}{c}0.002^{* * *} \\
(3.25)\end{array}$ & $\begin{array}{l}-0.003 \\
(-1.61)\end{array}$ & $\begin{array}{l}0.006 \\
(0.77)\end{array}$ & $\begin{array}{l}-0.002 \\
(-0.33)\end{array}$ \\
\hline Past 6-month return $(\%)_{\mathrm{t}-1}$ & $\begin{array}{l}0.000 \\
(0.82)\end{array}$ & $\begin{array}{c}0.000 \\
(0.36)\end{array}$ & $\begin{array}{l}0.002 \\
(1.24)\end{array}$ & $\begin{array}{l}0.006 \\
(1.08)\end{array}$ & $\begin{array}{l}0.003 \\
(0.76)\end{array}$ \\
\hline Past 1-year return $(\%)_{\mathrm{t}-1}$ & $\begin{array}{l}0.000 \\
(1.19)\end{array}$ & $\begin{array}{l}-0.000 \\
(-0.46)\end{array}$ & $\begin{array}{l}-0.002 \\
(-1.12)\end{array}$ & $\begin{array}{l}0.001 \\
(0.13)\end{array}$ & $\begin{array}{l}-0.000 \\
(-0.09)\end{array}$ \\
\hline Return since inception $(\%)_{\mathrm{t}-1}$ & $\begin{array}{l}0.000 \\
(0.54)\end{array}$ & $\begin{array}{l}0.000 \\
(1.28)\end{array}$ & $\begin{array}{c}0.003^{*} \\
(1.77)\end{array}$ & $\begin{array}{l}0.006 \\
(1.50)\end{array}$ & $\begin{array}{l}0.000 \\
(0.16)\end{array}$ \\
\hline $\log (\text { net investments })_{\mathrm{t}-1}$ & $\begin{array}{l}0.000 \\
(0.01)\end{array}$ & $\begin{array}{l}0.001 \\
(1.11)\end{array}$ & $\begin{array}{l}0.003 \\
(1.40)\end{array}$ & $\begin{array}{l}-0.015 \\
(-1.17)\end{array}$ & $\begin{array}{l}-0.000 \\
(-0.02)\end{array}$ \\
\hline $\log (\text { net investments })_{t-2}$ & $\begin{array}{l}0.000 \\
(0.83)\end{array}$ & $\begin{array}{l}-0.000 \\
(-0.15)\end{array}$ & $\begin{array}{l}0.000 \\
(0.12)\end{array}$ & $\begin{array}{l}0.007 \\
(0.65)\end{array}$ & $\begin{array}{l}-0.002 \\
(-0.27)\end{array}$ \\
\hline $\log (\text { net investments })_{\mathrm{t}-3}$ & $\begin{array}{l}0.000 \\
(0.61)\end{array}$ & $\begin{array}{l}0.001 \\
(0.79)\end{array}$ & $\begin{array}{l}0.001 \\
(0.47)\end{array}$ & $\begin{array}{l}0.003 \\
(0.27)\end{array}$ & $\begin{array}{l}0.010 \\
(1.45)\end{array}$ \\
\hline $\log (\text { net investments })_{\mathrm{t}-4}$ & $\begin{array}{l}-0.000 \\
(-0.25)\end{array}$ & $\begin{array}{l}0.000 \\
(0.19)\end{array}$ & $\begin{array}{l}0.003 \\
(1.18)\end{array}$ & $\begin{array}{l}0.005 \\
(0.58)\end{array}$ & $\begin{array}{c}-0.012^{*} \\
(-1.86)\end{array}$ \\
\hline $\log (\text { net investments })_{\mathrm{t}-5}$ & $\begin{array}{l}-0.000 \\
(-0.36)\end{array}$ & $\begin{array}{l}0.000 \\
(0.01)\end{array}$ & $\begin{array}{l}-0.003 \\
(-1.11)\end{array}$ & $\begin{array}{l}0.000 \\
(0.04)\end{array}$ & $\begin{array}{l}-0.003 \\
(-0.37)\end{array}$ \\
\hline $\log (\text { past } 1 \text {-month net investments })_{\mathrm{t}-1}$ & $\begin{array}{l}0.000 \\
(0.95)\end{array}$ & $\begin{array}{l}0.001 \\
(1.05)\end{array}$ & $\begin{array}{l}0.003 \\
(1.00)\end{array}$ & $\begin{array}{l}-0.004 \\
(-0.48)\end{array}$ & $\begin{array}{l}0.008 \\
(1.27)\end{array}$ \\
\hline $\log$ (funds of followers $)_{t-1}$ & $\begin{array}{c}0.003^{* * *} \\
(7.88)\end{array}$ & $\begin{array}{l}-0.001 \\
(-0.90)\end{array}$ & $\begin{array}{c}0.025^{* * *} \\
(3.62)\end{array}$ & $\begin{array}{c}-0.046^{* *} \\
(-2.36)\end{array}$ & $\begin{array}{l}0.012 \\
(1.04)\end{array}$ \\
\hline Log(age) & $\begin{array}{c}-0.010^{* * *} \\
(-12.87)\end{array}$ & $\begin{array}{c}-0.016^{* * *} \\
(-4.53)\end{array}$ & $\begin{array}{l}-0.013 \\
(-0.73)\end{array}$ & $\begin{array}{l}-0.029 \\
(-0.55)\end{array}$ & $\begin{array}{l}-0.022 \\
(-0.74)\end{array}$ \\
\hline Real money account t-1 $(\mathrm{d})$ & $\begin{array}{l}0.013^{*} \\
(1.88)\end{array}$ & $\begin{array}{l}-0.015 \\
(-0.80)\end{array}$ & $\begin{array}{l}0.002 \\
(0.02)\end{array}$ & $\begin{array}{l}-0.155 \\
(-0.44)\end{array}$ & $\begin{array}{c}-0.320^{*} \\
(-1.90)\end{array}$ \\
\hline$\#$ securitiest -1 & $\begin{array}{c}0.000^{* * *} \\
(3.18)\end{array}$ & $\begin{array}{c}0.001^{* *} \\
(2.38)\end{array}$ & $\begin{array}{l}-0.004 \\
(-1.49)\end{array}$ & $\begin{array}{l}0.013 \\
(1.56)\end{array}$ & $\begin{array}{l}0.003 \\
(0.53)\end{array}$ \\
\hline Turnover $(\%)_{\mathrm{t}-1}$ & $\begin{array}{c}0.000^{* * *} \\
(5.67)\end{array}$ & $\begin{array}{c}0.001^{* * *} \\
(4.22)\end{array}$ & $\begin{array}{l}0.001 \\
(0.81)\end{array}$ & $\begin{array}{l}-0.004 \\
(-1.40)\end{array}$ & $\begin{array}{c}0.003^{*} \\
(1.74)\end{array}$ \\
\hline
\end{tabular}




\begin{tabular}{|c|c|c|c|c|c|}
\hline Professional (d) & $\begin{array}{c}0.028^{* *} \\
(2.27)\end{array}$ & $\begin{array}{l}-0.036 \\
(-1.20)\end{array}$ & $\begin{array}{l}0.261 \\
(1.41)\end{array}$ & $\begin{array}{l}0.151 \\
(0.47)\end{array}$ & $\begin{array}{l}-0.043 \\
(-0.19)\end{array}$ \\
\hline \multirow[t]{2}{*}{ Experienced (d) } & 0.007 & 0.012 & 0.077 & 0.201 & -0.002 \\
\hline & $(0.86)$ & $(0.34)$ & $(0.83)$ & $(0.57)$ & $(-0.01)$ \\
\hline \multirow[t]{2}{*}{ Female (d) } & 0.012 & $-0.066^{* * *}$ & $0.798 * * *$ & -0.258 & $-0.297 * * *$ \\
\hline & $(1.18)$ & $(-3.16)$ & $(4.30)$ & $(-1.22)$ & $(-2.70)$ \\
\hline \multirow[t]{2}{*}{ \# portfolios ${ }_{\mathrm{t}-1}$} & -0.000 & -0.002 & -0.019 & $-0.147^{* * *}$ & -0.034 \\
\hline & $(-0.02)$ & $(-0.49)$ & $(-1.20)$ & $(-3.61)$ & $(-1.29)$ \\
\hline \multirow[t]{2}{*}{ Constant } & & $0.993^{* * *}$ & $3.102^{* * *}$ & $8.693^{* * *}$ & $0.885^{* *}$ \\
\hline & & $(8.73)$ & $(12.54)$ & $(3.85)$ & $(2.18)$ \\
\hline Day fixed effects & No & Yes & Yes & Yes & Yes \\
\hline Pseudo $\mathrm{R}^{2}$ & 0.072 & & & & \\
\hline Adj. $R^{2}$ & & 0.028 & 0.109 & 0.018 & 0.007 \\
\hline $\mathrm{N}$ & 475,288 & 19,004 & 19,004 & 19,004 & 19,004 \\
\hline
\end{tabular}


Table IA3: Comments, investments, and withdrawals

This table presents the results from panel regressions with portfolio and day fixed effects. The dependent variable is either the inverse hyperbolic sine of daily investments of followers (Column 1) or the inverse hyperbolic sine of daily withdrawals of followers (Column 2). The Appendix in the main paper provides detailed descriptions of all variables used throughout the study. Standard errors are clustered at the portfolio level. t-statistics are provided in parentheses. $* * *, * *, *$ denote statistical significance at the $1 \%, 5 \%, 10 \%$ level.

\begin{tabular}{|c|c|c|}
\hline & Log(investments) & Log(withdrawals) \\
\hline & (1) & $(2)$ \\
\hline Comment $(\mathrm{d})_{\mathrm{t}-1}$ & $\begin{array}{c}0.116^{* * *} \\
(4.96)\end{array}$ & $\begin{array}{c}0.041^{* *} \\
(2.36)\end{array}$ \\
\hline Return $(\%)_{\mathrm{t}-1}$ & $\begin{array}{l}0.000 \\
(0.37)\end{array}$ & $\begin{array}{c}-0.004^{* * *} \\
(-3.39)\end{array}$ \\
\hline Return $(\%)_{\mathrm{t}-2}$ & $\begin{array}{l}0.001 \\
(0.78)\end{array}$ & $\begin{array}{c}-0.004^{* * *} \\
(-3.58)\end{array}$ \\
\hline Return $(\%)_{\mathrm{t}-3}$ & $\begin{array}{l}-0.002 \\
(-1.56)\end{array}$ & $\begin{array}{c}-0.002^{* *} \\
(-2.14)\end{array}$ \\
\hline Return $(\%)_{t-4}$ & $\begin{array}{c}-0.005^{* * *} \\
(-3.05)\end{array}$ & $\begin{array}{c}-0.002^{* *} \\
(-2.50)\end{array}$ \\
\hline Return $(\%)_{\mathrm{t}-5}$ & $\begin{array}{l}-0.000 \\
(-0.13)\end{array}$ & $\begin{array}{l}-0.001 \\
(-1.42)\end{array}$ \\
\hline Past 1-month return $(\%)_{\mathrm{t}-1}$ & $\begin{array}{c}0.003^{* * *} \\
(2.90)\end{array}$ & $\begin{array}{l}-0.001 \\
(-1.49)\end{array}$ \\
\hline Past 3-month return $(\%)_{\mathrm{t}-1}$ & $\begin{array}{c}0.001^{* * *} \\
(2.64)\end{array}$ & $\begin{array}{l}-0.000 \\
(-0.86)\end{array}$ \\
\hline Past 6-month return $(\%)_{\mathrm{t}-1}$ & $\begin{array}{l}-0.000 \\
(-0.00)\end{array}$ & $\begin{array}{l}-0.001 \\
(-0.81)\end{array}$ \\
\hline Past 1-year return $(\%)_{\mathrm{t}-1}$ & $\begin{array}{l}0.000 \\
(0.46)\end{array}$ & $\begin{array}{l}-0.000 \\
(-0.27)\end{array}$ \\
\hline Return since inception $(\%)_{t-1}$ & $\begin{array}{l}0.001 \\
(1.25)\end{array}$ & $\begin{array}{l}0.001 \\
(1.04)\end{array}$ \\
\hline $\log (\text { net investments })_{\mathrm{t}-1}$ & $\begin{array}{c}0.079^{* * *} \\
(22.31)\end{array}$ & $\begin{array}{c}-0.030 * * * \\
(-9.24)\end{array}$ \\
\hline $\log (\text { net investments })_{\mathrm{t}-2}$ & $\begin{array}{c}0.064^{* * *} \\
(18.85)\end{array}$ & $\begin{array}{c}-0.022^{* * *} \\
(-5.80)\end{array}$ \\
\hline $\log (\text { net investments })_{t-3}$ & $\begin{array}{c}0.061^{* * *} \\
(13.67)\end{array}$ & $\begin{array}{c}-0.010^{* * *} \\
(-2.77)\end{array}$ \\
\hline $\log (\text { net investments })_{t-4}$ & $\begin{array}{c}0.057^{* * *} \\
(14.40)\end{array}$ & $\begin{array}{l}-0.005 \\
(-1.49)\end{array}$ \\
\hline $\log (\text { net investments })_{t-5}$ & $\begin{array}{c}0.059^{* * *} \\
(18.97)\end{array}$ & $\begin{array}{l}-0.001 \\
(-0.39)\end{array}$ \\
\hline $\log (\text { past } 1 \text {-month net investments })_{t-1}$ & $\begin{array}{c}0.017^{* * *} \\
(8.08)\end{array}$ & $\begin{array}{c}0.005^{* * *} \\
(3.10)\end{array}$ \\
\hline $\log (\text { funds of followers })_{t-1}$ & $\begin{array}{l}-0.006 \\
(-1.43)\end{array}$ & $\begin{array}{c}0.030^{* * *} \\
(6.39)\end{array}$ \\
\hline Log(age) & $\begin{array}{c}-0.050^{* * *} \\
(-5.37)\end{array}$ & $\begin{array}{c}-0.019^{* *} \\
(-2.04)\end{array}$ \\
\hline Real money account $(\mathrm{d})_{\mathrm{t}-1}$ & $\begin{array}{c}0.427^{* * *} \\
(3.75)\end{array}$ & $\begin{array}{c}0.696^{* * *} \\
(6.62)\end{array}$ \\
\hline \# securitiest-1 & $\begin{array}{c}0.006 \\
(1.37)\end{array}$ & $\begin{array}{c}0.006 \\
(1.13)\end{array}$ \\
\hline Turnover $(\%)_{\mathrm{t}-1}$ & $\begin{array}{c}0.003^{* * *} \\
(5.61)\end{array}$ & $\begin{array}{l}0.000 \\
(1.62)\end{array}$ \\
\hline
\end{tabular}


\# portfoliost-1

Portfolio fixed effects

Day fixed effects

Adj. $R^{2}$

$\mathrm{N}$
$-0.004$

$(-0.13)$

Yes

Yes

0.390

475,288
0.014

(0.42)

Yes

Yes

0.318

475,288 


\section{Table IA4: Comments and trades of followers in the longer run}

This table presents the results from panel regressions with portfolio and day fixed effects. The dependent variable is the inverse hyperbolic sine of average daily net investments of followers. We compute average daily net investments for each week after the posting of a comment. The Appendix in the main paper provides detailed descriptions of all variables used throughout the study. Standard errors are clustered at the portfolio level. t-statistics are provided in parentheses. $* * *$, $* *, *$ denote statistical significance at the $1 \%, 5 \%, 10 \%$ level.

\begin{tabular}{|c|c|c|c|c|c|c|c|c|}
\hline & \multicolumn{8}{|c|}{ Log(net investments) } \\
\hline & $\begin{array}{c}\mathrm{t}, \mathrm{t}+4 \\
(\text { week 1) }\end{array}$ & $\begin{array}{l}\mathrm{t}+5, \mathrm{t}+9 \\
(\text { week } 2)\end{array}$ & $\begin{array}{c}t+10, t+14 \\
(\text { week } 3)\end{array}$ & $\begin{array}{c}\mathrm{t}+15, \mathrm{t}+19 \\
(\text { week } 4)\end{array}$ & $\begin{array}{c}\mathrm{t}+20, \mathrm{t}+24 \\
(\text { week } 5)\end{array}$ & $\begin{array}{c}\mathrm{t}+25, \mathrm{t}+29 \\
(\text { week } 6)\end{array}$ & $\begin{array}{c}\mathrm{t}+30, \mathrm{t}+34 \\
(\text { week } 7)\end{array}$ & $\begin{array}{c}\mathrm{t}+35, \mathrm{t}+39 \\
(\text { week 8) }\end{array}$ \\
\hline & $(1)$ & $(2)$ & $(3)$ & $(4)$ & $(5)$ & $(6)$ & $(7)$ & $(8)$ \\
\hline Comment $(d)_{t-1}$ & $\begin{array}{c}0.151^{* * *} \\
(3.98)\end{array}$ & $\begin{array}{c}0.076^{*} \\
(1.77)\end{array}$ & $\begin{array}{l}0.086^{*} \\
(1.80)\end{array}$ & $\begin{array}{l}0.058 \\
(1.09)\end{array}$ & $\begin{array}{l}0.030 \\
(0.61)\end{array}$ & $\begin{array}{l}0.022 \\
(0.45)\end{array}$ & $\begin{array}{l}-0.047 \\
(-0.94)\end{array}$ & $\begin{array}{l}-0.025 \\
(-0.59)\end{array}$ \\
\hline Return $(\%)_{\mathrm{t}-1}$ & $\begin{array}{c}0.009 * * * \\
(3.27)\end{array}$ & $\begin{array}{c}0.006^{* * *} \\
(3.21)\end{array}$ & $\begin{array}{c}0.008^{* * *} \\
(4.07)\end{array}$ & $\begin{array}{c}0.008^{* * *} \\
(3.36)\end{array}$ & $\begin{array}{c}0.005^{* *} \\
(2.52)\end{array}$ & $\begin{array}{l}0.003^{*} \\
(1.73)\end{array}$ & $\begin{array}{l}-0.003 \\
(-1.04)\end{array}$ & $\begin{array}{l}0.000 \\
(0.12)\end{array}$ \\
\hline Return $(\%)_{\mathrm{t}-2}$ & $\begin{array}{c}0.006^{* * *} \\
(2.88)\end{array}$ & $\begin{array}{c}0.004^{* *} \\
(2.25)\end{array}$ & $\begin{array}{c}0.007^{* * * *} \\
(3.21)\end{array}$ & $\begin{array}{c}0.007^{* * *} \\
(3.09)\end{array}$ & $\begin{array}{c}0.004^{*} \\
(1.80)\end{array}$ & $\begin{array}{l}0.001 \\
(0.61)\end{array}$ & $\begin{array}{l}-0.004 \\
(-1.35)\end{array}$ & $\begin{array}{l}-0.000 \\
(-0.11)\end{array}$ \\
\hline Return $(\%)_{\mathrm{t}-3}$ & $\begin{array}{l}0.001 \\
(0.44)\end{array}$ & $\begin{array}{l}0.004^{*} \\
(1.79)\end{array}$ & $\begin{array}{c}0.006^{* * * *} \\
(2.65)\end{array}$ & $\begin{array}{c}0.007^{* * *} \\
(3.01)\end{array}$ & $\begin{array}{l}0.002 \\
(1.30)\end{array}$ & $\begin{array}{l}0.000 \\
(0.10)\end{array}$ & $\begin{array}{l}-0.003 \\
(-1.15)\end{array}$ & $\begin{array}{l}-0.000 \\
(-0.24)\end{array}$ \\
\hline Return $(\%)_{\mathrm{t}-4}$ & $\begin{array}{l}-0.001 \\
(-0.40)\end{array}$ & $\begin{array}{l}0.003 \\
(1.35)\end{array}$ & $\begin{array}{c}0.007^{* * *} \\
(3.11)\end{array}$ & $\begin{array}{c}0.005^{* *} \\
(2.43)\end{array}$ & $\begin{array}{l}0.001 \\
(0.38)\end{array}$ & $\begin{array}{l}-0.002 \\
(-0.59)\end{array}$ & $\begin{array}{l}-0.002 \\
(-0.89)\end{array}$ & $\begin{array}{l}-0.001 \\
(-0.61)\end{array}$ \\
\hline Return $(\%)_{\mathrm{t}-5}$ & $\begin{array}{l}0.002 \\
(1.17)\end{array}$ & $\begin{array}{l}0.001 \\
(0.79)\end{array}$ & $\begin{array}{c}0.005^{* * *} \\
(2.86)\end{array}$ & $\begin{array}{c}0.004^{* *} \\
(2.11)\end{array}$ & $\begin{array}{l}-0.000 \\
(-0.10)\end{array}$ & $\begin{array}{l}-0.002 \\
(-0.58)\end{array}$ & $\begin{array}{l}-0.000 \\
(-0.20)\end{array}$ & $\begin{array}{l}-0.001 \\
(-0.43)\end{array}$ \\
\hline Past 1-month return $(\%)_{\mathrm{t}-1}$ & $\begin{array}{c}0.009 * * * \\
(2.85)\end{array}$ & $\begin{array}{c}0.006^{* *} \\
(2.56)\end{array}$ & $\begin{array}{c}0.003^{*} \\
(1.92)\end{array}$ & $\begin{array}{l}0.001 \\
(0.78)\end{array}$ & $\begin{array}{l}0.000 \\
(0.12)\end{array}$ & $\begin{array}{l}0.002 \\
(0.97)\end{array}$ & $\begin{array}{c}0.004^{*} \\
(1.94)\end{array}$ & $\begin{array}{c}0.005^{* *} \\
(2.49)\end{array}$ \\
\hline Past 3-month return $(\%)_{\mathrm{t}-1}$ & $\begin{array}{c}0.001^{* *} \\
(2.01)\end{array}$ & $\begin{array}{c}0.002^{* * *} \\
(4.13)\end{array}$ & $\begin{array}{l}0.001 \\
(1.33)\end{array}$ & $\begin{array}{l}0.001 \\
(0.84)\end{array}$ & $\begin{array}{l}0.001 \\
(0.78)\end{array}$ & $\begin{array}{l}0.000 \\
(0.31)\end{array}$ & $\begin{array}{l}0.001 \\
(0.97)\end{array}$ & $\begin{array}{c}0.002^{* * *} \\
(2.66)\end{array}$ \\
\hline Past 6-month return $(\%)_{\mathrm{t}-1}$ & $\begin{array}{l}0.001 \\
(1.29)\end{array}$ & $\begin{array}{l}0.000 \\
(0.20)\end{array}$ & $\begin{array}{l}0.001 \\
(0.76)\end{array}$ & $\begin{array}{l}0.001 \\
(0.60)\end{array}$ & $\begin{array}{l}0.001 \\
(0.44)\end{array}$ & $\begin{array}{l}0.001 \\
(0.53)\end{array}$ & $\begin{array}{l}0.001 \\
(0.58)\end{array}$ & $\begin{array}{l}-0.001 \\
(-0.72)\end{array}$ \\
\hline Past 1-year return $(\%)_{\mathrm{t}-1}$ & $\begin{array}{l}-0.001 \\
(-1.15)\end{array}$ & $\begin{array}{l}0.000 \\
(0.00)\end{array}$ & $\begin{array}{l}0.000 \\
(0.17)\end{array}$ & $\begin{array}{l}0.001 \\
(0.59)\end{array}$ & $\begin{array}{l}0.002 \\
(0.94)\end{array}$ & $\begin{array}{l}0.002 \\
(0.95)\end{array}$ & $\begin{array}{l}0.001 \\
(0.35)\end{array}$ & $\begin{array}{l}0.002 \\
(0.74)\end{array}$ \\
\hline Return since inception $(\%)_{\mathrm{t}-1}$ & $\begin{array}{l}0.001 \\
(0.62)\end{array}$ & $\begin{array}{l}-0.000 \\
(-0.30)\end{array}$ & $\begin{array}{l}-0.001 \\
(-1.07)\end{array}$ & $\begin{array}{c}-0.002^{*} \\
(-1.65)\end{array}$ & $\begin{array}{c}-0.003^{* *} \\
(-2.37)\end{array}$ & $\begin{array}{c}-0.003^{* *} \\
(-2.25)\end{array}$ & $\begin{array}{l}-0.002 \\
(-1.42)\end{array}$ & $\begin{array}{l}-0.002 \\
(-1.05)\end{array}$ \\
\hline
\end{tabular}


$\log (\text { net investments })_{t-1}$

\begin{tabular}{|c|c|c|c|c|c|c|c|}
\hline $\begin{array}{c}0.171^{* * *} \\
(20.38)\end{array}$ & $\begin{array}{c}0.130^{* * *} \\
(16.08)\end{array}$ & $\begin{array}{c}0.100^{* * *} * \\
(12.24)\end{array}$ & $\begin{array}{c}0.078^{* * *} \\
(8.06)\end{array}$ & $\begin{array}{c}0.057^{* * *} \\
(5.49)\end{array}$ & $\begin{array}{c}0.033^{* * *} \\
(2.81)\end{array}$ & $\begin{array}{c}0.026^{* * *} \\
(2.58)\end{array}$ & $\begin{array}{c}0.021^{* *} \\
(2.26)\end{array}$ \\
\hline $0.144^{* * *}$ & $0.107^{* * *}$ & $0.087^{* * *}$ & $0.066^{* * *}$ & $0.048^{* * *}$ & $0.030^{* * *}$ & 0.014 & $0.016^{*}$ \\
\hline$(21.43)$ & $(13.90)$ & $(10.89)$ & $(7.46)$ & $(5.31)$ & $(2.67)$ & (1.61) & (1.68) \\
\hline $0.127^{* * *}$ & $0.094^{* * *}$ & $0.075^{* * *}$ & $0.052^{* * *}$ & $0.044^{* * *}$ & $0.031^{* * *}$ & 0.011 & 0.010 \\
\hline$(19.11)$ & $(12.84)$ & $(8.97)$ & $(6.15)$ & $(4.80)$ & $(3.30)$ & $(1.24)$ & (1.09) \\
\hline $0.116^{* * *}$ & $0.089^{* * *}$ & $0.065^{* * *}$ & $0.041^{* * *}$ & $0.042^{* * *}$ & $0.025^{* * *}$ & 0.013 & 0.005 \\
\hline$(17.38)$ & (11.69) & $(6.97)$ & $(5.27)$ & $(4.69)$ & $(2.92)$ & $(1.42)$ & $(0.64)$ \\
\hline $0.106^{* * *}$ & $0.083^{* * *}$ & $0.060 * * *$ & $0.042^{* * *}$ & $0.032^{* * *}$ & $0.023^{* * *}$ & $0.019^{* *}$ & 0.012 \\
\hline$(14.93)$ & (10.97) & $(6.85)$ & (4.66) & $(3.33)$ & $(2.58)$ & $(2.22)$ & (1.62) \\
\hline $0.030^{* * *}$ & $0.025^{* * *}$ & $0.018^{* * *}$ & $0.015^{* * *}$ & 0.009 & $0.017^{* * *}$ & $0.020 * * *$ & $0.018^{* * *}$ \\
\hline$(5.80)$ & $(4.58)$ & (3.09) & $(2.73)$ & $(1.53)$ & $(2.86)$ & $(3.06)$ & $(2.76)$ \\
\hline$-0.115^{* * *}$ & $-0.101 * * *$ & $-0.094^{* * *}$ & $-0.088^{* * *}$ & $-0.080 * * *$ & $-0.078^{* * *}$ & $-0.074^{* * *}$ & $-0.071^{* * *}$ \\
\hline$(-16.49)$ & $(-14.27)$ & $(-12.72)$ & $(-11.82)$ & $(-10.51)$ & $(-10.05)$ & $(-9.49)$ & $(-9.06)$ \\
\hline$-0.066^{* * *}$ & -0.006 & 0.022 & 0.036 & 0.034 & $0.051^{*}$ & $0.067^{* *}$ & $0.082^{* * *}$ \\
\hline$(-3.57)$ & $(-0.28)$ & $(0.99)$ & (1.49) & $(1.35)$ & $(1.96)$ & $(2.47)$ & $(2.93)$ \\
\hline$-0.910 * * *$ & $-1.133^{* * *}$ & $-1.286^{* * *}$ & $-1.394^{* * *}$ & $-1.470 * * *$ & $-1.441^{* * *}$ & $-1.417^{* * *}$ & $-1.340 * * *$ \\
\hline$(-6.72)$ & $(-7.26)$ & $(-7.12)$ & $(-7.17)$ & $(-7.12)$ & $(-7.15)$ & $(-6.96)$ & $(-6.41)$ \\
\hline 0.001 & 0.000 & -0.000 & -0.001 & -0.003 & -0.005 & -0.005 & -0.006 \\
\hline$(0.49)$ & $(0.06)$ & $(-0.09)$ & $(-0.28)$ & $(-0.66)$ & $(-0.84)$ & $(-0.89)$ & $(-0.89)$ \\
\hline $0.004^{* * *}$ & $0.003^{* * *}$ & $0.003^{* * *}$ & 0.002 & 0.001 & 0.000 & 0.001 & -0.000 \\
\hline$(4.59)$ & $(3.17)$ & $(2.58)$ & $(1.43)$ & $(0.60)$ & $(0.43)$ & (1.51) & $(-0.19)$ \\
\hline-0.045 & -0.057 & -0.061 & -0.068 & -0.070 & -0.084 & -0.075 & -0.069 \\
\hline$(-0.67)$ & $(-0.77)$ & $(-0.78)$ & $(-0.85)$ & $(-0.88)$ & $(-1.08)$ & $(-1.00)$ & $(-0.96)$ \\
\hline Yes & Yes & Yes & Yes & Yes & Yes & Yes & Yes \\
\hline Yes & Yes & Yes & Yes & Yes & Yes & Yes & Yes \\
\hline 0.176 & 0.131 & 0.106 & 0.090 & 0.083 & 0.078 & 0.075 & 0.073 \\
\hline 466,652 & 456,136 & 445,893 & 435,659 & 425,586 & 415,857 & 406,156 & 396,478 \\
\hline
\end{tabular}

$\log (\text { net investments })_{\mathrm{t}-2}$

$\log (\text { net investments) })_{\mathrm{t}-3}$

$\log (\text { net investments })_{\mathrm{t}-4}$

$\log (\text { net investments) })_{t-5}$

$\log \left(\right.$ past 1-month net investments) t-1 $_{1}$

$\log$ (funds of followers) $\mathrm{t}-1$

Log(age)

Real money account $(d)_{t-1}$

\# securitiest-1

Turnover $(\%)_{\mathrm{t}-1}$

\# portfolios ${ }_{\mathrm{t}-1}$

Portfolio fixed effects

Adj. $R^{2}$

466,652

445,893 
Table IA5: Number of comments, length of comments, comment tone, and trades of followers

This table presents the results from panel regressions with portfolio and day fixed effects. The dependent variable is the inverse hyperbolic sine of daily net investments of followers. We restrict the sample to days with at least one comment posted on the preceding day. The Appendix in the main paper provides detailed descriptions of all variables used throughout the study. Standard errors are clustered at the portfolio level. t-statistics are provided in parentheses. $* * *, * *, *$ denote statistical significance at the $1 \%, 5 \%, 10 \%$ level.

\begin{tabular}{|c|c|c|c|c|c|}
\hline & \multicolumn{5}{|c|}{$\log ($ net investments) } \\
\hline & $(1)$ & $(2)$ & $(3)$ & $(4)$ & $(5)$ \\
\hline $\log (\# \text { comments })_{\mathrm{t}-1}$ & $\begin{array}{l}0.086 \\
(1.05)\end{array}$ & & & & $\begin{array}{l}0.087 \\
(1.06)\end{array}$ \\
\hline $\log (\# \text { words per comment })_{\mathrm{t}-1}$ & & $\begin{array}{l}0.021 \\
(0.56)\end{array}$ & & & $\begin{array}{l}0.024 \\
(0.63)\end{array}$ \\
\hline$\%$ positive wordst-1 & & & $\begin{array}{l}0.009 * * \\
(2.05)\end{array}$ & & $\begin{array}{l}0.008^{*} \\
(1.96)\end{array}$ \\
\hline$\%$ negative wordst-1 & & & & $\begin{array}{l}-0.008 \\
(-1.01)\end{array}$ & $\begin{array}{l}-0.007 \\
(-0.87)\end{array}$ \\
\hline Return $(\%)_{\mathrm{t}-1}$ & $\begin{array}{l}0.031^{* *} \\
(2.07)\end{array}$ & $\begin{array}{c}0.031^{* *} \\
(2.07)\end{array}$ & $\begin{array}{l}0.031^{* *} \\
(2.06)\end{array}$ & $\begin{array}{c}0.031^{* *} \\
(2.07)\end{array}$ & $\begin{array}{l}0.031^{* *} \\
(2.07)\end{array}$ \\
\hline Return $(\%)_{\mathrm{t}-2}$ & $\begin{array}{c}0.041^{* * *} \\
(4.50)\end{array}$ & $\begin{array}{l}0.042^{* * *} \\
(4.54)\end{array}$ & $\begin{array}{c}0.041^{* * *} \\
(4.49)\end{array}$ & $\begin{array}{c}0.041^{* * *} \\
(4.50)\end{array}$ & $\begin{array}{c}0.041^{* * *} \\
(4.51)\end{array}$ \\
\hline Return $(\%)_{t-3}$ & $\begin{array}{l}0.010 \\
(0.78)\end{array}$ & $\begin{array}{l}0.010 \\
(0.79)\end{array}$ & $\begin{array}{l}0.010 \\
(0.77)\end{array}$ & $\begin{array}{l}0.010 \\
(0.78)\end{array}$ & $\begin{array}{l}0.010 \\
(0.78)\end{array}$ \\
\hline Return $(\%)_{\mathrm{t}-4}$ & $\begin{array}{l}0.008 \\
(0.76)\end{array}$ & $\begin{array}{l}0.008 \\
(0.75)\end{array}$ & $\begin{array}{l}0.008 \\
(0.74)\end{array}$ & $\begin{array}{l}0.008 \\
(0.74)\end{array}$ & $\begin{array}{l}0.008 \\
(0.76)\end{array}$ \\
\hline Return $(\%)_{t-5}$ & $\begin{array}{l}0.005 \\
(0.41)\end{array}$ & $\begin{array}{l}0.004 \\
(0.39)\end{array}$ & $\begin{array}{l}0.005 \\
(0.41)\end{array}$ & $\begin{array}{l}0.004 \\
(0.40)\end{array}$ & $\begin{array}{l}0.005 \\
(0.44)\end{array}$ \\
\hline Past 1-month return $(\%)_{\mathrm{t}-1}$ & $\begin{array}{l}0.005 \\
(0.96)\end{array}$ & $\begin{array}{l}0.005 \\
(0.99)\end{array}$ & $\begin{array}{l}0.005 \\
(0.96)\end{array}$ & $\begin{array}{l}0.005 \\
(0.98)\end{array}$ & $\begin{array}{l}0.005 \\
(0.95)\end{array}$ \\
\hline Past 3-month return $(\%)_{\mathrm{t}-1}$ & $\begin{array}{c}0.002^{* * *} \\
(3.48)\end{array}$ & $\begin{array}{l}0.002^{* * *} \\
(3.53)\end{array}$ & $\begin{array}{c}0.002^{* * *} \\
(3.52)\end{array}$ & $\begin{array}{c}0.002^{* * *} \\
(3.51)\end{array}$ & $\begin{array}{c}0.002^{* * *} \\
\quad(3.46)\end{array}$ \\
\hline Past 6 -month return $(\%)_{\mathrm{t}-1}$ & $\begin{array}{l}0.004 \\
(1.52)\end{array}$ & $\begin{array}{l}0.004 \\
(1.53)\end{array}$ & $\begin{array}{l}0.004 \\
(1.53)\end{array}$ & $\begin{array}{l}0.004 \\
(1.53)\end{array}$ & $\begin{array}{l}0.004 \\
(1.52)\end{array}$ \\
\hline Past 1-year return $(\%)_{\mathrm{t}-1}$ & $\begin{array}{l}0.004 \\
(1.14)\end{array}$ & $\begin{array}{l}0.004 \\
(1.13)\end{array}$ & $\begin{array}{l}0.004 \\
(1.14)\end{array}$ & $\begin{array}{l}0.004 \\
(1.13)\end{array}$ & $\begin{array}{l}0.004 \\
(1.15)\end{array}$ \\
\hline Return since inception $(\%)_{t-1}$ & $\begin{array}{c}0.008^{*} \\
(1.84)\end{array}$ & $\begin{array}{c}0.008^{*} \\
(1.85)\end{array}$ & $\begin{array}{c}0.008^{*} \\
(1.85)\end{array}$ & $\begin{array}{c}0.008^{*} \\
(1.85)\end{array}$ & $\begin{array}{c}0.008^{*} \\
(1.83)\end{array}$ \\
\hline $\log (\text { net investments })_{t-1}$ & $\begin{array}{c}0.150^{* * *} \\
(7.85)\end{array}$ & $\begin{array}{c}0.150^{* * *} \\
(7.85)\end{array}$ & $\begin{array}{c}0.150^{* * *} \\
(7.85)\end{array}$ & $\begin{array}{c}0.150^{* * *} \\
(7.84)\end{array}$ & $\begin{array}{c}0.150^{* * *} \\
(7.85)\end{array}$ \\
\hline $\log (\text { net investments })_{\mathrm{t}-2}$ & $\begin{array}{c}0.089 * * * \\
(5.48)\end{array}$ & $\begin{array}{l}0.090^{* * *} \\
(5.49)\end{array}$ & $\begin{array}{c}0.090^{* * *} \\
(5.50)\end{array}$ & $\begin{array}{c}0.090^{* * *} \\
(5.49)\end{array}$ & $\begin{array}{c}0.090^{* * *} \\
(5.49)\end{array}$ \\
\hline $\log (\text { net investments })_{t-3}$ & $\begin{array}{c}0.080^{* * *} \\
(4.12)\end{array}$ & $\begin{array}{c}0.080^{* * *} \\
(4.13)\end{array}$ & $\begin{array}{c}0.080^{* * *} \\
(4.12)\end{array}$ & $\begin{array}{c}0.080^{* * *} \\
(4.12)\end{array}$ & $\begin{array}{c}0.080^{* * *} \\
(4.12)\end{array}$ \\
\hline $\log (\text { net investments })_{\mathrm{t}-4}$ & $\begin{array}{c}0.096^{* * *} \\
(6.21)\end{array}$ & $\begin{array}{c}0.096 * * * \\
(6.21)\end{array}$ & $\begin{array}{c}0.096^{* * *} \\
(6.22)\end{array}$ & $\begin{array}{c}0.096^{* * *} \\
(6.22)\end{array}$ & $\begin{array}{c}0.096^{* * *} \\
(6.22)\end{array}$ \\
\hline $\log (\text { net investments })_{\mathrm{t}-5}$ & $\begin{array}{c}0.088^{* * *} \\
(5.13)\end{array}$ & $\begin{array}{c}0.088^{* * *} \\
(5.13)\end{array}$ & $\begin{array}{c}0.088^{* * *} \\
(5.13)\end{array}$ & $\begin{array}{c}0.087^{* * *} \\
(5.12)\end{array}$ & $\begin{array}{c}0.087^{* * *} * \\
(5.12)\end{array}$ \\
\hline $\log (\text { past } 1 \text {-month net investments })_{\mathrm{t}-1}$ & $\begin{array}{c}0.021^{* * *} \\
(2.84)\end{array}$ & $\begin{array}{c}0.021^{* * *} \\
(2.84)\end{array}$ & $\begin{array}{c}0.021^{* * *} \\
(2.85)\end{array}$ & $\begin{array}{c}0.021^{* * *} \\
(2.85)\end{array}$ & $\begin{array}{c}0.021^{* * *} \\
(2.85)\end{array}$ \\
\hline $\log (\text { funds of followers })_{t-1}$ & $\begin{array}{c}-0.103^{* * *} \\
(-6.62)\end{array}$ & $\begin{array}{c}-0.103^{* * *} \\
(-6.62)\end{array}$ & $\begin{array}{c}-0.103^{* * *} \\
(-6.63)\end{array}$ & $\begin{array}{c}-0.103^{* * *} \\
(-6.61)\end{array}$ & $\begin{array}{c}-0.103^{* * *} \\
(-6.66)\end{array}$ \\
\hline
\end{tabular}




\begin{tabular}{|c|c|c|c|c|c|}
\hline Log(age) & $\begin{array}{l}-0.032 \\
(-0.57)\end{array}$ & $\begin{array}{l}-0.033 \\
(-0.59)\end{array}$ & $\begin{array}{l}-0.033 \\
(-0.58)\end{array}$ & $\begin{array}{l}-0.034 \\
(-0.60)\end{array}$ & $\begin{array}{l}-0.032 \\
(-0.56)\end{array}$ \\
\hline \multirow[t]{2}{*}{ Real money account $(\mathrm{d})_{\mathrm{t}-1}$} & -0.152 & -0.152 & -0.150 & -0.151 & -0.154 \\
\hline & $(-0.56)$ & $(-0.56)$ & $(-0.56)$ & $(-0.56)$ & $(-0.57)$ \\
\hline \multirow[t]{2}{*}{$\#$ securities $_{\mathrm{t}-1}$} & -0.007 & -0.007 & -0.007 & -0.007 & -0.008 \\
\hline & $(-1.25)$ & $(-1.20)$ & $(-1.21)$ & $(-1.21)$ & $(-1.27)$ \\
\hline \multirow[t]{2}{*}{ Turnover $(\%)_{\mathrm{t}-1}$} & $0.003^{*}$ & $0.004^{*}$ & $0.004^{*}$ & $0.004^{*}$ & $0.003^{*}$ \\
\hline & $(1.78)$ & $(1.93)$ & $(1.90)$ & $(1.93)$ & $(1.78)$ \\
\hline \multirow[t]{2}{*}{ \# portfoliost-1 } & -0.066 & -0.070 & -0.067 & -0.069 & -0.067 \\
\hline & $(-0.33)$ & $(-0.35)$ & $(-0.33)$ & $(-0.34)$ & $(-0.33)$ \\
\hline Portfolio fixed effects & Yes & Yes & Yes & Yes & Yes \\
\hline Day fixed effects & Yes & Yes & Yes & Yes & Yes \\
\hline Adj. $R^{2}$ & 0.170 & 0.170 & 0.171 & 0.170 & 0.171 \\
\hline $\mathrm{N}$ & 19,190 & 19,190 & 19,190 & 19,190 & 19,190 \\
\hline
\end{tabular}




\section{Table IA6: Determinants of comments - matched sample}

This table presents the results from a logit regression. The dependent variable is a dummy variable that equals one on days on which traders post at least one comment, and zero otherwise. We focus on a subsample after propensity score matching. The table shows marginal effects. The Appendix in the main paper provides detailed descriptions of all variables used throughout the study. Standard errors are clustered at the portfolio level. t-statistics are provided in parentheses. $* * *, * *, *$ denote statistical significance at the $1 \%, 5 \%, 10 \%$ level.

\begin{tabular}{|c|c|}
\hline & Comment $(\mathrm{d})$ \\
\hline & $(1)$ \\
\hline Return $(\%)_{\mathrm{t}-1}$ & $\begin{array}{l}-0.001 \\
(-0.75)\end{array}$ \\
\hline Return $(\%)_{\mathrm{t}-2}$ & $\begin{array}{c}-0.003^{* * *} \\
(-2.93)\end{array}$ \\
\hline Return $(\%)_{\mathrm{t}-3}$ & $\begin{array}{l}0.000 \\
(0.15)\end{array}$ \\
\hline Return $(\%)_{\mathrm{t}-4}$ & $\begin{array}{l}0.001 \\
(0.50)\end{array}$ \\
\hline Return $(\%)_{\mathrm{t}-5}$ & $\begin{array}{l}0.002 \\
(1.57)\end{array}$ \\
\hline Past 1-month return $(\%)_{\mathrm{t}-1}$ & $\begin{array}{c}0.002^{* *} \\
(2.37)\end{array}$ \\
\hline Past 3-month return $(\%)_{\mathrm{t}-1}$ & $\begin{array}{r}0.000 \\
(0.61)\end{array}$ \\
\hline Past 6-month return $(\%)_{\mathrm{t}-1}$ & $\begin{array}{l}0.000 \\
(0.05)\end{array}$ \\
\hline Past 1-year return $(\%)_{\mathrm{t}-1}$ & $\begin{array}{l}-0.000 \\
(-0.36)\end{array}$ \\
\hline Return since inception $(\%)_{\mathrm{t}-1}$ & $\begin{array}{l}0.000 \\
(0.41)\end{array}$ \\
\hline $\log (\text { net investments })_{t-1}$ & $\begin{array}{l}0.001 \\
(1.47)\end{array}$ \\
\hline $\log (\text { net investments })_{\mathrm{t}-2}$ & $\begin{array}{l}-0.001 \\
(-0.43)\end{array}$ \\
\hline $\log (\text { net investments })_{t-3}$ & $\begin{array}{c}0.001 \\
(1.31)\end{array}$ \\
\hline $\log (\text { net investments })_{\mathrm{t}-4}$ & $\begin{array}{l}-0.000 \\
(-0.04)\end{array}$ \\
\hline $\log (\text { net investments })_{\mathrm{t}-5}$ & $\begin{array}{l}0.000 \\
(0.38)\end{array}$ \\
\hline $\log$ (past 1-month net investments) $)_{\mathrm{t}-1}$ & $\begin{array}{l}-0.000 \\
(-0.12)\end{array}$ \\
\hline $\log (\text { funds of followers })_{t-1}$ & $\begin{array}{l}-0.001 \\
(-0.46)\end{array}$ \\
\hline Log(age) & $\begin{array}{l}0.004 \\
(0.59)\end{array}$ \\
\hline Real money account t-1 $(\mathrm{d})$ & $\begin{array}{l}-0.000 \\
(-0.01)\end{array}$ \\
\hline$\#$ securities $_{\mathrm{t}-1}$ & $\begin{array}{l}-0.000 \\
(-0.54)\end{array}$ \\
\hline Turnover $(\%)_{\mathrm{t}-1}$ & $\begin{array}{l}0.000 \\
(0.48)\end{array}$ \\
\hline
\end{tabular}


Professional (d)

0.036

(0.61)

Experienced (d)

$-0.031$

$(-0.41)$

Female (d)

$-0.018$

$(-0.30)$

\# portfoliost-1

$-0.001$

$(-0.10)$

Pseudo $\mathrm{R}^{2}$

0.002

N

38,008 


\section{Table IA7: Comments and trades of followers - deletion of comments with confounding portfolio changes}

This table presents the results from panel regressions with portfolio and day fixed effects. The dependent variable is either the inverse hyperbolic sine of daily net investments of followers (Columns 1 and 5), the inverse hyperbolic sine of daily investments of followers (Column 2), the inverse hyperbolic sine of daily withdrawals of followers (Column 3 ), or the inverse hyperbolic sine of average daily net investments of followers in the week after the posting of a comment (Column 4). We drop comments with confounding portfolio changes. In Column 5 , we focus on days with at least one comment posted on the preceding day. The variables Return $(\%)_{t-1}$, Return $(\%)_{t-2}$, Return $(\%)_{t-3}$, Return $(\%)_{t-4}$, Return (\%) $)_{-5}$, Past 1-month return (\%) $)_{t-1}$, Past 3-month return $(\%)_{t-1}$, Past 6-month return (\%) - $_{-1}$, Past 1-year return $(\%)_{t-1}$, Return since inception $(\%)_{t-1}$, Log(net investments) $)_{t-1}$, Log $(\text { net investments })_{t-2}$, Log $($ net

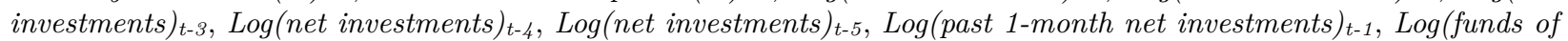
followers $_{t-1}, \log ($ age $)$, Real money account $(d)_{t-1}$, \# securities st-1 $_{\text {, Turnover }}(\%)_{t-1}$, and \# portfolios t-1 $_{\text {are included }}$ as controls in every regression but not reported. The Appendix in the main paper provides detailed descriptions of all variables used throughout the study. Standard errors are clustered at the portfolio level. t-statistics are provided in parentheses. $* * *, * *, *$ denote statistical significance at the $1 \%, 5 \%, 10 \%$ level.

\begin{tabular}{|c|c|c|c|c|c|}
\hline & $\begin{array}{c}\log (\text { net } \\
\text { investments) }\end{array}$ & $\begin{array}{c}\text { Log(invest- } \\
\text { ments) }\end{array}$ & $\begin{array}{l}\log \text { (with- } \\
\text { drawals) }\end{array}$ & $\begin{array}{c}\log (\text { net } \\
\text { investments) } \\
(\text { week } 1)\end{array}$ & $\begin{array}{c}\log (\text { net } \\
\text { investments) }\end{array}$ \\
\hline & $(1)$ & $(2)$ & $(3)$ & $(4)$ & $(5)$ \\
\hline Comment $(\mathrm{d})_{\mathrm{t}-1}$ & $\begin{array}{c}0.066^{* *} \\
(2.17)\end{array}$ & $\begin{array}{c}0.113^{* * *} \\
(3.20)\end{array}$ & $\begin{array}{l}0.031 \\
(1.29)\end{array}$ & $\begin{array}{c}0.122^{* *} \\
(2.29)\end{array}$ & \\
\hline $\log (\# \text { comments })_{\mathrm{t}-1}$ & & & & & $\begin{array}{l}0.035 \\
(0.17)\end{array}$ \\
\hline $\log (\# \text { words per comment })_{\mathrm{t}-1}$ & & & & & $\begin{array}{l}0.015 \\
(0.21)\end{array}$ \\
\hline$\%$ positive words $_{\mathrm{t}-1}$ & & & & & $\begin{array}{l}0.007 \\
(0.95)\end{array}$ \\
\hline$\%$ negative words $\mathrm{s}_{\mathrm{t}-1}$ & & & & & $\begin{array}{l}-0.003 \\
(-0.18)\end{array}$ \\
\hline Controls & Yes & Yes & Yes & Yes & Yes \\
\hline Portfolio fixed effects & Yes & Yes & Yes & Yes & Yes \\
\hline Day fixed effects & Yes & Yes & Yes & Yes & Yes \\
\hline Adj. $R^{2}$ & 0.124 & 0.376 & 0.307 & 0.169 & 0.133 \\
\hline $\mathrm{N}$ & 462,667 & 462,667 & 462,667 & 454,274 & 6,569 \\
\hline
\end{tabular}




\section{Table IA8: Comments and trades of followers - deletion of comments with confounding news}

This table presents the results from panel regressions with portfolio and day fixed effects. The dependent variable is either the inverse hyperbolic sine of daily net investments of followers (Columns 1 and 5), the inverse hyperbolic sine of daily investments of followers (Column 2), the inverse hyperbolic sine of daily withdrawals of followers (Column 3 ), or the inverse hyperbolic sine of average daily net investments of followers in the week after the posting of a comment (Column 4). We drop comments with confounding news on one of the portfolio holdings. In Column 5 , we focus on days with at least one comment posted on the preceding day. The variables Return $(\%)_{t-1}$, Return $(\%)_{t-2}$, Return $(\%)_{t-3}$, Return $(\%)_{t-4}$, Return (\%) $)_{-5}$, Past 1-month return (\%) $)_{t-1}$, Past 3-month return $(\%)_{t-1}$, Past 6-month return (\%) - $_{-1}$, Past 1-year return $(\%)_{t-1}$, Return since inception $(\%)_{t-1}$, Log(net investments) $)_{t-1}$, Log $(\text { net investments })_{t-2}$, Log $($ net

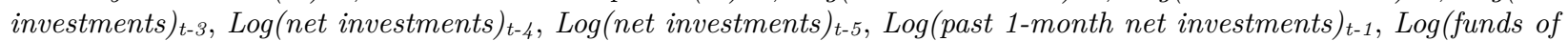

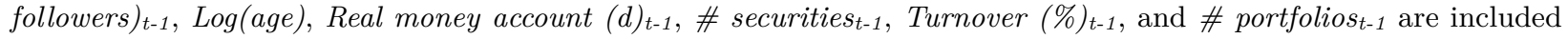
as controls in every regression but not reported. The Appendix in the main paper provides detailed descriptions of all variables used throughout the study. Standard errors are clustered at the portfolio level. t-statistics are provided in parentheses. $* * *, * *, *$ denote statistical significance at the $1 \%, 5 \%, 10 \%$ level.

\begin{tabular}{|c|c|c|c|c|c|}
\hline & $\begin{array}{c}\log (\text { net } \\
\text { investments) }\end{array}$ & $\begin{array}{c}\text { Log(invest- } \\
\text { ments) }\end{array}$ & $\begin{array}{l}\log \text { (with- } \\
\text { drawals) }\end{array}$ & $\begin{array}{c}\log (\text { net } \\
\text { investments) } \\
(\text { week } 1)\end{array}$ & $\begin{array}{c}\log (\text { net } \\
\text { investments) }\end{array}$ \\
\hline & $(1)$ & $(2)$ & $(3)$ & $(4)$ & $(5)$ \\
\hline Comment $(\mathrm{d})_{\mathrm{t}-1}$ & $\begin{array}{c}0.185^{* * *} \\
(2.79)\end{array}$ & $\begin{array}{c}0.220^{* * *} \\
(4.02)\end{array}$ & $\begin{array}{l}0.041 \\
(1.60)\end{array}$ & $\begin{array}{c}0.186^{* *} \\
(2.18)\end{array}$ & \\
\hline $\log (\# \text { comments })_{\mathrm{t}-1}$ & & & & & $\begin{array}{l}0.271 \\
(1.26)\end{array}$ \\
\hline $\log (\# \text { words per comment })_{\mathrm{t}-1}$ & & & & & $\begin{array}{l}-0.006 \\
(-0.06)\end{array}$ \\
\hline$\%$ positive words $_{\mathrm{t}-1}$ & & & & & $\begin{array}{l}0.014 \\
(0.96)\end{array}$ \\
\hline$\%$ negative words $\mathrm{s}_{\mathrm{t}-1}$ & & & & & $\begin{array}{l}-0.019 \\
(-0.96)\end{array}$ \\
\hline Controls & Yes & Yes & Yes & Yes & Yes \\
\hline Portfolio fixed effects & Yes & Yes & Yes & Yes & Yes \\
\hline Day fixed effects & Yes & Yes & Yes & Yes & Yes \\
\hline Adj. $R^{2}$ & 0.125 & 0.369 & 0.300 & 0.169 & 0.225 \\
\hline $\mathrm{N}$ & 460,191 & 460,191 & 460,191 & 451,838 & 4,093 \\
\hline
\end{tabular}




\section{Table IA9: Comments and trades of followers - general vs. firm-specific comments}

This table presents the results from panel regressions with portfolio and day fixed effects. The dependent variable is either the inverse hyperbolic sine of daily net investments of followers (Columns 1 and 5), the inverse hyperbolic sine of daily investments of followers (Column 2), the inverse hyperbolic sine of daily withdrawals of followers (Column 3 ), or the inverse hyperbolic sine of average daily net investments of followers in the week after the posting of a comment (Column 4). In Panel A, we focus on general comments and drop firm-specific comments. In Panel B, we focus on firm-specific comments and drop general comments. In Column 5, we focus on days with at least one comment posted on the preceding day. The variables Return $(\%)_{t-1}$, Return $(\%)_{t-2}$, Return $(\%)_{t-3}, \operatorname{Return}(\%)_{t-4}$, Return $(\%)_{t-5}$, Past 1-month return $(\%)_{t-1}$, Past 3-month return $(\%)_{t-1}$, Past 6-month return $(\%)_{t-1}$, Past 1-year return $(\%)_{t-1}$, Return since inception $(\%)_{t-1}$, Log (net investments) $t_{-1}$, Log(net investments) $)_{t-2}$, Log $(\text { net investments) })_{t-3}$, $\log (\text { net investments })_{t-4}, \log (\text { net investments })_{t-5}$, Log (past 1-month net investments $)_{t-1}$, Log $(\text { funds of followers })_{t-1}$,

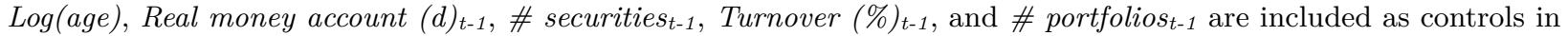
every regression but not reported. The Appendix in the main paper provides detailed descriptions of all variables used throughout the study. Standard errors are clustered at the portfolio level. t-statistics are provided in parentheses. $* * *, * *, *$ denote statistical significance at the $1 \%, 5 \%, 10 \%$ level.

Panel A: General comments

\begin{tabular}{|c|c|c|c|c|c|}
\hline & $\begin{array}{c}\log (\text { net } \\
\text { investments) }\end{array}$ & $\begin{array}{c}\text { Log(invest- } \\
\text { ments) }\end{array}$ & $\begin{array}{c}\text { Log(with- } \\
\text { drawals) }\end{array}$ & $\begin{array}{c}\log (\text { net } \\
\text { investments) } \\
\text { (week 1) }\end{array}$ & $\begin{array}{c}\log (\text { net } \\
\text { investments) }\end{array}$ \\
\hline & $(1)$ & $(2)$ & $(3)$ & $(4)$ & $(5)$ \\
\hline Comment $(\mathrm{d})_{\mathrm{t}-1}$ & $\begin{array}{c}0.071^{* *} \\
(2.13)\end{array}$ & $\begin{array}{c}0.137^{* * *} \\
(4.19)\end{array}$ & $\begin{array}{l}0.041 \\
(1.56)\end{array}$ & $\begin{array}{c}0.129^{* * *} \\
(2.75)\end{array}$ & \\
\hline $\log (\# \text { comments })_{\mathrm{t}-1}$ & & & & & $\begin{array}{l}-0.113 \\
(-0.65)\end{array}$ \\
\hline $\log (\# \text { words per comment })_{\mathrm{t}-1}$ & & & & & $\begin{array}{l}0.078 \\
(1.44)\end{array}$ \\
\hline$\%$ positive words $\mathrm{s}_{\mathrm{t}-1}$ & & & & & $\begin{array}{c}0.015^{* *} \\
(1.98)\end{array}$ \\
\hline$\%$ negative words $\mathrm{t}_{\mathrm{t}-1}$ & & & & & $\begin{array}{l}-0.020 \\
(-1.32)\end{array}$ \\
\hline Controls & Yes & Yes & Yes & Yes & Yes \\
\hline Portfolio fixed effects & Yes & Yes & Yes & Yes & Yes \\
\hline Day fixed effects & Yes & Yes & Yes & Yes & Yes \\
\hline Adj. $R^{2}$ & 0.126 & 0.376 & 0.310 & 0.171 & 0.145 \\
\hline $\mathrm{N}$ & 465,675 & 465,675 & 465,675 & 457,151 & 9,577 \\
\hline
\end{tabular}


Panel B: Firm-specific comments

\begin{tabular}{|c|c|c|c|c|c|}
\hline & $\begin{array}{c}\log (\text { net } \\
\text { investments) }\end{array}$ & $\begin{array}{l}\text { Log (invest- } \\
\text { ments) }\end{array}$ & $\begin{array}{l}\text { Log (with- } \\
\text { drawals) }\end{array}$ & $\begin{array}{c}\log (\text { net } \\
\text { investments) } \\
\text { (week 1) }\end{array}$ & $\begin{array}{c}\log (\text { net } \\
\text { investments) }\end{array}$ \\
\hline & $(1)$ & $(2)$ & $(3)$ & $(4)$ & $(5)$ \\
\hline Comment $(\mathrm{d})_{\mathrm{t}-1}$ & $\begin{array}{l}0.013 \\
(0.28)\end{array}$ & $\begin{array}{c}0.062^{* *} \\
(2.38)\end{array}$ & $\begin{array}{c}0.041^{*} \\
(1.86)\end{array}$ & $\begin{array}{c}0.133^{* *} \\
(2.37)\end{array}$ & \\
\hline $\log (\# \text { comments })_{\mathrm{t}-1}$ & & & & & $\begin{array}{l}-0.100 \\
(-0.85)\end{array}$ \\
\hline $\log (\# \text { words per comment })_{\mathrm{t}-1}$ & & & & & $\begin{array}{l}-0.064 \\
(-0.82)\end{array}$ \\
\hline$\%$ positive words $_{\mathrm{t}-1}$ & & & & & $\begin{array}{l}0.002 \\
(0.28)\end{array}$ \\
\hline$\%$ negative words $_{\mathrm{t}-1}$ & & & & & $\begin{array}{l}0.004 \\
(0.37)\end{array}$ \\
\hline Controls & Yes & Yes & Yes & Yes & Yes \\
\hline Portfolio fixed effects & Yes & Yes & Yes & Yes & Yes \\
\hline Day fixed effects & Yes & Yes & Yes & Yes & Yes \\
\hline Adj. $R^{2}$ & 0.126 & 0.379 & 0.308 & 0.170 & 0.185 \\
\hline $\mathrm{N}$ & 464,244 & 464,244 & 464,244 & 455,881 & 8,146 \\
\hline
\end{tabular}




\section{Table IA10: Comments and trades of followers - deletion of popular portfolios}

This table presents the results from panel regressions with portfolio and day fixed effects. The dependent variable is either the inverse hyperbolic sine of daily net investments of followers (Columns 1 and 5), the inverse hyperbolic sine of daily investments of followers (Column 2), the inverse hyperbolic sine of daily withdrawals of followers (Column 3 ), or the inverse hyperbolic sine of average daily net investments of followers in the week after the posting of a comment (Column 4). We drop the $5 \%$ of portfolios with the most follower funds. In Column 5 , we focus on days with at least one comment posted on the preceding day. The variables Return $(\%)_{t-1}$, Return $(\%)_{t-2}$, Return $(\%)_{t-3}$, Return $(\%)_{t-4}$, Return $(\%)_{t-5}$, Past 1-month return $(\%)_{t-1}$, Past 3-month return $(\%)_{t-1}$, Past 6-month return (\%) $)_{t-1}$, Past 1-year return $(\%)_{t-1}$, Return since inception $(\%)_{t-1}$, Log(net investments) $)_{t-1}$, Log $(\text { net investments })_{t-2}$, Log $(n e t$

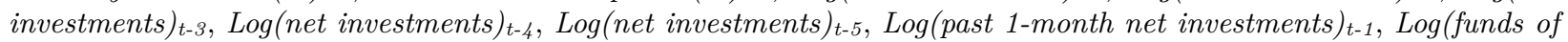
followers $_{t-1}, \log ($ age $)$, Real money account $(d)_{t-1}$, \# securities $t$, , Turnover $(\%)_{t-1}$, and \# portfolios t-1 $_{\text {are included }}$ as controls in every regression but not reported. The Appendix in the main paper provides detailed descriptions of all variables used throughout the study. Standard errors are clustered at the portfolio level. t-statistics are provided in parentheses. $* * *, * *, *$ denote statistical significance at the $1 \%, 5 \%, 10 \%$ level.

\begin{tabular}{|c|c|c|c|c|c|}
\hline & $\begin{array}{c}\log (\text { net } \\
\text { investments) }\end{array}$ & $\begin{array}{c}\text { Log(invest- } \\
\text { ments) }\end{array}$ & $\begin{array}{l}\text { Log(with- } \\
\text { drawals) }\end{array}$ & $\begin{array}{c}\log (\text { net } \\
\text { investments) } \\
\text { (week 1) }\end{array}$ & $\begin{array}{c}\log (\text { net } \\
\text { investments) }\end{array}$ \\
\hline & $(1)$ & $(2)$ & $(3)$ & $(4)$ & $(5)$ \\
\hline Comment $(\mathrm{d})_{\mathrm{t}-1}$ & $\begin{array}{c}0.059^{* * *} \\
(4.27)\end{array}$ & $\begin{array}{c}0.062^{* * *} \\
(4.84)\end{array}$ & $\begin{array}{l}0.005 \\
(0.82)\end{array}$ & $\begin{array}{c}0.113^{* * *} \\
(4.61)\end{array}$ & \\
\hline $\log (\# \text { comments })_{\mathrm{t}-1}$ & & & & & $\begin{array}{l}0.040 \\
(0.82)\end{array}$ \\
\hline $\log (\# \text { words per comment })_{\mathrm{t}-1}$ & & & & & $\begin{array}{l}0.010 \\
(0.46)\end{array}$ \\
\hline$\%$ positive words $\mathrm{t}_{\mathrm{t}-1}$ & & & & & $\begin{array}{l}0.001 \\
(0.54)\end{array}$ \\
\hline$\%$ negative words $\mathrm{s}_{\mathrm{t}-1}$ & & & & & $\begin{array}{l}0.000 \\
(0.00)\end{array}$ \\
\hline Controls & Yes & Yes & Yes & Yes & Yes \\
\hline Portfolio fixed effects & Yes & Yes & Yes & Yes & Yes \\
\hline Day fixed effects & Yes & Yes & Yes & Yes & Yes \\
\hline Adj. $R^{2}$ & 0.035 & 0.090 & 0.053 & 0.085 & 0.053 \\
\hline $\mathrm{N}$ & 440,929 & 440,929 & 440,929 & 432,725 & 15,721 \\
\hline
\end{tabular}




\section{Table IA11: The predictive power of comments for future performance - robustness tests}

This table presents the results from panel regressions with portfolio and day fixed effects. The dependent variable is either the 1-month cumulative abnormal return (CAR) of portfolios (Columns 1 and 2) or the daily alpha of portfolios (Columns 3 to 8). In Columns 2, 4, 6, and 8, we restrict the sample to days with at least one comment posted on the preceding day. Daily abnormal returns (alphas) are calculated as the difference between daily excess returns and predicted excess returns using different factor models. The factor exposures used to predict excess returns are estimated over 6-month rolling windows from t-126 to t-1. In Columns 1 and 2, we use a four-factor model that includes the MSCI Europe Index as proxy for the market, a SMB factor (return difference between the MSCI Europe Small Cap Index and the MSCI Europe Index), a HML factor (return difference between the MSCI Europe Value Index and the MSCI Europe Growth Index), and a momentum factor (MSCI Europe Momentum Index). In Columns 3 and 4, we use a four-factor model based on MSCI World indices rather than MSCI Europe indices. In Columns 5 and 6, we use the CAPM with the MSCI Europe Index as proxy for the market. In Columns 7 and 8 , we use a six-factor model based on MSCI Europe indices that additionally includes two at-the-money option factors constructed as in Agarwal and Naik (2004) using options on the Euro Stoxx 50. Excess returns are in excess of the return on the J.P. Morgan 3 Month Euro Cash Index. The variables Return (\%)t-1, Return (\%)t-2, Return $(\%)_{t-3}$, Return $(\%)_{t-4}$, Return $(\%)_{t-5}$, Past 1-month return $(\%)_{t-1}$, Past 3-month return $(\%)_{t-1}$, Past 6 -month return $(\%)_{t-1}$, Past 1-year return $(\%)_{t-1}$, Return since

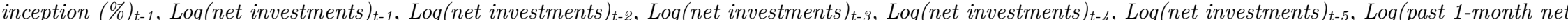
investments $)_{t-1}, \log (\text { funds of followers })_{t-1}, \log ($ age $)$, Real money account $(d)_{t-1}$, \# securities $t_{t-1}$, Turnover $(\%)_{t-1}$, and \# portfoliost-1 are included as controls in every regression but not reported. The Appendix in the main paper provides detailed descriptions of all variables used throughout the study. Standard errors are clustered at the portfolio level. t-statistics are provided in parentheses. $* * *, * *, *$ denote statistical significance at the $1 \%, 5 \%, 10 \%$ level.

\begin{tabular}{|c|c|c|c|c|c|c|c|c|}
\hline & & & \multicolumn{6}{|c|}{ Alpha (\%) } \\
\hline & \multicolumn{2}{|c|}{ 1-month CAR (\%) } & \multicolumn{2}{|c|}{$\begin{array}{l}\text { Four-factor model using } \\
\text { MSCI World indices }\end{array}$} & \multicolumn{2}{|c|}{ CAPM } & \multicolumn{2}{|c|}{ Six-factor model } \\
\hline & $(1)$ & $(2)$ & $(3)$ & $(4)$ & $(5)$ & $(6)$ & $(7)$ & $(8)$ \\
\hline Comment $(d)_{t-1}$ & $\begin{array}{c}0.272 \\
(0.75)\end{array}$ & & $\begin{array}{l}0.001 \\
(0.07)\end{array}$ & & $\begin{array}{l}0.007 \\
(0.45)\end{array}$ & & $\begin{array}{l}0.008 \\
(0.48)\end{array}$ & \\
\hline $\log (\# \text { comments })_{\mathrm{t}-1}$ & & $\begin{array}{l}0.173 \\
(1.13)\end{array}$ & & $\begin{array}{l}-0.061 \\
(-1.38)\end{array}$ & & $\begin{array}{l}-0.051 \\
(-1.06)\end{array}$ & & $\begin{array}{l}-0.070 \\
(-1.50)\end{array}$ \\
\hline $\log (\# \text { words per comment })_{\mathrm{t}-1}$ & & $\begin{array}{l}-0.118 \\
(-1.63)\end{array}$ & & $\begin{array}{l}0.020 \\
(1.00)\end{array}$ & & $\begin{array}{l}0.016 \\
(0.82)\end{array}$ & & $\begin{array}{l}0.020 \\
(0.95)\end{array}$ \\
\hline$\%$ positive words & & $\begin{array}{l}0.007 \\
(0.94)\end{array}$ & & $\begin{array}{l}0.002 \\
(0.99)\end{array}$ & & $\begin{array}{l}0.003 \\
(1.29)\end{array}$ & & $\begin{array}{l}0.001 \\
(0.54)\end{array}$ \\
\hline$\%$ negative words & & $\begin{array}{l}0.001 \\
(0.11)\end{array}$ & & $\begin{array}{l}0.003 \\
(0.81)\end{array}$ & & $\begin{array}{l}0.003 \\
(0.79)\end{array}$ & & $\begin{array}{l}0.001 \\
(0.41)\end{array}$ \\
\hline Controls & Yes & Yes & Yes & Yes & Yes & Yes & Yes & Yes \\
\hline Portfolio fixed effects & Yes & Yes & Yes & Yes & Yes & Yes & Yes & Yes \\
\hline Day fixed effects & Yes & Yes & Yes & Yes & Yes & Yes & Yes & Yes \\
\hline Adj. $R^{2}$ & 0.188 & 0.401 & 0.035 & 0.084 & 0.048 & 0.105 & 0.046 & 0.107 \\
\hline $\mathrm{N}$ & 433,615 & 17,488 & 412,819 & 15,364 & 412,819 & 15,364 & 412,819 & 15,364 \\
\hline
\end{tabular}




\section{Table IA12: Performance of trades of followers - robustness tests}

This table presents the results from OLS regressions. The dependent variable is either the daily excess return of an aggregate calendar-time portfolio consisting of all individual portfolios of traders weighted based on investments of followers made within three weeks (on the day) after the posting of a comment (Columns $1,4,7$, and 10), the daily excess return of an aggregate calendar-time portfolio consisting of all individual portfolios of traders weighted based on investments of followers made on all other days (Columns 2, 5, 8, and 11), or the return difference between the two portfolios (Columns 3 , 6, 9, and 12). Daily alphas are estimated based on different factor models. In Columns 1 to 3, we use a four-factor model that includes the MSCI Europe Index as proxy for the market, a SMB factor (return difference between the MSCI Europe Small Cap Index and the MSCI Europe Index), a HML factor (return difference between the MSCI Europe Value Index and the MSCI Europe Growth Index), and a momentum factor (MSCI Europe Momentum Index). In Columns 4 to 6, we use a four-factor model based on MSCI World indices rather than MSCI Europe indices. In Columns 7 to 9, we use the CAPM with the MSCI Europe Index as proxy for the market. In Columns 10 to 12, we use a six-factor model based on MSCI Europe indices that additionally includes two at-the-money option factors constructed as in Agarwal and Naik (2004) using options on the Euro Stoxx 50. Excess returns are in excess of the return on the J.P. Morgan 3 Month Euro Cash Index. Standard errors are adjusted for heteroskedasticity. t-statistics are provided in parentheses. $* * *, * *, *$ denote statistical significance at the $1 \%, 5 \%, 10 \%$ level.

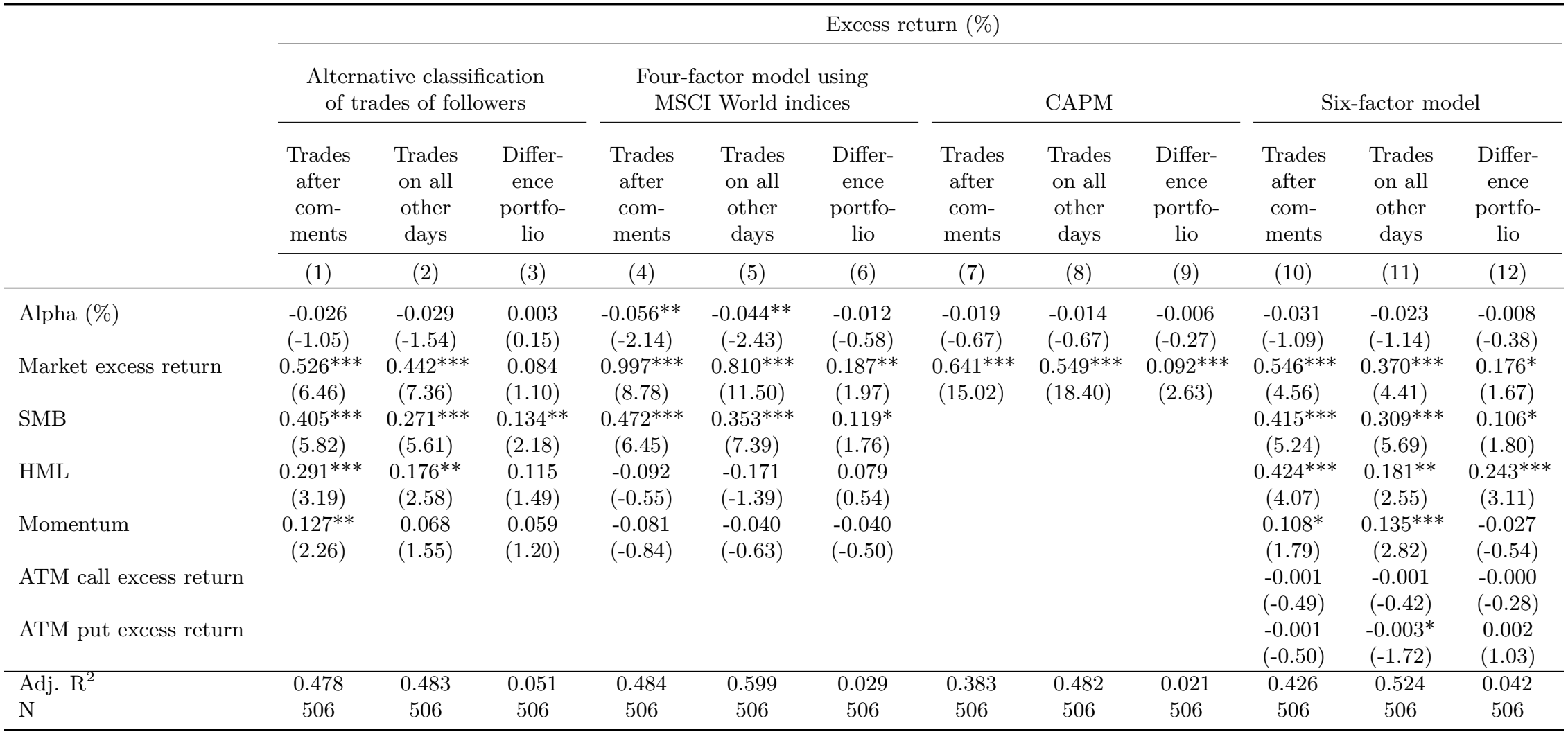


Table IA13: Descriptive statistics of the experiment

This table presents descriptive statistics on subject characteristics. The Appendix in the main paper provides detailed descriptions of all variables used throughout the study.

\begin{tabular}{|c|c|c|c|c|c|c|}
\hline & Mean & Minimum & Median & Maximum & $\begin{array}{l}\text { Standard } \\
\text { deviation }\end{array}$ & $\mathrm{N}$ \\
\hline Time (minutes) & 11.04 & 3.08 & 10.00 & 29.18 & 5.18 & 800 \\
\hline Female (d) & 0.446 & 0.000 & 0.000 & 1.000 & 0.497 & 800 \\
\hline Age (years) & 35.00 & 18.00 & 33.00 & 68.00 & 12.00 & 800 \\
\hline $18 \leq$ age $\leq 29(\mathrm{~d})$ & 0.399 & 0.000 & 0.000 & 1.000 & 0.490 & 800 \\
\hline $30 \leq$ age $\leq 39(\mathrm{~d})$ & 0.301 & 0.000 & 0.000 & 1.000 & 0.459 & 800 \\
\hline $40 \leq$ age $\leq 49(\mathrm{~d})$ & 0.140 & 0.000 & 0.000 & 1.000 & 0.347 & 800 \\
\hline $50 \leq$ age $\leq 59(\mathrm{~d})$ & 0.120 & 0.000 & 0.000 & 1.000 & 0.325 & 800 \\
\hline Age $\geq 60(\mathrm{~d})$ & 0.040 & 0.000 & 0.000 & 1.000 & 0.196 & 800 \\
\hline College education (d) & 0.404 & 0.000 & 0.000 & 1.000 & 0.491 & 800 \\
\hline Financial industry (d) & 0.083 & 0.000 & 0.000 & 1.000 & 0.275 & 800 \\
\hline Invested in stocks or equity funds (d) & 0.477 & 0.000 & 0.000 & 1.000 & 0.500 & 800 \\
\hline Invested in ideas shared online (d) & 0.212 & 0.000 & 0.000 & 1.000 & 0.409 & 800 \\
\hline Financial literacy $(0-12)$ & 7.67 & 0.00 & 8.00 & 12.00 & 2.60 & 800 \\
\hline
\end{tabular}




\section{Appendix B: Discussion of the robustness tests in Tables IA7 to}

\section{IA10}

In Tables IA7 to IA10, we present results of various robustness tests of our main results presented in Tables 2 to 5 in the main paper. First, results in Table IA2 in the Internet Appendix suggest that traders tend to post comments when they make changes to their portfolios. To address the concern that these portfolio changes are the drivers of followers' transactions as opposed to the comments themselves and that portfolio changes are not adequately controlled for in our previous analyses, we drop days on which traders post comments and execute transactions. This leaves us with 6,569 portfolio-days with at least one comment ( $34.2 \%$ of the initial sample). We then rerun the main tests from Tables 2 to 5 in the main paper. Table IA7 in the Internet Appendix shows the results of this robustness test. The documented effects are similar to the effects in the baseline specifications. In Column 3, when focusing on withdrawals, the coefficient estimate on the lagged comment dummy variable turns insignificant, suggesting that comments primarily matter for investment decisions but not for withdrawal decisions. Moreover, in Column 5, we no longer find a significant relation between the positivity of comments and the trading behavior of followers.

Second, an alternative explanation for the documented relation between comments of traders and investment decisions of followers could be that comments and investment decisions reflect news that both traders and followers observe directly. While day fixed effects should control for marketwide news announcements, our setting does not yet account for firm-specific news announcements. To control for firm-specific news, we obtain business press data from RavenPack. ${ }^{1}$ RavenPack collects firm news from leading news providers, including Dow Jones Newswires, the Wall Street Journal, and Barron's. It covers over 40,000 listed stocks in more than 100 countries (more than $98 \%$ of the investable global market). ${ }^{2}$ There is at least one news article in the RavenPack dataset for $87.4 \%$ of all stocks in our sample. We retain all articles with a relevance score of more than $75 .^{3}$ We then match these articles to the portfolio holdings of the traders. We drop days with comment postings and confounding news on one of the portfolio holdings. This leaves us with

\footnotetext{
${ }^{1}$ RavenPack provides different versions of news data. In this study, we utilize the combined data of the Dow Jones Edition and the PR Edition.

${ }^{2}$ Numerous studies have used RavenPack data in an international context (e.g., Lin et al., 2014; Shroff et al., 2014; Dang et al., 2015; You et al., 2018).

${ }^{3}$ RavenPack suggests that relevance scores above 75 or even above 90 may be applied to eliminate noise.
} 
4,093 portfolio-day observations with at least one comment ( $21.3 \%$ of the initial sample). We again rerun the main regression specifications from Tables 2 to 5 in the main paper. Results are presented in Table IA8 in the Internet Appendix. Despite the substantial drop in the number of comments in our sample, our findings remain qualitatively unchanged, except for the results on withdrawals (Column 3) and comment tone (Column 5) that turn statistically insignificant.

In another test to address the concern that our results are driven by confounding firm-specific news, we make use of an additional feature of our data. When posting a comment, traders have to classify it as either general or firm-specific comments. Figure 3 in the main paper provides examples of both types of comments. While firm-specific comments might be affected by corporate news announcements, general comments tend to talk about portfolios more broadly. In our sample, $52.0 \%$ of all comments are firm-specific comments and the remaining $48.0 \%$ are general comments. We re-estimate the main regression specifications from Tables 2 to 5 in the main paper separately for general comments and firm-specific comments. Results of this robustness test are presented in Table IA9 in the Internet Appendix. When focusing on general comments in Panel A, the coefficient on the lagged comment dummy and the coefficient on the percentage of positive words are positive and statistically significant, which is consistent with our results in Tables 2 to 5. However, when focusing on firm-specific comments in Panel B, coefficient estimates in Columns 1 and 5 turn statistically insignificant. Hence, it is unlikely that firm-specific news is the main driver of our results.

Finally, we analyze whether our results are driven by a few very popular investment strategies shared on our social trading platform. The most popular $5 \%$ of portfolios in terms of follower funds manage about $86.6 \%$ of the money of followers. We exclude these portfolios from our sample and repeat our set of tests. Table IA10 in the Internet Appendix presents the results. Inferences are largely unchanged, except that we no longer find a significant relation between the posting of comments and withdrawals in Column 3 and between the positivity of comments and net investments in Column 5. 


\section{Appendix C: Additional information on the experiment}

We provide one possible translation of the description of the experiment on Clickworker and the instructions.

\section{Description of the experiment on Clickworker}

"This experiment is conducted as part of a research project at the University of St. Gallen. The aim of this experiment is to better understand the decision-making of individual investors in the Internet era. The experiment consists of two sections: In section 1, you have to make an investment decision. Section 2 is a short survey. The experiment will take around 10 minutes."

\section{Instructions}

Screen 1 (welcome screen)

"Dear Participant, this experiment is conducted as part of a research project at the University of St. Gallen. The aim of this experiment is to better understand the decision-making of individual investors in the Internet era. The experiment consists of two sections: In section 1, you have to make an investment decision. Section 2 is a short survey.

The experiment will take around 10 minutes. For completing the experiment, we offer a participation fee of EUR 2.50. In addition, you can win a performance-related bonus of up to EUR 15.00 in Amazon gift cards. The performance-related bonus depends on your investment decision in section 1 of the experiment. After the experiment, we will randomly select 100 participants who will receive the performance-related bonus." 


\section{Screen 2 (instructions)}

"On the following page, we will provide you with information on two investment opportunities. The two investment opportunities are two trading strategies shared on a social trading platform. The returns of the two trading strategies depend on the securities contained in the two portfolios. What are social trading platforms? Social trading platforms are online social networks. On these platforms, individuals and professionals can share trading strategies. Investors can study the shared trading strategies and can invest using them. Individuals and professionals who share trading strategies are called 'traders'. Investors who invest using the shared trading strategies are called 'followers'.

After having studied the two trading strategies, you have to choose one.

We calculate the performance-related bonus based on a simulation of the one-year return of the chosen trading strategy according to the following formula: EUR $10 \times(1+1$-year return of trading strategy)

Example: The simulation results in a 1-year return of the chosen trading strategy of $10 \%$. In this case, your performance-related bonus would be EUR 11.00.

Hence, your performance-related bonus depends on your investment decision. The maximum performance-related bonus will be EUR 15.00. After the experiment, we will randomly select 100 participants who will receive the performance-related bonus. The performance-related bonus will be paid with Amazon gift cards. Please provide your email address at the end of the experiment." 


\section{Screen 3 (investment opportunities)}

[Subjects see two profile pages from our social trading platform. We either display the positive comment or the negative comment on one of the two profile pages. We vary the order of the profile pages. This table presents the information provided on the two profile pages.]

\begin{tabular}{|c|c|c|}
\hline & Profile page 1 & Profile page 2 \\
\hline Name of trading strategy & Long-term Investment & Dividend Increase \\
\hline Trader & [Name] & [Name] \\
\hline Date & 27-Sep-2018 & 27-Sep-2018 \\
\hline $\begin{array}{l}\text { Description of trading } \\
\text { strategy }\end{array}$ & $\begin{array}{l}\text { I invest in stocks with low volatility and } \\
\text { high dividend yield. I also diversify } \\
\text { across industries (e.g., telecom, } \\
\text { automotive, banking, resources). }\end{array}$ & $\begin{array}{l}\text { I invest in companies that have steadily } \\
\text { increased their dividends over the past } \\
10 \text { years. My portfolio is diversified } \\
\text { across industries and across regions. }\end{array}$ \\
\hline Inception date & September 2016 & September 2016 \\
\hline $\begin{array}{l}\text { Amount of money } \\
\text { invested by followers }\end{array}$ & EUR 13,405 & EUR 14,087 \\
\hline Trader is professional & No & No \\
\hline Trader is experienced & Yes & Yes \\
\hline $\begin{array}{l}\text { Trader is invested in own } \\
\text { trading strategy }\end{array}$ & Yes & Yes \\
\hline \multirow[t]{2}{*}{ Price chart } & 140 & 140 \\
\hline & ${ }_{\text {Sep-16 }}^{100} 110$ & $\begin{array}{l}130 \\
120 \\
110 \\
90 \\
\text { Sep-16 Mar-17 }\end{array}$ \\
\hline Return since inception & $21.2 \%$ & $21.2 \%$ \\
\hline Past 1-year return & $13.2 \%$ & $19.3 \%$ \\
\hline Past 6-month return & $4.0 \%$ & $1.7 \%$ \\
\hline Past 3-month return & $0.2 \%$ & $6.4 \%$ \\
\hline Past 1-month return & $-0.3 \%$ & $-3.5 \%$ \\
\hline Current portfolio & $\begin{array}{l}\text { Coca-Cola (stock): } 25.4 \% \\
\text { McDonalds (stock): } 15.1 \% \\
\text { IBM (stock): } 14.3 \% \\
\text { Nestlé (stock): } 10.3 \% \\
\text { Fielmann (stock): } 9.2 \% \\
\text { Other securities ( } 5 \text { stocks): } 23.4 \% \\
\text { Cash: } 2.3 \%\end{array}$ & $\begin{array}{l}\text { Lindt Sprüngli (stock): } 21.3 \% \\
\text { Fuchs Petrolub (stock): } 16.0 \% \\
\text { Reckitt Benckiser (stock): } 13.7 \% \\
\text { Coca-Cola (stock): } 12.1 \% \\
\text { Nestlé (stock): } 11.7 \% \\
\text { Other securities (5 stocks): } 22.8 \% \\
\text { Cash: } 2.5 \%\end{array}$ \\
\hline Recent trades & $\begin{array}{l}\text { 9/19/18: Coca-Cola, }+200 \text { shares } \\
\text { 9/19/18: IBM, }+85 \text { shares } \\
\text { 5/14/18: Fresenius, }-140 \text { shares } \\
\text { 4/17/18: Coca-Cola, }+350 \text { shares } \\
\text { 4/17/18: BASF, }-140 \text { shares }\end{array}$ & $\begin{array}{l}\text { 9/20/18: L'Oréal, }-27 \text { shares } \\
\text { 9/20/18: Swedish Match, }+270 \text { shares } \\
\text { 7/16/18: L'Oréal, }-54 \text { shares } \\
\text { 4/17/18: L'Oréal, }-27 \text { shares } \\
\text { 4/17/18: Swedish Match, }+100 \text { shares }\end{array}$ \\
\hline
\end{tabular}




\section{Screen 4 (investment decision)}

"Which trading strategy do you choose? Assume the transaction costs and fees to be identical for both trading strategies."

Screens 5 to 13 (survey) 


\section{References}

Dang, T.L., F. Moshirian, and B. Zhang, 2015, Commonality in news around the world, Journal of Financial Economics 116, 82-110.

Lin, C., M. Massa, and H. Zhang, 2014, Mutual funds and information diffusion: The role of country-level governance, Review of Financial Studies 27, 3343-3387.

Shroff, N., R.S. Verdi, and G. Yu, 2014, Information environment and the investment decisions of multinational corporations, Accounting Review 89, 759-790.

You, J., B. Zhang, and L. Zhang, 2018, Who captures the power of the pen?, Review of Financial Studies 31, 43-96. 